Aus dem Institut für Medizinische Mikrobiologie

(Prof. Dr.med. U. Groß)

im Zentrum Hygiene und Humangenetik

der Medizinischen Fakultät der Universität Göttingen

\title{
Epidemiologie Virulenz-assoziierter Markergene in Campylobacter jejuni-Subpopulationen
}

\author{
INAUGURAL-DISSERTATION
}

zur Erlangung des Doktorgrades

für Zahnheilkunde

der Medizinischen Fakultät der

Georg-August-Universität zu Göttingen

vorgelegt von

Carolin Ohk

aus

Salzwedel

Göttingen 2014 
Dekan:

1. Berichterstatter:

2. Berichterstatter:
Prof. Dr. rer. nat. H. K. Kroemer

Prof. Dr. med.UU. Groß

Prof. Dr. med. H. Schwörer

Tag der mündlichen Prüfung: $\quad 20.10 .2014$ 


\section{Inhaltsverzeichnis}

$1 \quad$ Einleitung ........................................................................................................................ 1

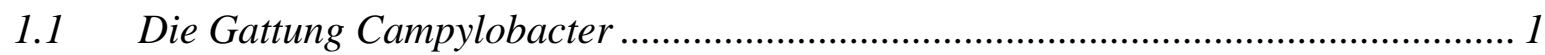

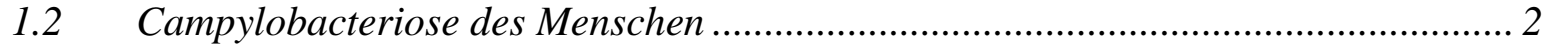

1.2.1 Infektionsquellen und Übertragungswege .................................................. 2

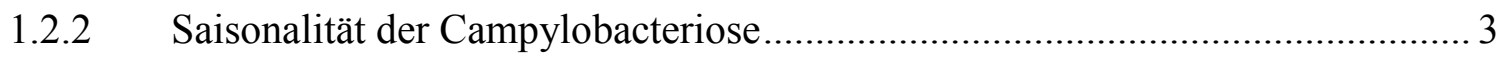

1.3 Klinik der Campylobacteriose und assoziierte Erkrankungen.................................. 4

1.3.1 Klinisches Erscheinungsbild und Verlauf ..................................................... 4

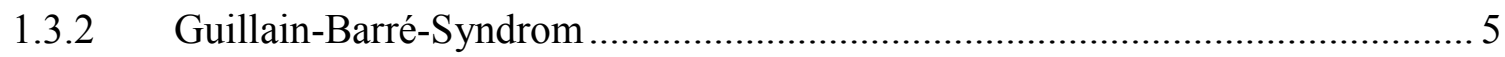

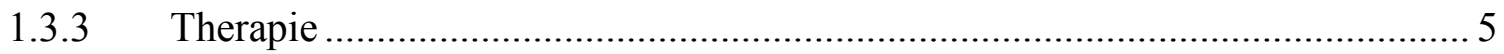

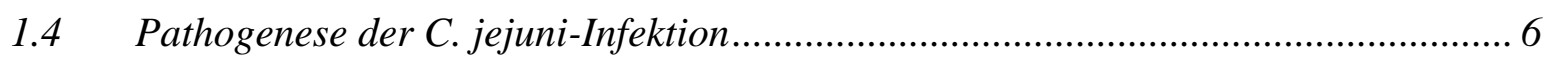

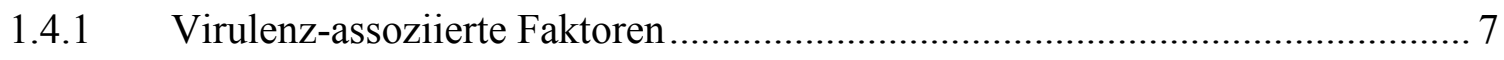

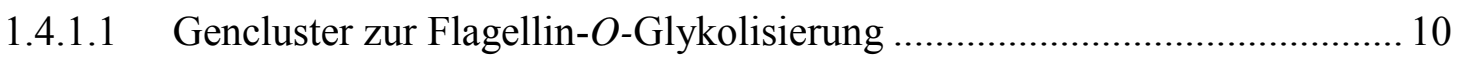

1.4.1.2 Lipooligosaccharid-Sialyltransferase-Marker ........................................... 11

1.4.1.3 Camplyobacter-Invasions-Antigen B ................................................... 11

1.4.1.4 Zytolethales distendierendes Toxin (Cytolethal Distending Toxin) ............. 11

1.4.1.5 Phospholipase A der äußeren Membran ................................................... 12

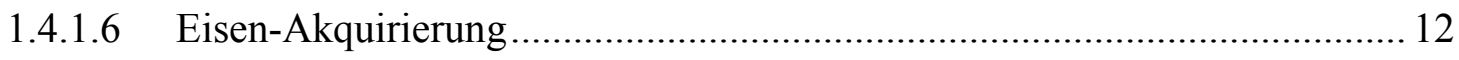

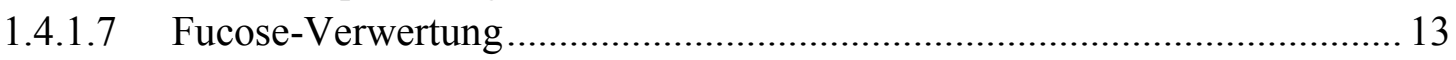

1.5 Zusammenhang verschiedener C. jejuni-Gruppen............................................. 14

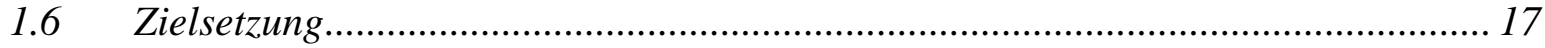

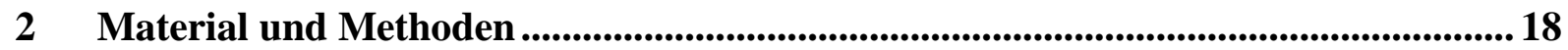

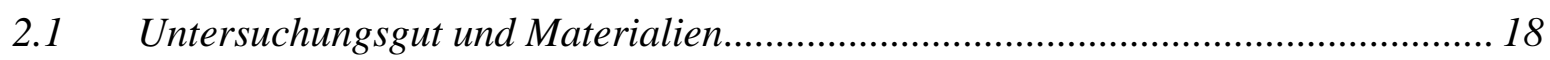

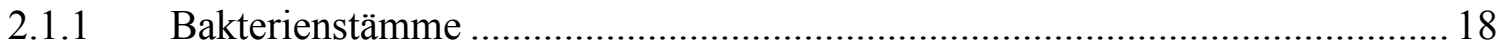

2.1.2 Charakterisierung der C. jejuni -Untergruppen ........................................... 18

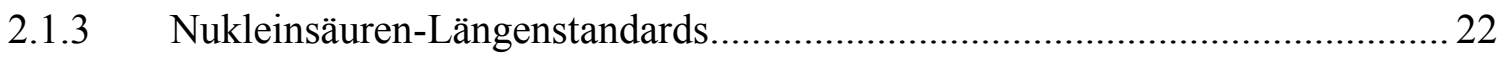

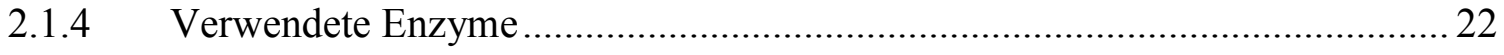

2.1.5 Puffer und Nährmedien.............................................................................. 22

2.1.6 Weitere Chemikalien, Reagenzien, Verbrauchsmittel und Geräte .................... 23

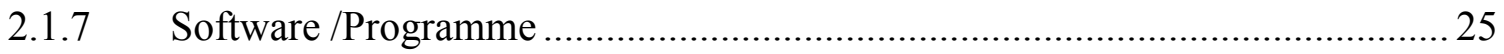

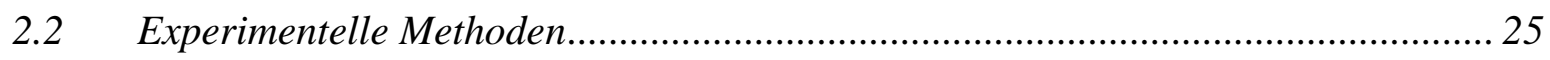

2.2.1 Anzucht und Lagerung von Campylobacter jejuni........................................26

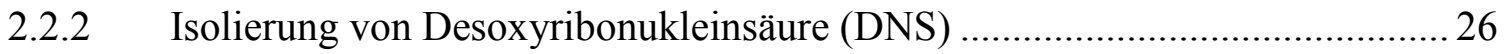

2.2.3 Konzentrationsbestimmung von DNS …..................................................... 27

2.2.4 Polymerasekettenreaktion (PCR) ................................................................. 27

2.2.5 Nachweis der PCR-Produkte mittels Agarose-Gelelektrophorese .................... 31

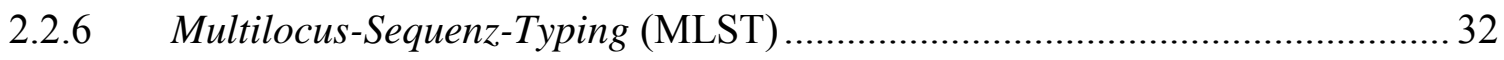




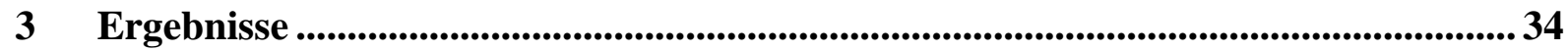

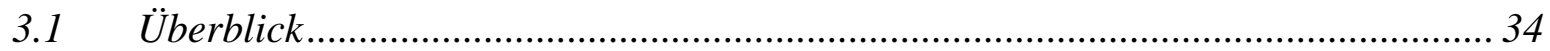

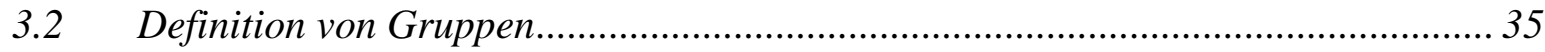

3.3 Verteilung der Marker innerhalb der definierten Gruppen ................................... 39

3.3.1 Campylobacter-Invasions-Antigen und Zytolethales distendierendes Toxin... 40

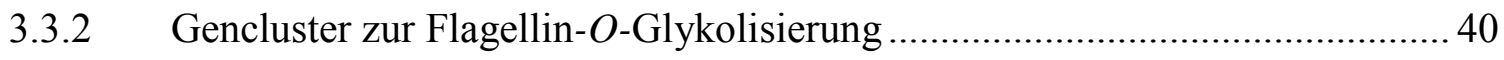

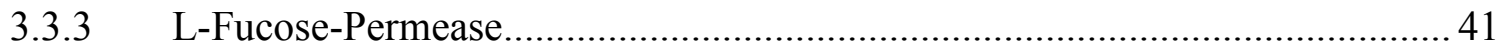

3.3.4 Enterochelin-Aufnahmeprotein und Phospholipase A der äußeren Membran 42

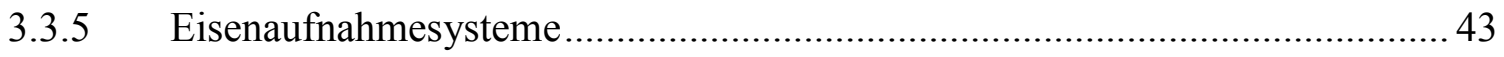

3.3.6 Marker für die Lipooligosaccharid-Sialyltransferase ...................................... 44

3.4. Verteilung der Markergene nach Isolat-Ursprung ............................................. 48

3.5 Verteilung der Marker innerhalb der Spezies ..................................................... 49

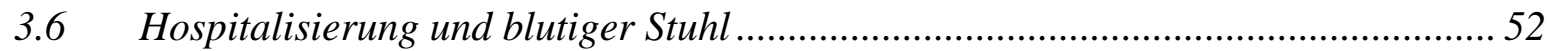

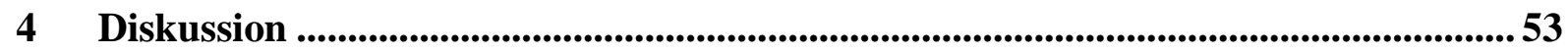

4.1 Gencluster zur Flagellin-O-Glykolisierung .................................................... 53

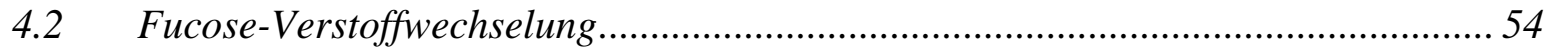

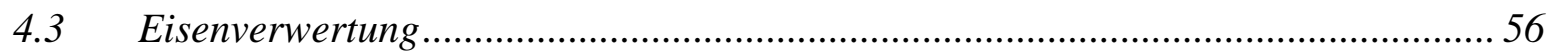

4.4 Zusammensetzung des Lipooligosaccharids ...................................................... 57

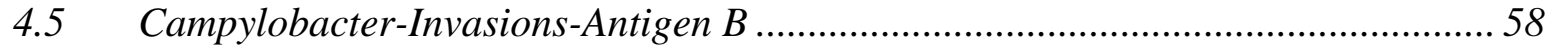

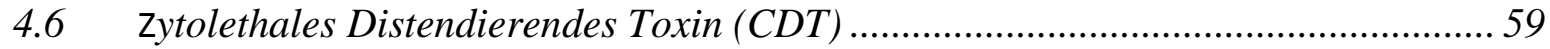

$4.7 \quad$ Phospholipase A der äußeren Membran .................................................................5

4.8 Schlussfolgerungen bezüglich der Marker-Verteilung......................................... 59

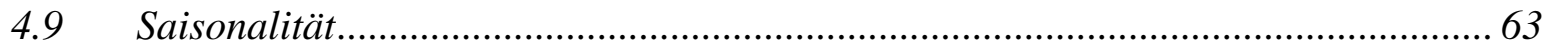

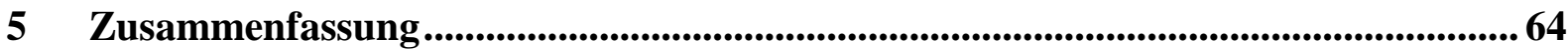

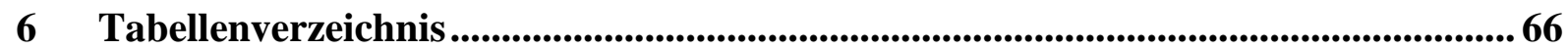

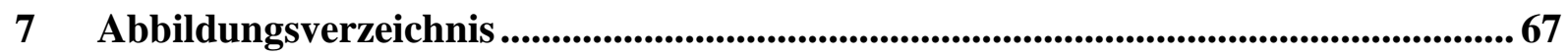

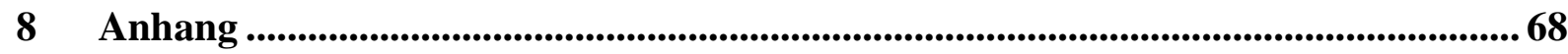

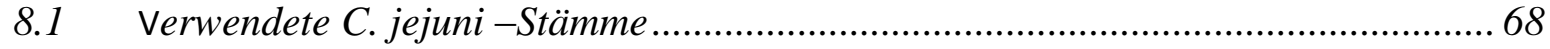

8.2 Bisherige Veröffentlichungen der Ergebnisse ......................................................... 77

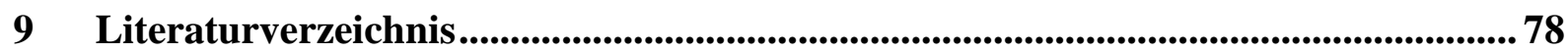




\section{Abkürzungsverzeichnis}

Abb.
ansB

BFR
BHI-Medium
bp
bzw.

$\mathrm{C}$.
${ }^{\circ} \mathrm{C}$
$\mathrm{CC}$
$\mathrm{CadF}$
$\mathrm{CDT}$
ceuE
$\mathrm{Cia}$
$\mathrm{konz}$.
$\mathrm{CO}_{2}$
cstII/cstIII
cj...

dNTP

DNS

DNA

dmsA

EDTA

EFSA

et al.

EP

EMP

fucP

GBS

$g g t$

$\mathrm{H}_{2} \mathrm{O}$

i.d.R.

$\mathrm{kb}$

$\mathrm{kDa}$
Abbildung

periplasmatische Asparaginase mit akzessorischem sec-Signal (Gen)

Bundesinstitut für Risikobewertung

Brain Heart Infusion-Medium (Herz-Hirn-Bouillon)

Basenpaare

beziehungsweise

Campylobacter

Grad Celcius

klonaler Komplex (eng. clonal complex)

Campylobacter adhesion to fibronectin

cytolethal distending toxin

campylobacter enterochelin uptake binding protein $\mathrm{E}$ (Gen)

Campylobacter-Invasions-Antigen

konzentriert

Kohlenstoffdioxid

Gen für die Lipooligosaccharid- Sialyltransferase II bzw. III

Gen-Nummerierung basierend auf dem Genom des Campylobacter jejuni-Stamms NCTC 11168

desoxy-Nukleosidtriphosphat (dATP, dCTP, dGTP, dTTP)

Desoxyribonukleinsäure

Deoxyribonucleic Acid

Dimethylsulfoxid-Oxidoreduktase-Untereinheit A (Gen)

Ethylendiamintetraacetat

Europäische Behörde für Lebensmittelsicherheit

et alii

extracellular polysaccharide

Embden-Meyerhof-Parnas-Weg (Glykolyse)

L-Fucose-Permease (Gen)

Guillain-Barré-Syndrom

$\gamma$-Glutamyl-Transpeptidase (Gen)

Wasser

in der Regel

Kilo-Basenpaare

Kilodalton 
1

LLC

LOS

$\mu$

$\mathrm{m}$

$\mathrm{M}$

$\mathrm{Mb}$

MFS

min

MLST

MM

$\mathrm{N}_{2}$

$\mathrm{O}_{2}$

PCR

pldA

RKI

ssp.

ST

Tab.

TAE

Taq

${ }_{t l p} 7_{m+c}$

Tris

UPGMA

UV

V

v.a.

VBNC

vgl.

$(\mathrm{v} / \mathrm{v})$

z.B.
Liter

LOS Locus Klasse

Lipooligosaccharid

mikro $\left(10^{6}\right)$

milli $\left(10^{3}\right)$; Meter

Molar

Mega-Basenpaare

Miller-Fischer-Syndrom

Minute

multilocus sequence typing

Mastermix

Stickstoff

Sauerstoff

polymerase chain reaction

Phospholipase A (Gen)

Robert Koch-Institut

Subspezies

Sequenztyp

Tabelle

Tris-Acetat-EDTA-Puffer

Thermus aquaticus

transducer-like protein (m-Membran, c-cytoplasmatisch)

Tris-(hydroxylmethyl)-aminomethan

unweighted - pair Group Method with Arithmetic Mean ultraviolett

Volt

vor allem

viable but non-culturable

vergleiche

$\%(\mathrm{v} / \mathrm{v})$ entspricht Volumenprozent: Anteilsvolumen in

Gesamtvolumen

zum Beispiel 


\section{$1 \quad$ Einleitung}

\subsection{Die Gattung Campylobacter}

Weltweit stellen Campylobacter-Infektionen die häufigste Ursache für bakterielle MagenDarm-Erkrankungen dar und sind somit häufiger als Infektionen mit Salmonella enterica oder enteropathogenen Escheria coli (ALLOS 2001). Zur Gattung Campylobacter gehören 18 verschiedene Spezies (HUMPHREY et al. 2007). Mehr als $95 \%$ der CampylobacterInfektionen werden durch Campylobacter jejuni und Campylobacter coli verursacht und gehören damit zu den wichtigsten humanpathogen Campylobacter-Arten (BUTZLER 2004).

Campylobacter jejuni sind gebogene, schlanke, s-förmig oder spiralig gewundene gramnegative Stäbchenbakterien. Die Stäbchen sind 0,5-5 $\mu \mathrm{m}$ lang und 0,2-0,5 $\mu \mathrm{m}$ dick. Zudem sind die Bakterien monotrich oder amphotrich begeißelt, was zur typischen korkenzieherartigen Bewegung führt (VANDAMME und DE LEY 1991).

Das Bakterium C. jejuni gehört mit einem Wachstumsoptimum von $42{ }^{\circ} \mathrm{C} \mathrm{zu}$ den thermophilen Arten. Unterhalb von $30^{\circ} \mathrm{C}$ findet kein Wachstum mehr statt. Für ein optimales Wachstum benötigt $C$. jejuni eine mikroaero- und capnophile Atmosphäre mit $5 \%$ Sauerstoff und 3-5 \% Kohlenstoffdioxid (PARK 2002).

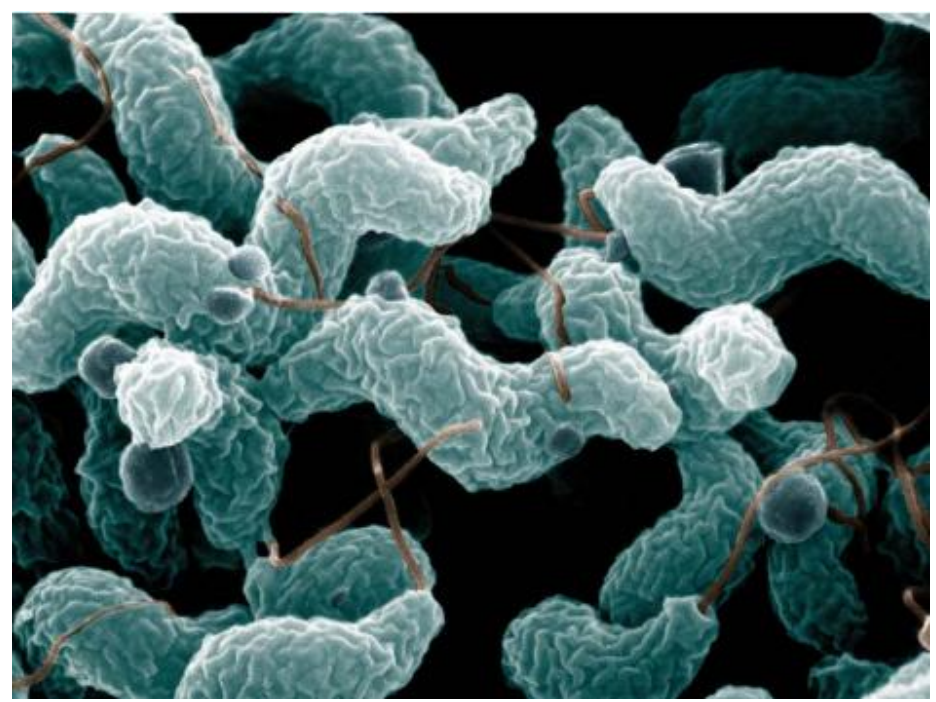

Abb. 1: Elektronenmikroskopische Darstellung von $C$. jejuni (Quelle: http://www.wikipedia.de/Campylobacter/jejuni; 03.01.09) 


\subsection{Campylobacteriose des Menschen}

Infektionen durch Bakterien der Gattung Campylobacter ssp. sind weltweit verbreitet. Mit Inzidenzraten von mehr als 40/100.000 Einwohner/Jahr wird C. jejuni als häufigster bakterieller Durchfallerreger in Europa angegeben (EFSA 2010).

Wie in vielen anderen Ländern zeigt sich auch in Deutschland, dass Campylobacter ssp. und S. enterica die beiden häufigsten bakteriellen Enteritserreger sind. Die Zahl der gemeldeten Campylobacter-Infektionen lag 2005 laut statistischen Angaben des RKI mit 62.129 gemeldeten Fällen erstmals über der Zahl der Salmonellosen von 52.257 (ANONYMUS 2006). Von den 2011 in Deutschland gemeldeten Campylobacter-Erkrankungen mit Angaben zur Spezies entfielen $69 \%$ auf $C$. jejuni, $6 \%$ auf $C$. coli und $24 \%$ auf $C$. coli/ $C$. jejuni (nicht differenziert). Die übrigen Spezies z.B. C. lari, C. upsaliensis bzw. C. fetus konnten in weniger als $1 \%$ der Campylobacteriose-Fälle nachgewiesen werden (RKI 2011). Im Jahr 2012 wurden dem Robert Koch-Institut bis zur 49. Kalenderwoche 60.390 durch Campylobacter-Arten verursachte Enteriden gemeldet (ANONYMUS 2012).

Etwa $17 \%$ der mit Lebensmittel-Infektionen assoziierten Krankenhausaufenthalte können auf Campylobacter ssp. zurückgeführt werden (MEAD et al. 1999).

Generell sind alle Altersgruppen von Campylobacter-Infektionen betroffen. Es zeigen sich jedoch 2 Inzidenzgipfel, zum einen im Alter zwischen null und vier Jahren und zum anderen zwischen 15 und 44 Jahren (BUTZLER 2004).

\subsubsection{Infektionsquellen und Übertragungswege}

Die durch Campylobacter verursachte Infektion, die so genannte Campylobacteriose, ist wie die Salmonellose eine im Wesentlichen durch Nahrungsmittel übertragene Erkrankung.

Hauptinfektionsquelle für Campylobacter-Infektionen sind unzureichend erhitztes Geflügelfleisch und kreuzkontaminierte Nahrungsmittel sowie die daraus hergestellten Produkte (DEMING et al. 1987). Gerade die im Geflügelinterstitium vorherrschenden $42{ }^{\circ} \mathrm{C}$ bilden ein natürliches Reservoir und fördern die Vermehrung von $C$. jejuni (ALTEKRUSE et al. 1999). Auch Säugetiere tragen C. jejuni als Bestandteil der kommensalen Darmflora natürlicherweise in sich und stellen somit ein weiteres Erregerreservoir dar (BUTZLER 2004). 
Der Erreger kann u.a. im Darmtrakt von Nutztieren wie Schweinen, Rindern oder Schafen vorkommen. Weitere Infektionsquellen sind der Verzehr von rohem Rinder- und Schweinehackfleisch sowie der Konsum von nicht-pasteurisierter Milch und kontaminiertem Trinkwasser. Darüber hinaus können nach dem Baden in kontaminierten Oberflächengewässern Infektionen auftreten (FRIEDMAN et al. 2000). Als Reservoir für $C$. jejuni wurden aber auch junge Hunde und Katzen identifiziert, vorrangig sind diese aber Überträger der thermophilen Art Campylobacter upsaliensis (ACKE et al. 2009).

Erstmalig wurde Anfang des 20. Jahrhunderts von Campylobacter-Infektionen bei Nutztieren berichtet. Um Campylobacter-Infektionen vorzubeugen, sollten lebensfähige $C$. jejuni durch gründliches Erhitzen abgetötet werden, insbesondere vor dem Verzehr von Geflügelfleisch. Daneben müssen Kreuzkontaminationen bei der Lebensmittelzubereitung vermieden werden, beispielsweise durch den Einsatz unterschiedlicher Schneidbretter zur Fleisch- und Rohkostzubereitung. Immungeschwächte Personen, Schwangere und ältere Personen sollten auf den Verzehr von Rohmilch verzichten.

Eine direkte Übertragung durch Schmierinfektion von Mensch zu Mensch ist möglich, hat aber nur eine geringe epidemiologische Bedeutung und beschränkt sich eher auf Kleinkinder und immunsupprimierte Personen (FRIEDMAN et al. 2000 , ALLOS 2001).

\subsubsection{Saisonalität der Campylobacteriose}

Ein typisches Charakteristikum der Epidemiologie der Campylobacteriose ist die ausgeprägte Saisonalität (HUMPHREY et al. 2007). LOUIS et al. demonstrierten 2005 - anhand statistischer Auswertungen von Campylobacter-Infektionen in England und Wales im Zeitraum von 1990-1999 im Zusammenhang mit den Wetterbedingungen- ein jährlich auftretendes saisonales Muster von Campylobacter-Infektionen mit Häufung in den Sommermonaten. Die deutlichsten saisonalen Muster wurden von LOUIS et al. für Kinder unter 5 Jahren erfasst, wie auch schon von BUTZLER beschrieben (LOUIS et al. 2005, BUTZLER 2004).

Auch die statistischen Erhebungen des RKI von 2011 zeigen einen saisonalen Verlauf mit den höchsten Fallzahlen in den Monaten Juni bis September (RKI 2011). 
Das gehäufte Auftreten von Campylobacter-Infektionen in den Sommermonaten wird begünstigt durch eine höhere Besiedlung von Masthähnchen und anderen Nutztieren mit $C$. jejuni und damit erheblicheren Keimbelastungen von tierischen Lebensmitteln.

In den Sommermonaten herrscht dazu ein verändertes Freizeitverhalten (Grillen und Picknicken) vor. Temperaturbedingt verändern sich die Übertragungswege, zum Beispiel durch Wasseraktivitäten, dabei kann die orale Aufnahme von Oberflächenwasser zur Infektion führen (NICHOLS 2005, KONKEL et al. 2001).

\subsection{Klinik der Campylobacteriose und assoziierte Erkrankungen}

\subsubsection{Klinisches Erscheinungsbild und Verlauf}

Das klinische Spektrum der Campylobacteriose ist vielgestaltig und reicht vom asymptomatischen Verlauf bis zur schweren peripheren Neuropathie (BUTZLER 2004). Bereits eine geringe Infektionsdosis von ca. 500 Bakterien ist ausreichend, um eine Erkrankung auszulösen (BLACK et al. 1988).

Typischerweise äußern sich die meisten Campylobacter-Infektionen, nach einer Inkubationszeit von ein bis drei Tagen und einer unspezifischen Prodromalphase, in einer akuten unkomplizierten Enterokolitis mit wässrigen, später blutigen Diarrhöen. Weiterhin können krampfartige abdominale Schmerzen, Fieber, Übelkeit und Erbrechen im Rahmen der Erkrankung auftreten (BUTZLER 2004, WASSENAAR et al. 1999). Eine Unterscheidung zu anderen gastrointestinalen Infektionen beispielsweise durch S. enterica ist nur über eine Kultivierung der Erreger aus Stuhlproben möglich. Normalerweise findet sich Campylobacter bei gesunden Personen nur äußerst selten im Stuhl.

Abhängig von der Population sind bis zu $50 \%$ der infizierten Personen bei Ausbruch asymptomatisch (ALLOS 2001). In Einzelfällen treten extraintestinale Manifestationen wie zum Beispiel das Guillain-Barré-Syndrom oder eine reaktive Arthritis auf (BUTZLER 2004). 


\subsubsection{Guillain-Barré-Syndrom}

Eine äußerst schwerwiegende postinfektiöse Folgeerkrankung der Campylobacteriose ist das 1916 erstmals von Georges Guillain, Jean-Alexandre Barré und André Strohl als aufsteigende Lähmung beschriebene Guillain-Barré-Syndrom (GUILLAIN et al. 1916).

Es handelt sich hierbei um eine periphere, meist reversible Neuropathie, die etwa ein bis drei Wochen nach einer Campylobacter-Infektion auftreten kann. Dabei werden Antikörper insbesondere gegen die Sialinsäuregruppen des Campylobacter-Lipooligosaccharides (LOS) gebildet, die mit den Zuckerresten der Ganglioside peripherer Nerven kreuzreagieren (molekulare Mimikry), was nachfolgend eine Schädigung des Axons auslösen kann (GODSCHALK et al. 2004, YUKI et al. 2004). Die Möglichkeit ein GBS zu entwickeln ist dabei unabhängig vom Serotyp des Infektionsstammes (REES et al. 1995, ENDTZ et al. 2000).

Klinisch kommt es als Folge der Immunreaktion zur Zerstörung der Myelinscheide der peripheren Nerven mit Lähmungen der Arme und Beine (seltener der Atemmuskulatur) bis hin zu möglichen Hirnnervenschädigungen. Postinfektiöse Verläufe als Miller-Fisher-Syndrom oder Bickerstaff-Enzephalitis sind seltener (GODSCHALK et al. 2007).

Betrifft die Neuropathie nur das Gesicht mit Lähmung der Augenmuskeln, Ataxie und Areflexie, so spricht man vom Miller-Fischer-Syndrom, einer Variante des GBS. Die Erkrankung geht mit der Bildung von Autoantikörpern einher, die gegen das Gangliosid GQ1b gerichtet sind (CHIBA et al. 1993). Bei Patienten mit einer Bickerstaff-Enzephalitis sind zusätzlich zur Ophthalmoplegie und Ataxie noch Symptome wie Schläfrigkeit, Koma oder Hyperreflexie diagnostizierbar (ODAKA et al. 2003).

Zwar geht eine Campylobacter-Infektion mit einem erhöhten Risiko einher, ein GuillainBarré-Syndrom zu entwickeln, dennoch entsteht nur bei jeder 1000. Campylobacteriose ein GBS als Spätfolge (SCHMIDT-OTT et al. 2006, HUMPHREY et al. 2007). Bei 32-45 \% der Patienten konnte C. jejuni als Auslöser für GBS identifiziert werden (JACOBS et al. 1996, HAO et al. 1998).

\subsubsection{Therapie}

Campylobacter-Infektionen sind vorwiegend selbstlimitierend. Therapeutisch sind daher symptomatische Maßnahmen wie die Substitution von Flüssigkeit und Elektrolyten ausreichend. Eine antibiotische Behandlung ist im Allgemeinen nicht indiziert. Bei schweren 
Verläufen mit hohem Fieber, blutigem Stuhl und anhaltendem Krankheitsverlauf sowie bei Rückfällen der Erkrankung sollte eine antibiotische Therapie in Erwägung gezogen werden. Als Risikopatienten gelten auch immungeschwächte Patienten wie HIV-Infizierte. Aber auch Schwangere gehören zur Risikogruppe. Antibiotika der Wahl sind dann Makrolide wie Erythromycin und Gyrasehemmer wie Ciprofloxacin (ALLOS 2001). Ein aufkommendes Problem sind Antibiotikaresistenzen bei $C$. jejuni. In Deutschland sind bereits mehr als $10 \%$ der C. jejuni-Isolate resistent gegen Erythromycin. Noch gravierender ist die Resistenzlage bei dem Fluorchinolon Ciprofloxacin. Gegen dieses Antibiotikum sind bereits circa $30 \%$ aller Campylobacter-Isolate resistent (TIETZE 2008).

\subsection{Pathogenese der C. jejuni-Infektion}

Von grundlegender Bedeutung für die Beurteilung einer Gesundheitsgefährdung durch Campylobacter jejuni ist die Kenntnis von Pathogenitäts-und Virulenzmerkmalen.

Nach der oralen Aufnahme von $C$. jejuni gelangen die Bakterien zunächst in den unteren Darmtrakt (Jejunum, Ileum und Kolon). Das kann zur asymptomatischen Kolonisierung oder Durchfallsypmtomen führen (JANSSEN et al. 2008).

Initialer Schritt zur Kolonisierung ist die Überwindung der humanen Intestinalflora. Der menschliche Verdauungstrakt beherbergt eine Vielzahl kommensaler Bakterien, Archaeen und Eukaryoten, die zusammenfassend als Darmflora bezeichnet werden. Dieses komplexe bakterielle Ökosystem etabliert sich innerhalb der ersten Lebensjahre und bietet einen physiologischen Widerstand gegen pathogene Erreger. Im Zustand des mikrobiellen Gleichgewichts besteht die Intestinalflora $\mathrm{zu}$ über $90 \%$ aus obligaten Anaerobiern. Vorherrschend sind Mitglieder der Gattungen Bacteroides spp., Bifidobacterium spp., Eubacterium spp., Fusobacterium spp. sowie der Ordnungen Clostridiales und Lactobacillales. Im gesunden Zustand machen Escherichia coli und andere naheverwandte Enterobakterienarten nur einen geringen Teil der Flora aus (GUARNER und MALAGELADA 2003, LEY et al.2008).

Physiologische Funktion der kommensalen Darmflora ist die Kolonisationsresistenz, die eine Besiedlung des Darms durch pathogene Bakterien verhindert (STECHER und HARDT 2008). Genetische Prädisposition, Umweltfaktoren, fettreiche Ernährung oder antibiotische Behandlungen (PENDERS et al. 2006, LOZUPONE et al. 2012) können die Barrierefunktion 
der Darmmukosa stören, so dass eine überschießende Entzündungsreaktion folgt und eine Kolonisierung mit $C$. jejuni erleichtert wird (BERESWILL et al. 2011). Die vorherrschenden Bedingungen im menschlichen Verdauungssystem stimulieren die Synthese von Virulenzassoziierten Faktoren, die an der Entstehung einer Campylobacteriose beteiligt sind (MALIKKALE et al. 2008, Konkel et al. 2001).

Die pathogenen Mechanismen der durch $C$. jejuni hervorgerufenen Vielfalt an klinischen Präsentationen sind trotz der enormen Bedeutung als Lebensmittel-assoziierter Erreger noch wenig verstanden. Man geht davon aus, dass verschiedene Virulenz-assoziierte Faktoren zusammenwirken. Diese können aufgrund der hohen genetischen Variabilität der Isolate unterschiedlich stark ausgeprägt sein. Zu den Pathogenitätsmerkmalen gehören die chemotaktisch gesteuerte Motilität, die Fähigkeit von C. jejuni zur Adhäsion und Invasion und die Produktion von Toxinen. Weitere beeinflussende Größen sind die Widerstandsfähigkeit gegenüber externen Stressoren, der Erwerb und die Verwertung von extrazellulärem Eisen sowie die Variabilität der Oberflächenantigene (WASSENAAR und BLASER 1999, KONKEL et al. 2001).

\subsubsection{Virulenz-assoziierte Faktoren}

Ungewöhnlich für Lebensmittel-assoziierte Erreger hat $C$. jejuni nur eingeschränkte Möglichkeiten, in der Umwelt zu überdauern. Dieses Phänomen findet seine Erklärung in der unzureichenden Aerotoleranz und einem sehr eng begrenztem Wachstumsbereich von $32{ }^{\circ} \mathrm{C}$ bis $42{ }^{\circ} \mathrm{C}$ (PARK 2002). Das sequenzierte Genom des C. jejuni-Isolates NCTC 11186 konnte zeigen, dass $C$. jejuni über keine Stationärphase-Regulatoren zur Erhöhung der Stressresistenz bei erschwerten Umwelteinflüssen verfügt (PARKHILL et al. 2000). Allerdings reagiert $C$. jejuni auf thermischen Stress und sinkende $\mathrm{pH}-$ Werte im umgebenden Medium durch Übergang in den sogenannten ,viable but non-culturable“ (VBNC)-Zustand (ROLLINS und COLWILL 1986). Unter derartigen Stressbedingungen werden verstärkt Hitzeschockproteine gebildet, womit das Überleben des Erregers gesichert werden soll (DASTI et al. 2010).

Eine weitere erforderliche Voraussetzung zur Invasion der Darmschleimhaut schafft die Motalität und Chemotaxis von C. jejuni. Wie bereits unter Punkt 1.1 beschrieben, besitzen die Bakterien ein oder zwei polare Flagellen. Diese Geißeln sind aus $O$-glykosyliertem Flagellin 
aufgebaut und besitzen eine wichtige Bedeutung in der Kolonisation des Interstitiums und verleihen $C$. jejuni eine hohe Motilität. $C$. jejuni-Mutanten mit einem inaktivierten Flagellum besitzen nur eine reduzierte Adhäsions- und Invasionsfähigkeit (WASSENAAR und BLASER 1999). Neben dem Antrieb von C. jejuni ermöglicht das Flagellum die Autoagglutination und Biofilmbildung, bedingt durch eine Schicht von Lipooligosacchariden (GUERRY 2007). Die Sequenzierung von NCTC 11168 führte zur Erkenntnis, dass das Flagellum aus über 50 verschiedenen Proteinen zusammengesetzt ist (PARKHILL et al. 2000). Die Flagellenproteine sind umfangreich glykolisiert und für den funktionellen Aufbau essentiell. Die Gencluster zur Glykolisierung der Flagellenproteine sind unter den verschiedenen Stämmen hoch variabel (GUERRY 2007).

C. jejuni verfügt, ähnlich wie Yersinien und Salmonellen, über ein flagellares Typ-IIIhomologes Sekretionssystem, welches die Virulenz vieler gramnegativer Erreger mitbestimmt. Über den flagellaren Typ-III-homologen Sekretionsapparat werden im Rahmen des Zell- und Gewebsinvasionsprozesses z.B. sogenannte Cia (Campylobacter-InvasionsAntigene) in die Wirtszelle injiziert (DASTI et al. 2010). Durch das Flagellen-Segment werden die Cia Kontakt- oder Stimulus-abhängig sezerniert und unterstützen die Wirtsinvasion einiger C. jejuni-Stämme (KONKEL et al. 2001).

Die Adhäsion von C. jejuni an die Oberfläche der Wirtsepithelzellen wird u.a. durch den Fibronektin-bindenden Faktor CadF (Campylobacter adhesion to fibronectin, outer membrane fibronectin-binding protein, cj1478c) vermittelt. Fibronektin wird von vielen Bakterien als Brückenmolekül zur initialen Anheftung an die Zielzellen genutzt. Das $c a d F-G e n$ ist ein ubiquitär bei allen $C$. jejuni-Stämmen vorkommendes $37 \mathrm{kDa}$ großes Membranprotein (KONKEL et al. 1997).

Die Invasion und Schädigung des Darmepithels (zytopathischer Effekt) kann ferner durch das von Campylobacter produzierte Toxin CDT (cytolethal distending toxin) hervorgerufen werden, dessen Hauptfunktion jedoch auch in der Wirtszelladhäsion liegt. CDT wurde bisher als einziges „klassisches“ Toxin im C. jejuni-Genom identifiziert. Enterotoxine, wie sie sich bei anderen Enteritiserregern, wie z.B. bei Vibrio cholerae oder Shigellen, nachweisen lassen, fehlen (WASSENAAR 1997).

Weiterhin wird die Invasivität von $C$. jejuni durch die Zusammensetzung des Lipooligosaccharids (LOS) beeinflusst. Wie bei vielen anderen Krankheitserregern auch, entsteht durch die Lipooligosaccharide an der Zelloberfläche eine Antigenvariabilität innerhalb der Spezies. Dies spielt eine bedeutsame Rolle in der Interaktion zwischen 
Bakterium und Wirt (PARKER et al. 2008). Während der Kolonisierung des Darms dienen die Lipooligosaccharide des Bakteriums als Adhäsine (MCSWEEGAN und WALKER 1986).

Mittels PCR erfolgt die Unterscheidung in sog. LOS-Klassen, diese Einteilung ist aufgrund der verschiedenen Lipooligosaccharid-Genloci (sog. LOS-Cluster) möglich (PARKER et al. 2005). Von PARKER et al. ( 2005 und 2008 ) wurden bislang 19 LOS-Klassen beschrieben:

A 1/2, B 1/2, C-S. Diese 19 LOS-Klassen können in zwei Gruppen geteilt werden. Ein Teil der Stämme besitzt eine $N$-Acetylneuraminsäure-Transferase und somit ein sialylisiertes LOS. Die Stämme mit sialylisiertem LOS besitzen eine deutlich höhere Zellinvasivität als die Stämme der anderen LOS-Klassen (LOUWEN et al. 2008). Da die sialylierten Lipooligosaccharide als Bestandteil der äußeren Membran Ähnlichkeit mit der Oberflächenstruktur peripherer Nerven und des Hirnstammes aufweisen, sind die sialylierten LOS-Klassen stärker mit neurologischen Störungen wie dem GBS assoziiert (GODSCHALK et al. 2004).

Wesentlich für das Wachstum von Bakterien ist Eisen. Eisen ist ein essentieller Bestandteil beispielsweise als Kofaktor bei der DNS-Synthese oder bei Elektronen-Transfer-Reaktionen und daher für die Vermehrung der Bakterien unverzichtbar (PALYADA et al. 2004). Ist Eisen nur mäßig verfügbar, wird das Wachstum eingeschränkt. Ein begrenztes Eisenangebot dient zudem als Signal, die Genexpression bestimmter Faktoren, z.B. von Hämolysinen oder Siderophoren zu verstärken (LITWIN und CALDERWOOD 1993). Auf der Gegenseite führt aber eine unkontrollierte Eisenaufnahme zu oxidativem Stress und zum Abbruch des Bakterienwachstums (TOUATI 2000). Unter physiologischen Bedingungen ist Eisen allerdings schlecht löslich. Die Bereitstellung von freiem Eisen im Menschen ist für Bakterien dementsprechend sehr gering. Somit bestimmt die Befähigung des Bakteriums, Eisen auch unter limitierten Voraussetzungen im Wirt zu akquirieren, dessen Virulenz und Überleben (GRANT et al. 1997). Da die Verfügbarkeit von freiem Eisen im Wirtsgewebe aufgrund von Komplexbildungen sehr gering ist, haben viele Bakterien ein spezielles Eisen-Akquirierungs-System entwickelt. Dieses besteht aus hochspezifischen Chelatoren für Eisen-Ionen, s.g. Siderophore, wodurch Eisen aus bestehenden Komplexen im Wirt gelöst werden kann (RATLEDGE und DOVER 2000). C. jejuni verfügt wie die meisten gramnegativen Bakterien über eine Vielzahl von Sytemen zur Eisenaufnahme und -verwertung, von denen bisher allerdings nur einige näher charakterisiert worden sind. Das Genom von NCTC 11168 kodiert fünf EisenAufnahme-Systeme, die hauptsächlich in Operonen organisiert sind: ein Enterochelin- 
Aufnahme-Protein $(c e u B C D E)$, ein Eisenaufnahmeprotein ( $f f r A / c j 0755)$, ein SiderophoreRezeptor der äußeren Membran (cj0178), ein System zur Hämin-Aufnahme (chuABCD ) und cj0173c-0175c, eine an ein periplasmatisches Bindeprotein gekoppelte Komponente (PARKHILL et al. 2000).

Im Jahr 2000 wurde die komplette Genom-Sequenz des C. jejuni-Stammes NCTC 11168 publiziert (PARKHILL et al. 2000). Das Genom weist eine Größe von 1,64 Mb und einen G+CGehalt von 30,6\% auf und kodiert insgesamt für 1,654 Proteine. Die kodierenden Sequenzen (CDS) entsprechen etwa 94,3\% des Gesamtgenoms und machen es damit zum dichtesten bakteriellen Chromosom, das bisher sequenzanalysiert wurde. Eine außergewöhnliche Beobachtung im Genom von NCTC 11168 sind hypervariable Sequenzen, die häufig in Genen für Proteine der Biosynthese oder von Oberflächenstrukturen nachgewiesen wurden. Diese beträchtliche Variabilität innerhalb des Genomsequenz könnte ein wichtiger Bestandteil der Überlebensstrategie von $C$. jejuni sein. Die hypervariablen Regionen im $C$. jejuniChromosom treffen vornehmlich mit den Genclustern für LOS- und EP-Biosynthese sowie für die Modifikation der Flagellen zusammen (PARKHILL et al. 2000).

Im Folgenden werden die potentiellen Virulenz-assoziierten Faktoren bzw. die entsprechenden Gene: cj1321-1326, ciaB, cdtB, fucP, cj0178, cj0755, ceuE, pldA und cstII/cstIII genauer erläutert, da diese im Zuge der Arbeit näher analysiert werden sollen.

\subsubsection{Gencluster zur Flagellin- $O$-Glykolisierung}

CHAMPION et al. (2005) entdeckten, dass ein Cluster von sechs Genen cj1321-1326 zur Flagellin- $O$-Glykolisierung überwiegend in Stämmen aus Nutztierbeständen auftritt. Sie stellten die Hypothese auf, dass dieser Sechs-Gen-Cluster eine spezielle Flagellin-Glykoform hauptsächlich in Stämmen von Nutztierbeständen kodiert und damit eine Rolle bei der Wirtszellinvasion spielt. 


\subsubsection{Lipooligosaccharid-Sialyltransferase-Marker}

Ein weiterer Faktor, der das Invasionspotential eines $C$. jejuni-Isolates bestimmt, ist die Zusammensetzung des Lipooligosaccharids (LOS). Die C. jejuni-Stämme der unter Punkt 1.4.1 beschriebenen LOS-Klassen A1/2, B1/2, C, M und R besitzen Gene bzw. Enzyme für die Sialylierung des LOS. Zu diesen Genen gehören ein Homolog des neuBCA-Gens, das für eine Neuraminsäure-Synthease kodiert sowie ein Homolog des cstII-Gens (Tabelle1, Punkt 2.6.2), welches eine Sialinsäure-Transferase verschlüsselt (GILBERT et al. 2002).

Alle anderen, nicht neuraminsäurehaltigen LOS-Klassen besitzen dementsprechend nicht die erforderlichen cst-Gene für die Sialylierung des LOS (PARKER et al. 2008). Das cstIII-Gen (orf7c) findet sich bei LOS-Klasse C-Isolaten (PARKER et al. 2005), cstII (orf7ab) dagegen bei LOS-Klasse A und B-Isolaten (PARKER et al. 2005). PARKER et al. (2005) konnten in einer Studie von 123 getesteten $C$. jejuni-Isolaten durch PCR ableiten, dass mehr als 60,0 \% der Isolate LOS-Klasse A, B oder C angehören.

Dass das Invasionspotential mit bestimmten LOS-Klassen korreliert, konnten bereits diverse Arbeiten belegen. So gehört die Mehrheit der hyperinvasiven Isolate der LOS-Klasse C, die wiederum mit dem MLST-CC 21 assoziiert ist, an (FEARNLEY et al. 2008).

\subsubsection{Camplyobacter-Invasions-Antigen B}

Beim Invasionsprozess kommt auch dem sog. Campylobacter-Invasions-Antigen (Cia) eine besondere Bedeutung zu. Bisher wurden acht verschiedene Cia von KONKEL et al. 1999 nachgewiesen. Das C. jejuni-Protein $\mathrm{CiaB}(73 \mathrm{kDa})$ ist für die Invasion von C. jejuni erforderlich und wird im Verlauf der Zellinvasion direkt in das Zytoplasma der Zielzelle injiziert, $c i a B$-Defektmutanten waren dazu nicht in der Lage. Die Sekretion der anderen Cia (CiaA; CiaC-CiaH) ist CiaB-abhängig (KONKEL et al.1999).

\subsubsection{Zytolethales distendierendes Toxin (Cytolethal Distending Toxin)}

Das Zytotoxin CDT besteht aus drei Untereinheiten (CdtA, CdtB und CdtC), von denen CdtB die aktive zytotoxische Komponente darstellt. Nach Bindung von $\mathrm{CdtA}$ und $\mathrm{CdtC}$ an die Wirtszelloberfläche kommt es zur Aktivierung von CdtB. Die B-Untereinheit wird ins 
Zytoplasma der Wirtszelle transloziert und anschließend in den Zellkern geschleust. CdtB führt zum Zellzyklusarrest in der G2/M-Übergangsphase (KARLYSHEV und WREN 2001, PICKETT und WHITEHOUSE 1999). CDT induziert damit einen für Campylobacter typischen zytopathischen Effekt - ein Aufblähen und Anschwellen der Epithelzellen. Des Weiteren sterben vereinzelt Zellen ab (WHITEHOUSE et al. 1998). Daneben scheint das Toxin auch eine Rolle in der Modifikation der Immunantwort zu spielen (DASTI et al. 2010).

\subsubsection{Phospholipase A der äußeren Membran}

Ebenso wurde das Gen pldA in den Kreis der zu untersuchenden Virulenz-assoziierten Faktoren einbezogen.

Das Gen pldA kodiert für die Phospholipase A der äußeren C. jejuni-Membran. Dieses 35 kDa schwere Protein weist eine bedeutsame Ähnlichkeit zur Phospholipase der äußeren Membran von E. coli auf. Zahlreiche Bakterien nutzen Phospolipasen zur Lyse von Erythrozyten, beispielsweise Helicobacter pylori (ANSORG et al. 1993). Damit tragen Phospolipasen auch zum krankheitserregenden Potential der Bakterien bei (GRANT et al. 1997). GRANT et al. (1997) konnten zeigen, dass Phospholipase A auch bei Campylobacter zur zell-assoziierten hämolytischen Aktivität beiträgt und somit eine Bedeutung als Virulenz-assoziierter-Faktor einnimmt.

\subsubsection{Eisen-Akquirierung}

Da das Spurenelement Eisen wie für nahezu alle lebenden Organismen auch für $C$. jejuni essentiell ist, wurden in den Betrachtungen die Gene dreier Eisenaufnahmesysteme berücksichtigt: ein Bindeprotein zur Enterochelin Aufnahme (ceuE), ein SiderophoreRezeptor der äußeren Membran (cj0178) und ein Eisenaufnahmeprotein (cj0755).

Um Eisen aus bestehenden Komplexen im Wirt herauszulösen, haben Bakterien verschiedene Taktiken zur verbesserten Eiseneinlagerung wie Siderophore-vermittelte Eisenaufnahme-systeme entwickelt. C. jejuni ist selbst nicht in der Lage Siderophore zu produzieren (PICKETT et al. 1992), bzw. es wurden im Genom von NCTC 11168 keine GenHomologe für Siderophore gefunden (PARKHILL et al. 2000). Diese Tatsache legt nahe, dass $C$. jejuni in der Lage ist, exogene Siderophore, produziert von anderen Bakterien, zu 
nutzen. Diese werden durch ein Transportsystem im Darmtrakt abgefangen (van VLIET et al. 2002). Durch сеи (campylobacter enterochelin uptake-binding-protein, сеиBCDE) werden Komponenten eines Bindungs-Protein-abhängigen Transportsystems speziell für Enterochelin kodiert (van VLIET et al. 2002).

Das Gen ceuE kodiert ein Lipoprotein (34,5 bis 36,2 kDa), welches als Bindungsprotein an der Aufnahme des Siderophores Enterochelin (auch bezeichnet als Enterobactin) beteiligt ist (RICHARDSON und PARK 1995).

Die Eisenverfügbarkeit hat Einfluss auf die Besiedlung des Magen-Darmtraktes während der Infektion mit $C$. jejuni, weswegen zwei weitere Gene in die Betrachtungen einbezogen wurden. Ebenso wie ceuE sind die Genprodukte von cj0178 und cj0755(cfrA) an der bakteriellen Eisenaufnahme beteiligt. Das Gen cj0178 kodiert einen Siderophore-Rezeptor der äußeren Membran und cj0755 kodiert ein Eisenaufnahmeprotein.

\subsubsection{Fucose-Verwertung}

Die Stoffwechselleistung eines Organismus ist keine klassische Komponente, um Aussagen über dessen Virulenz zu treffen, gleichwohl ist die Verfügbarkeit von Nährstoffen ein essentieller Faktor, um im Wirt zu überleben und Krankheiten zu initieren (MURAOKA und ZHANG 2011).

C. jejuni metabolisiert nur wenige Aminosäuren (Prolin, Serin) und hauptsächlich Intermediärprodukte des Tricarbonsäurezyklus (Zitratzyklus), z.B. durch Reduktion von Fumarat zu Succinat, als Energiequelle zum Wachstum und zur Wirtszellinvasion (LEE und NEWELL 2006, KELLY 2001). Die zusätzliche Metabolisation der Aminosäuren Glutamin und Gluthation wird für eine Gruppe von $C$. jejuni-Stämmen durch Expression von $g g t$ ermöglicht. Außerdem konnten HOFREUTER et al. (2008) zeigen, dass ansB-positive Stämme Asparagin metabolisieren können. Assoziiert mit diesem erweiterten AminosäureMetabolismus, existiert ein alternativer anerober Stoffwechselweg, dessen Leitenzym die Dimethyl-Sulfoxide-Oxidoreduktase (dmsA-D) ist (HOFREUTER et al. 2006 und 2008). Eine Schlüsselrolle in der Utilisation der Aminosäuren Glutamat und Aspartat spielt das ubiquitär bei allen $C$. jejuni-Stämmen vorkommende PEBla-Transportsystem. Dieses periplasmatische Bindungsprotein PEB1a ist eine Komponente des ABC-Transporters PEB1 und unabdingbare 
Vorraussetzung für die Nutzung der Aminosäuren Glutamat und Aspartat als Kohlenstoffquelle (PEI et al. 1991, PEI und BLASER 1993).

C. jejuni ist nicht in der Lage, Glukose als Kohlenstoffquelle zu nutzen, da dem Bakterium das Enzym Phosphofruktokinase fehlt (PARKHILL et al. 2000, VELAYUDHAN und KELLY 2002). Das NCTC 11168-Genom weist aufgrund einer Phosphofruktokinase-Absenz nur einen unvollständigen EMP-Weg auf (PARKHILL et al. 2000). Weshalb davon ausgegangen wird, dass das Wachstum im Wesentlichen von der Verfügbarkeit freier Amino-und Ketosäuren aus dem Stoffwechsel des Wirtsorganismus bzw. von dessen intestinaler Standortflora abhängt (LEE und NEWELL 2006). Dagegen konnten STAHL et al. 2011 zeigen, dass einige C. jejuni-Stämme in der Lage sind L-Fucose aufzunehmen und zu metabolisieren, da einzelne Stämme in ihrer Studie im Beisein von Fucose ein verstärktes Wachstum offenbarten. Fucose ist ein integraler Bestandteil der intestinalen Mucosa und kann während der Darmkolonisation des Wirts aufgenommen werden. Als Hauptquelle für Fucose dient der Wirt selbst. Ein Großteil der zelloberflächen-assoziierten Mucine ist fucolysiert. Auch der Wirt selbst sezerniert fucolysierte Glycane. Diese können als Kohlenstoffquelle von C. jejuni genutzt werden (STAHL et al. 2011).

MURAOKA und ZHANG identifizierten 2011 einen Genort, der für die Nutzung von Fucose als Substrat notwendig ist. Dieser Fucose-Phänotyp ist Stamm-spezifisch und kann die Anpassung an nährstoffreiche Umgebungen verbessern. Das Gen fucP ist ein Bestandteil dieser Genregion und kodiert eine Permease um L-Fucose ins Bakterium zu transportieren (STAHL et al. 2011).

Die Möglichkeit einzelner C. jejuni-Stämme, Fucose als Substrat zu nutzen, kann einen enormen Wettbewerbsvorteil bedeuten (MURAOKA und ZHANG 2011).

\subsection{Zusammenhang verschiedener $C$. jejuni-Gruppen}

Der Zusammenhang verschiedener $C$. jejuni-Gruppen verschiedener Herkunft wurde bereits 2011 entsprechend Stoffwechsel-assoziierter genetischer Marker beleuchtet. Dazu wurden diese Isolate auf das Vorhandensein sechs Metabolismus-assoziierter genetischer Marker überprüft Um zu beurteilen, ob ihre Präsenz mit verschiedenen klonalen Komplexen von $C$. jejuni korreliert (ZAUTNER et al. 2011). 
Metabolismus-assoziierte Marker:

- $\quad \boldsymbol{a n s} \boldsymbol{B}$ (periplasmatische Asparaginase)

- $\boldsymbol{d} \boldsymbol{m} \boldsymbol{s} \boldsymbol{A}$ (eine Untereinheit der Dimethylsulfoxid-Oxidoreduktase),

- $\quad c j 1585 c$ (Oxidoreduktase)

- cjj81-176-1367/71 (Serin-Protease)

- $\quad t l p 7_{m+c}$ (transducer-like Protein, zusammengesetzt aus $c j 0951 c$ und $c j 0952 c$ )

- $\quad$ ggt (periplasmatische $\gamma$-Glutamyl-Transpeptidase)

\begin{tabular}{|c|c|c|c|c|c|c|c|c|}
\hline \multirow[t]{2}{*}{ Group or subgroup } & \multicolumn{6}{|c|}{ Most prevalent marker genes $\underline{\underline{a}}$} & \multirow[t]{2}{*}{$\mathrm{CC}$} & \multirow[t]{2}{*}{$\operatorname{Origin}(\mathbf{s})^{\underline{b}}$} \\
\hline & \multicolumn{6}{|c|}{ 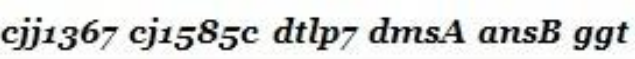 } & & \\
\hline 1a & $\mathrm{x}$ & $\mathrm{x}$ & $\mathrm{x}$ & & & & 21 & $\mathrm{~b}$ \\
\hline $1 \mathrm{~b}$ & $\mathrm{x}$ & $\mathrm{x}$ & & & & & $21,48,49,206,446$ & $h, c, b, t$ \\
\hline $2 a$ & $\mathrm{x}$ & & & $\mathrm{x}$ & $\mathrm{x}$ & $\mathrm{x}$ & 22,42 & $\mathrm{~h}, \mathrm{c}, \mathrm{b}$ \\
\hline $2 b$ & & & & $\mathrm{x}$ & $\mathrm{x}$ & $\mathrm{X}$ & 45,283 & h, c \\
\hline $3^{a}$ & $\mathrm{x}$ & $\mathrm{x}$ & & & & & $52,353,354,443,658,828$ & $\mathrm{~h}, \mathrm{c}, \mathrm{t}$ \\
\hline $3^{b}$ & $\mathrm{x}$ & $\mathrm{x}$ & $\mathrm{x}$ & & & & 61 & $\mathrm{~b}$ \\
\hline 4 & & & & $\mathrm{x}$ & & & 1034,1332 & $\mathrm{t}$ \\
\hline 5 & $\mathrm{x}$ & $\mathrm{x}$ & & & & & None & c \\
\hline 6 & $\mathrm{x}$ & & & $\mathrm{x}$ & $\mathrm{x}$ & & 257 & $h, t$ \\
\hline
\end{tabular}

${ }^{a}$ cjj1367, cjij1176-1367/1371 gene (cj1365c), encoding a serine protease; cj1585c, gene encoding an oxidoreductase and replacing $d m s A$ to $-D$ in NCTC 11168; dt/p7, cj0951c and cj0952c genes, encoding the heterodimeric form of transducer-like protein 7; dms A, gene encoding the dimethyl sulfoxide oxidoreductase subunit $\mathrm{A}$; ansB, gene encoding an asparaginase with an accessory $\mathrm{N}$-terminal secdependent secretion signal for periplasmic localization of the enzyme; ggt, gene encoding the-glutamyl-transpeptidase.

${ }^{b}$ h, human; c, chicken; b, bovine; t, turkey.

\section{Abb. 2: Verteilung gentischer $C$. jejuni-Marker, MLST-CC und Isolat-Herkunft}

Abbildung übernommen von ZAUTNER et al. 2011,S.2361

(Übersetzung der Bildunterschrift: ${ }^{a}$ prävalente Marker: cjj1367, cjj811-76-1367/71(cj1365c) kodiert eine Serin-Protease, $c j 1585 c$ (Oxidoreduktase), $t l p 7_{m+c}$ (dimeres Transducer-likeProtein), dmsA (kodiert eine Untereinheit der Dimethylsulfoxid-Oxidoreduktase A), ansB (eine periplasmatische Asparaginase) und ggt (eine periplasmatische $\gamma$-GlutamylTranspeptidase) ${ }^{b}$ Ursprung(engl.origin) : h-Mensch, c-Huhn, b-Rind, t-Pute ; CC-klonaler Komplex Gruppe/ Untergruppe (engl.group or subgroup): Einteilung der 266 Isolate in Gruppen 
Abbildung 2 gibt die Verteilung der Metabolismus-assoziierten genetischen Marker, die MLST-CC-Zugehörigkeit und die Isolat-Herkunft wieder. Zusammen mit den Ergebnissen der MLST-Typisierung konnten die 266 Isolate in 6 Haupt- und 9 Untergruppen unterteilt werden, was ebenfalls aus Abb. 2 ersichtlich wird. Die Gruppen zeigen nur eine mäßige Korrelation mit der Isolat-Herkunft (ZAUTNER et al. 2011).

Gruppe 1-Isolate sind positiv für cjj811-76-1367/71 und cj1585c. Isolate dieser Gruppe gehören zu den MLST-CC 21, 48, 49, 206 oder 446. Die Isolate aus Gruppe 3 sind wie Gruppe 1 positiv für cjj811-76-1367/71 und cj1585c. Allerdings gehören sie den MLST-CC 52, 353, 354, 443, 658 und 828 an. In Untergruppe $3 \mathrm{~b}$ wurden $t l p 7_{m+c}$ positive Isolate detektiert.

Gruppe 2-Isolate sind überwiegend positiv für $d m s A$, ansB und ggt und gehören den MLSTCC 22, 42, 45 oder 283 an. Die Mehrheit der Gruppe 4-Isolate gehört zu den MLST-CC 1034 und 1332 und ist $a n s B^{+}$. Gruppe 5-Isolate sind positiv für cjj811-76-1367/71 und $c j 1585 c$. Schließlich finden sich in Gruppe 6 MLST-CC 257- Isolate, die positiv für cjj811-761367/71, dmsA und ans B, aber nicht für $g g t$ sind.

Zur Unterscheidung von MLST-CC 45 und 283- von MLST-CC 22 und 42 Isolaten, die zusätzlich cjj811-76-1367/71 positiv sind, können die in Zusammenhang stehenden Marker ansB, $d m s A$ und ggt betrachtet werden. Außerdem kann eine Differenzierung zwischen CC 21, CC 48 und CC 206 vorgenommen werden, da diese Isolate ausschließlich cj1585c- und cjj811-76-1367/71-positiv sind. Der aus zwei Genen zusammengesetzte Marker $t l p 7_{\mathrm{m}+\mathrm{c}}$ ist typisch für MLST-CC 21, 53 und 61 und korreliert stark mit bovinem Isolatursprung (ZAUTNER et al. 2011). 


\subsection{Zielsetzung}

C. jejuni ist weltweit der häufigste bakterielle Enteritiserreger, deshalb besteht ein epidemiologisches Interesse daran, das gesundheitsgefährdende Potential verschiedener Stämme zu analysieren. Die Virulenz von C. jejuni wird, wie zuvor beschrieben, von unterschiedlichen Faktoren und Eigenschaften des Bakteriums bestimmt.

Ziel der vorliegenden Arbeit ist die molekular-epidemiologische Untersuchung einer 266 Isolate umfassenden C. jejuni-Stammsammlung auf die Präsenz zehn weiterer Virulenzassoziierter Faktoren: cj1321-1326 (ein sechs Gene umfassender Komplex zur Flagellin- $O$ Glykolisierung), ciaB (Campylobacter-Invasions-Antigen B), cdtB (kodiert die Untereinheit B des zytolethalen distendierenden Toxins - CDT), fucP (L-Fucose-Permease Gen), cj0178/cj0755 (Eisentransporter), ceuE (ein Enterochelin-bindendes Aufnahme-Protein), pldA (Phospholipase A der äußeren Membran) und cstII/cstIII (die LipooligosaccharidSialyltransferase-Isoenzyme II und III) um die bestehende Gruppendefinition zu überprüfen und anhand der neuen Marker weiter zu konkretisieren.

Außerdem sollten die klinischen Parameter Hospitalisierung und blutige Diarrhö für die Isolate, welche aus humanen Stuhlproben angezüchtet wurden, in die Untersuchungen einbezogen werden, um die Isolat-Gruppen mit der höchsten Virulenz zu identifiziern. 


\section{Material und Methoden}

\subsection{Untersuchungsgut und Materialien}

\subsubsection{Bakterienstämme}

In der vorliegenden Arbeit wurden 266 C. jejuni-Isolate, davon 129 vom Menschen, 67 von Hühnern, 43 von Rindern und 27 von Puten untersucht. Diese wurden bereits in einer vorherigen Studie MLST typisiert (ZAUTNER et al. 2011). Eine Übersicht über alle verwendeten $C$. jejuni-Stämme gibt Tabelle 13 im Anhang. Als Referenzstamm dienten die Stämme NCTC 11168 und 81-176.

Von Herrn Prof. Dr. Thomas Alter (Bundesinstitut für Risikobewertung, Berlin) wurden freundlicherweise die Rinder-, Puten- und ein Teil der Hühner-Isolate bereitgestellt, weitere Hühner-Isolate stammen von Frau Dr. Ingrid Hänel vom Friedrich-Löffler-Institut in Jena.

Aus dem Stuhllabor des Institutes für Medizinische Mikrobiologie der Universitätsmedizin Göttingen stammen die humanen Isolate, welche freundlicherweise von Frau Zimmermann an die Campylobacter-Arbeitsgruppe weitergegeben wurden.

Die Gattung wurde initial mittels API Campy (Biomerieux) identifiziert. Die Speziesdifferenzierung zwischen $C$. coli und $C$. jejuni erfolgte mittels Multiplex-PCR (nach VANDAMME et al. 1997) und MALDI-TOF MS mit dem Massenspektrometer Autoflex III TOF/TOF und BioTyper3.0-Software (Bruker Daltonics, Bremen).

Die Referenzstämme NCTC 11168 und 81-176 wurden von der ATCC (American Type Culture Collection) gekauft.

\subsubsection{Charakterisierung der C. jejuni -Untergruppen}

In einer vorrangegangen Studie wurde bereits durch Kombination von MLST mit dem Nachweis von sechs Markergenen die Existenz von sechs $C$. jejuni- Untergruppen gezeigt (ZAUTNER et al. 2011). 
Zur breiteren Charakterisierung wurden dieselben 266 Isolate auf das Vorhandensein zehn weiterer Markergene, sowie auf eine Assoziation mit den klinischen Parametern Hospitalisierung und Blut im Stuhl untersucht.

Von den 266 C. jejuni-Isolaten wurden über die Hälfte (129 Isolate) aus humaner Fäzes angezüchtet. Diese menschlichen Isolate stammen zum Teil aus Stuhlproben von in der Universitätsmedizin Göttingen hospitalisierten Patienten (40 \%) und zum anderen Teil von ambulanten Patienten aus Arztpraxen in und um Göttingen (60 \%). Für 104 der 129 Proben liegen Informationen über die Parameter wässriger Stuhl (85 \% der Proben) und blutiger Stuhl (15\% der Proben) vor.

Virulenz-assoziierte Marker:

- $\quad$ cj1321-cj1326 - ein Sechs-Gen-Komplex zur Flagellin-O-Glykolisierung

- $\boldsymbol{f u c}$ - das L-Fucose-Permease Gen

- $\boldsymbol{c e u} \boldsymbol{E}$ - ein Enterochelin-bindendes Aufnahme-Protein

- $\quad$ pldA - Phospholipase A der äußeren Membran

- $\quad$ cstII und cstIII - Lipooligosaccharid- Sialyltransferase-Isoenzyme II und III

- $\quad \boldsymbol{c i a B}$ - das Campylobacter- Invasions-Antigen B

- $\boldsymbol{c d t B}$ - kodiert die cytolethal distending toxin (CDT) Untereinheit B

- $\quad$ j0178 - Siderophore-Rezeptor der äußeren Membran

- $\quad \boldsymbol{c j 0 7 5 5 / c f r A ~ - ~ e i n ~ E i s e n a u f n a h m e p r o t e i n ~}$

Alle Primer für die Polymerasekettenreaktion sind in Tab.1 aufgeführt und wurden von der Firma Sigma-Aldrich (Steinheim) bezogen.

Vor Gebrauch sind die Primer entsprechend der Herstellerangaben mit Aqua bidest verdünnt und auf eine Konzentration von $100 \mu \mathrm{M} / \mathrm{ml}$ (Stammlsg.)eingestellt worden .Nach der Herstellung einer 1:10-Verdünnung wurden die Stammlösungen und Verdünnungen bei -20 ${ }^{\circ} \mathrm{C}$ aufbewahrt. 
Tabelle 1: Primer für die Amplifikation der Markergene

\begin{tabular}{|c|c|c|c|c|}
\hline Gen & Bezeichnung & Sequenz $5^{6}-3^{6}$ & Annealing & Referenz \\
\hline \multirow[t]{2}{*}{ cj1321 } & CjNCTC11168-1321_f & AAAATGTCATCATCATAGGAGCG & \multirow[t]{2}{*}{$60,0^{\circ} \mathrm{C}$} & \multirow{2}{*}{$\begin{array}{l}\text { CHAMPION } \\
\text { et al. } 2005\end{array}$} \\
\hline & CjNCTC11168-1321_r & TCTAAGTTTACGCAAGGCAACA & & \\
\hline \multirow[t]{2}{*}{ cj1322 } & CjNCTC11168-1322_f & GACTTTGGTTTAATGGGTAAGCA & $59,6^{\circ} \mathrm{C}$ & \multirow{2}{*}{$\begin{array}{l}\text { CHAMPION } \\
\text { et al. } 2005\end{array}$} \\
\hline & CjNCTC11168-1322_r & TTCCGGCGTTAAAATTAGAAAA & & \\
\hline \multirow[t]{2}{*}{ cj1323 } & CjNCTC11168-1323_f & AGAACGATTTACCCCATTGAAA & $59,7^{\circ} \mathrm{C}$ & \multirow{2}{*}{$\begin{array}{l}\text { CHAMPION } \\
\text { et al. } 2005\end{array}$} \\
\hline & CjNCTC11168-1323_r & ATTTGCTAAAGCTCCTCGATTG & & \\
\hline \multirow[t]{2}{*}{ cj1324 } & CjNCTC11168-1324_f & TGCCGTAAGTGGAGGTAAAGAT & $60,0^{\circ} \mathrm{C}$ & \multirow{2}{*}{$\begin{array}{l}\text { CHAMPION } \\
\text { et al. } 2005\end{array}$} \\
\hline & CjNCTC11168-1324_r & TCTGCACACATTGTTCTATCCC & & \\
\hline \multirow[t]{2}{*}{ cj1325 } & CjNCTC11168-1325_f & ACGGATTACTTTTTCCAGATGGT & $60,0^{\circ} \mathrm{C}$ & \multirow{2}{*}{$\begin{array}{l}\text { CHAMPION } \\
\text { et.al } 2005\end{array}$} \\
\hline & CjNCTC11168-1325_r & TTTGCTTTGAAAATACGCTGAA & & \\
\hline \multirow[t]{2}{*}{ cj1326 } & CjNCTC11168-1326_f & TACATTTCATCGATAAAGCCGA & $59,7^{\circ} \mathrm{C}$ & \multirow{2}{*}{$\begin{array}{l}\text { CHAMPION } \\
\text { et al. } 2005\end{array}$} \\
\hline & CjNCTC11168-1326_r & AAATATAATGGTGTGCCGATCC & & \\
\hline \multirow[t]{4}{*}{ fucP } & cj0486FWD & GATAGAGCATTAAATTGGGATG & $52,0{ }^{\circ} \mathrm{C}$ & \multirow{4}{*}{$\begin{array}{l}\text { MURAOKA } \\
\text { und ZHANG } \\
2011\end{array}$} \\
\hline & cj0486REV & CCTATAAAGCCATACCAAGCC & & \\
\hline & rpoC & GAACTTGCTATTGCTGAGCC & & \\
\hline & rpsL & ACCCTAGTGCAAACTCCCCT & & \\
\hline \multirow[t]{3}{*}{ ceuE } & ceuE-811-76F01 & GATAGAGTCGCAGGCGTTCC & $60,0{ }^{\circ} \mathrm{C}$ & diese Studie \\
\hline & ceuE405F & GATAAAGTCGTTGGCGTTCC & & FEODOROFF \\
\hline & ceuE405R & GCGAGATTGGAGGACCAAAGG & & et al. 2010 \\
\hline \multirow[t]{3}{*}{ pldA } & pldA-81178F01 & AAACTTATGCGTTTTT & $45,0{ }^{\circ} \mathrm{C}$ & diese Studie \\
\hline & pldA-84fwd & AGCTTATGCGTTTTT & & FEODOROFF \\
\hline & pld-981rev & TATAAGGCTTTCTCCA & & et al. 2010 \\
\hline
\end{tabular}




\begin{tabular}{|c|c|c|c|c|}
\hline \multirow[t]{3}{*}{ cstII } & orf7ab & $\begin{array}{l}\text { ACTACACTTTAAAACATTTAATC } \\
\text { C AАAATCA }\end{array}$ & $56,0^{\circ} \mathrm{C}$ & \multirow[t]{3}{*}{$\begin{array}{l}\text { PARKER } \\
\text { et al. } 2005\end{array}$} \\
\hline & orf7ab & CCATAAGCCTCACTAGAAGGTA & & \\
\hline & & TGAGTATA & & \\
\hline \multirow[t]{3}{*}{ cstIII } & orf7c & $\begin{array}{l}\text { TTGAAGATAGATATTTTGTGGGT } \\
\text { AAA }\end{array}$ & $56,0^{\circ} \mathrm{C}$ & $\begin{array}{l}\text { PARKER } \\
\text { et al. } 2005\end{array}$ \\
\hline & orf7c & CTTTAAGTAGTGTTTTATGTCAC & & \\
\hline & & TTGG & & \\
\hline \multirow[t]{4}{*}{$c i a B$} & ciaB-F & TCATGCGGTGGCATTAGAATGG & $57,5^{\circ} \mathrm{C}$ & Tareen \\
\hline & & G & & et al. 2011 \\
\hline & ciaB-R & CATCATTTGGAACGACTTGAGCT & & \\
\hline & & GAGA & & \\
\hline \multirow[t]{2}{*}{$c d t B$} & $\operatorname{cgtB}-\mathrm{F}$ & TGCAAGGCTCATCCGCAGCC & $59,0^{\circ} \mathrm{C}$ & Tareen \\
\hline & $\operatorname{cgtB}-\mathrm{R}$ & TGGCGTCCTGTTGGAGTGGC & & et al. 2011 \\
\hline \multirow[t]{2}{*}{$\operatorname{cj0178}$} & cj0178-F01 & TGTAGGCGGGGGTGGCAAGA & $54,0^{\circ} \mathrm{C}$ & \multirow{2}{*}{$\begin{array}{l}\text { diese } \\
\text { Studie }\end{array}$} \\
\hline & cj0178-R01 & ACGACCGCGAGCAGAATTGC & & \\
\hline \multirow{2}{*}{$\begin{array}{l}\text { cj0755/ } \\
\text { cfrA }\end{array}$} & cj0755/cfrA-F01 & ATGGCCGCGAAGTCGTAGGG & \multirow[t]{2}{*}{$54,0{ }^{\circ} \mathrm{C}$} & \multirow{2}{*}{$\begin{array}{l}\text { diese } \\
\text { Studie }\end{array}$} \\
\hline & cj0755/cfrA-R01 & AGCGATCTATTTGCCACTCGCCT & & \\
\hline
\end{tabular}




\subsubsection{Nukleinsäuren-Längenstandards}

Um die Größe von DNS-Fragmenten zu ermitteln, wurden der Längenstandard „GeneRuler ${ }^{\mathrm{TM}}$ 1kb Plus DNA Ladder“ (Fermentas GmbH, St. Leon-Rot) und der „Smart-Ladder“ (Eurogentec, Köln) verwandt.

Längenstandard „GeneRuler ${ }^{\mathrm{TM}} 1 \mathrm{~kb}$ Plus DNA Ladder“:

Fragmentgrößen in bp: 20000/10000/7000/5000/4000/3000/2000/1500/1000/700/

$$
500 / 400 / 300 / 200 / 75
$$

Längenstandard „SmartLadder“:

Fragmentgrößen in bp: 10000/8000/6000/5000/4000/3000/2500/2000/1500/1000/

$800 / 600 / 400 / 200$

\subsubsection{Verwendete Enzyme}

Tabelle 2: Enzyme

\begin{tabular}{ll}
\hline Enzym & Hersteller/Ort \\
\hline Taq-DNS-Polymerase & Roche/ Basel, Schweiz \\
Proteinkinase K & QIAGEN/Venlo, Niederlande
\end{tabular}

\subsubsection{Puffer und Nährmedien}

Elektrophoresepuffer-Lösung

TAE-Puffer (50x)

$$
\begin{aligned}
& \text { 20ml TAE(50×) } \\
& \text { mit } 980 \mathrm{ml} \mathrm{H}_{2} \mathrm{O}
\end{aligned}
$$

2M Tris

50mM EDTA (pH 7, 5-7, 8)

$5,75 \%(v / v)$ Essigsäure

MERCK KGaA/Darmstadt

BHI-Medium 

Lysispuffer ATL und AL
QIAGEN/Venlo, Niederlande
Elutionspuffer AE
QIAGEN/Venlo, Niederlande

\subsubsection{Weitere Chemikalien, Reagenzien, Verbrauchsmittel und Geräte}

\section{Tabelle 3: Chemikalien und Reagenzien}

\begin{tabular}{ll}
\hline Substanz & Hersteller/Ort \\
\hline $6 \times$ DNA Loading Dye & MBI Fermentas, St. Leon-Rot
\end{tabular}

Agarose NEED Ultra-Qualität Roti®garose Carl Roth GmbH/Karlsruhe für die DNS/RNS-Elekrophorese

Ethidiumbromid, $95 \%$ (HPLC) SIGMA-ALDRICH®/St.Louis,USA

Nukleinsäuren-Längenstandard Fermentas GmbH/St.Leon-Rot

„GenRulerTM 1kb Plus DNA Ladder”

Nukleinsäuren-Längenstandard Eurogentec/Köln

"SmartLadder"

PCR Grade Nucleotide Mix

Roche/Basel, Schweiz

(dATP,dCTP,dGTP,dTTP)

PCR reaction buffer, $10 \times$ konz.

Roche/Basel, Schweiz

Columbia -Agar (Basis)

MERCK KGaA/Darmstadt

Ethanol, absolut

MERCK KGaA/Darmstadt

Schafsblut, defibriniert

OXOID Ltd./Hampshire, England 
Glycerin, etwa $87 \%$ reinst

MERCK KGaA/Darmstadt

Aqua bidest

Tabelle 4: Verwendete Verbrauchsmaterialien

\begin{tabular}{ll}
\hline Produkt & Hersteller/Ort \\
\hline Entsorgungsbeutel & Labor-Brand/Gießen \\
Filter-Pipettenspitzen & SARSTEDT/Nümbrecht \\
Flächendesinfektionsmittel "Biguacid & ANTISEPTICA/Pulheim/Brauweiler \\
Liquid” & \\
Labortücher (Kimwipes) & Kimberly-Clark/Dallas,USA \\
Nitrilhandschuhe: "Nitro-Tex®EP” & Ansell/Brüssel,Belgien \\
PCR-Reagiergefäß 0,2 ml & Biozym/Hessisch Oldendorf \\
Pipettenspitzen (verschiedene Farben) & SARSTEDT/Nümbrecht \\
Pipettierhilfe : Pipetus ${ }^{\circledR}-A k k u$ & Hirschmann Laborgeräte GmbH \& Co.KG/ \\
& Eberstadt \\
Reagiergefäß 0,5 ml & Eppendorf/Hamburg \\
Reagiergefäß 2,0 ml & SARSTEDT/Nümbrecht \\
Schutzhandschuhe & Microflex Corporation/Wien,Österreich \\
Campy Gen TM CN25 & OXOID Ltd. /Hampshire, England \\
Einweg-Impfschlingen(1 $\mu 1$ u. 10 $\mu 1)$ & SARSTEDT/Nümbrecht \\
Wattetupfer & COPAN innovation/Brescia, Italien \\
&
\end{tabular}

Tabelle 5: Verwendete Geräte

\begin{tabular}{|c|c|}
\hline Gerät & Hersteller/Ort \\
\hline $\begin{array}{l}\text { Digitaler Graphikdrucker Digital Graphic } \\
\text { Printer UP-D890 }\end{array}$ & Biometra/Göttingen \\
\hline Elektrophoresekammer & Von Keutz/Reiskirchen \\
\hline Feinwaage LP6200S & Sartorius AG/ Göttingen \\
\hline $\begin{array}{l}\text { Geldokumentationstation „Transilluminator } \\
\text { BioDoc2 TM“ }\end{array}$ & Biometra/Göttingen \\
\hline
\end{tabular}


diverse Glaswaren

Kamera Axio Cam

Kühlschrank

Mikrowelle

Mini-Zentrifuge/vortex $2400 \mathrm{~N}$

PCR-Gerät T3 Thermocycler

Spannungsgerät „Biometra Standard Power

Pack 25“

Zentrifuge Centrifuge $5415 \mathrm{R}$

NanoDrop ND-1000

Brutschrank $\left(37^{\circ} \mathrm{C}\right)$

Thermomixer compact
SCHOTT AG/Mainz

Carl Zeiss AG/Oberkochen

Liebherr/Bulle, Schweiz

Blomberg/Neu-Isenburg

CombiSpin FVL- BIOSAN/Riga, Litauen

Biometra/Göttingen

Biometra/Göttingen

Eppendorf/Hamburg

Thermo SCIENTIFIC/Waltham, USA

ThermoSCIENTIFIC/Waltham,USA

Eppendorf/Hamburg

\subsubsection{Software /Programme}

Zur Konstruktion des (Unweighted-pair Group Method with Arithmetic mean) UPGMADendogramms wurde die MEGA4 Software (www.megasoftware.net/mega4/mega.html) genutzt (KUMAR et al. 2008).

Außerdem wurde die von Keith Jolley und Man-Suen Chan entwickelte $C$. jejuni MLSTWebsite (http//pubmlst.org/campylobacter/) zur Bestimmung der klonalen Komplexe herangezogen.

Zur statistischen Analyse wurde die MS-Excel-Software eingesetzt. Mit dem Chi-QuadratTest $\left(\chi^{2}\right.$-Test) wurden signifikante Unterschiede bzw. Gemeinsamkeiten der Markergene in den definierten Gruppen überprüft.

\subsection{Experimentelle Methoden}

In der vorliegenden Arbeit wurde die PCR in Kombination mit der AgaroseGelelektrophorese genutzt, um das Vorhandensein bzw. Nichtvorhandensein der in Tab.1 aufgeführten Gene nachzuweisen. 
Die zu amplifizierende DNS wurde aus den 266 C. jejuni-Isolaten extrahiert (siehe Punkt 2.1.1).

\subsubsection{Anzucht und Lagerung von Campylobacter jejuni}

Die Anzucht der Bakterienisolate erfolgte auf Columbia-Schafblutagarplatten mit $5 \%$ Schafblutzusatz. Unter capno- und mikroaerophilen Bedingungen $\left(5-10 \% \mathrm{CO}_{2}, 5 \% \mathrm{O}_{2}\right.$ und 85-90\% $\mathrm{N}_{2}$ ) wurden die beimpften Agarplatten bei $42{ }^{\circ} \mathrm{C}$ für 24 Stunden vor der DNSIsolierung inkubiert. Diese capno- und mikroaerophile Atmosphäre konnte durch Einsatz eines CampyGen ${ }^{\mathrm{TM}}$ CN25-Gasentwicklerbeutels pro 2,5 1 Fassungsvermögen in einem Anaerobier-/Mikroaerophilentopf erzeugt werden.

Zur langfristigen Lagerung können die Bakterienstämme als Glycerinkulturen (20 \% Glycerin in BHI) oder Microbank-Röhrchen (Pro-Lab Diagnostics, Toronto, Kanada) aufbewahrt werden. Mit einer Impföse bzw. einem Tupfer wurden dazu Campylobacter-Kolonien von der Columbia-Schafblutagarplatte entnommen und in das Glycerin-BHI-Gemisch bzw. in das Microbankröhrchen gegeben.

\subsubsection{Isolierung von Desoxyribonukleinsäure (DNS)}

Zur Gewinnung der genomischen DNS wurde das Q1Amp®-DNA-Mini-Kit (QIAGEN/Venlo) entsprechend der Herstellerangaben verwendet. Die Bakterien sind zuvor, wie in Punkt 2.2.1 beschrieben, angezüchtet worden. Die ausplattierten Bakterien wurden in $100 \mu \mathrm{l}$ Puffer ATL resuspendiert und mit $20 \mu$ Proteinase $\mathrm{K}$ bei $56{ }^{\circ} \mathrm{C}$ und $750 \min ^{-1} 1-3$ Stunden im Thermomixer inkubiert, bis die Bakterien vollständig lysiert waren. Die Proben wurden dann nach kurzem Zentrifugieren mit $200 \mu$ Puffer AL versetzt. Zum Denaturieren der Proteinkinase K und zum Stopp der Reaktion sind die Proben anschließend für 10 min bei $70{ }^{\circ} \mathrm{C}$ inkubiert worden. Es folgte eine erneute Zentrifugation der Proben und die Zugabe von $200 \mu 100 \%$ Ethanol. Die kompletten Proben wurden anschließend auf den Membranfilter einer vorbereiteten QIAamp-Spinsäule gegeben und bei $8000 \mathrm{~min}^{-1}$ für $1 \mathrm{~min}$ zentrifugiert.

Dieser Durchlauf konnte verworfen werden. Es folgten weitere Waschschritte bis die Spinsäule frei von Pufferresten war. Danach wurde die Spinsäule in ein sauberes $1,5 \mathrm{ml}$ 
Eppendorfgefäß gestellt. Zur Eluation der DNS von der Säule wurden $180 \mu 1$ des vorgewärmten Elutionspuffers AE auf die Membran gegeben und bei Raumtemperatur 10 min inkubiert. Die Proben sind dann bei $8000 \mathrm{~min}^{-1}$ zentrifugiert worden. Die so gewonnene DNS wurde bei $-20{ }^{\circ} \mathrm{C}$ gelagert.

\subsubsection{Konzentrationsbestimmung von DNS}

Mit Hilfe des NanoDrop-Photometers ND-1000 (ThermoScientific, Waltham, USA) wurde die Konzentration von DNS gemessen.

\subsubsection{Polymerasekettenreaktion (PCR)}

Die PCR ist eine schnelle und effiziente Methode zur Amplifikation und zum Nachweis von DNS. Das Prinzip wurde 1971 durch Kjell Kleppe bzw. 1983 durch Kary Mullis entdeckt und beruht auf der Amplifikation eines spezifischen DNS-Abschnitts, welcher durch zwei Primer gegenläufiger Orientierung festgelegt wird. Während der PCR kommt es zu einer zyklischen Wiederholung von drei Schritten: Denaturierung, Annealing und Elongation. Diese drei Schritte sind durch einen zyklischen Wechsel der Reaktionstemperaturen für genau definierte Zeiten gekennzeichnet. Hierzu wird die PCR in einem dafür konzipierten Thermocycler durchgeführt, der die Temperatur für den jeweiligen Schritt präzise einstellt. Initial wird der Deckel des Gerätes auf $105{ }^{\circ} \mathrm{C}$ vorgeheizt und die DNS wird in einem Reaktionsschritt bei $95^{\circ} \mathrm{C}$ denaturiert.

Im Anschluß folgten i.d.R. 30 Amplifikationszyklen. Aufgrund der zyklisch hohen Temperaturen von $95^{\circ} \mathrm{C}$ ist die Verwendung einer thermostabilen DNS-Polymerase notwendig. In dieser Arbeit wurde die 1965 durch Thomas Dale Brock isolierte Taq-DNS-Polymerase (Roche) eingesetzt.

Im Folgenden wird der Ablauf eines Amplifikationszyklus beschrieben: (entsprechend Stufe 2 in Tab. 8)

\section{1) Denaturierung}

Auftrennung des zu amplifizierenden DNS-Doppelstrangs durch Erhöhung der Temperatur auf $95^{\circ} \mathrm{C}$. 


\section{2) Annealing (Hybridisierung)}

In dieser Phase binden die Primer durch sukzessives Herabsetzen der Reaktionstemperatur an den komplementären Bereich des jeweiligen DNS-Einzelstrangs. Es kann nur eine stabile Verbindung erzielt werden, wenn Primer und DNS-Abschnitt komplementär zueinander sind, d.h. sich zwischen ihren korrespondierenden Basen Wasserstoffbrücken ausbilden können. Die genaue Annealing-Temperatur ist abhängig von der Länge und der Basenzusammensetzung der Primer. Die jeweiligen Annealing-Temperaturen der verwendeten Primer -Paare finden sich in Tab.1.

Wird die Annealing-Temperatur zu niedrig gewählt, besteht eine erhöhte Wahrscheinlichkeit dafür, dass sich die Primer auch unspezifisch an nicht hundertprozentig komplementäre Regionen auf den DNS-Einzelsträngen anlagern und sogenannte „Geisterbanden“ durch unspezifische Produkte entstehen können. Bei zu hohen Annealing-Temperaturen besteht die Gefahr, dass sich die Primer gar nicht anlagern können und somit kein Amplifikat entsteht.

\section{3) Elongation}

In diesem Reaktionsschritt kommt es zur Ausbildung eines neuen DNS-Doppelstranges indem die hitzebeständige Taq-Polymerase in $5^{`} \rightarrow 3^{`}$ freie Nukleotide an die Primer anfügt.

$\mathrm{Zu}$ Beginn jeder Versuchsreihe wurden die benötigten Mengen an Reagenzien für den PCRReaktionsansatz berechnet, und es wurde ein Mastermix gemäß diesen Berechnungen hergestellt. Dieser Mastermix ist dann auf 0,2 ml PCR-Reaktionsgefäße zu gleichen Teilen aufgeteilt worden, und in jedes Reaktionsgefäß wurden $1 \mu 1$ DNS-Template hinzupipettiert. Anschließend wurden die Komponenten mit einem Vortexer nochmals vorsichtig vermischt.

\section{Tabelle 6: PCR-Ansatz für eine Probe}

Für die PCR wurde i.d.R. nur ein $1 / 2$ Mastermix hergestellt. Die Menge für einen ganzen Ansatz ist in der Spalte „Menge“ jeweils in Klammern angegeben.

\begin{tabular}{lcl}
\hline Komponente & Konzentration & Menge in $\boldsymbol{\mu l}$ \\
\hline $\mathbf{1 0 \times P C R - P u f f e r}$ & $10 \times$ & $2,5(5)$ \\
dNTPs (dATP,sCTP,dGTP,dTTP) & jeweils $10 \mathrm{mM}$ & $0,5(1)$ \\
Vorwärts-Primer & $10 \mu \mathrm{M}$ & $0,5(1)$ \\
\hline
\end{tabular}




\begin{tabular}{lcl}
\hline Rückwärts-Primer & $10 \mu \mathrm{M}$ & $0,5(1)$ \\
Taq-DNS-Polymerase & $5 \mathrm{U} / \mu \mathrm{l}$ & $0,25(0,5)$ \\
Template-DNS & $50-150 \mathrm{ng} / \mu \mathrm{l}$ & $0,5(1,0)$ \\
Aqua bidest & - & $20,3(40,5)$ \\
Gesamtvolumen & & $25(50)$ \\
\hline
\end{tabular}

Bei den Polymerasenkettenreaktionen wurden generell eine Positiv- und eine NegativKontrolle mitgeführt. Die Negativ-Kontrolle bestand aus einem kompletten Reaktionsansatz, jedoch ohne die zu amplifizierende Ziel-DNS. Bei einer positiven Negativkontrolle wurde der gesamte PCR-Ansatz wiederholt, da eine Verunreinigung des Reaktionsansatzes wahrscheinlich war.

Als Positiv-Kontrolle dienten die Genom-sequenzierten $C$. jejuni-Referenzstämme NCTC 11168 und 81-176, die in den jeweiligen Relationen als eindeutig positiv charakterisiert waren. Bei fehlender Positiv-Kontroll-Bande wurde die PCR ebenfalls wiederholt.

Tabelle 7: Thermocycler-Programm für die PCR

( Programm für die Multiplex-PCR entsprechend Tab. 9)

\section{Temperatur Zeit}

$\begin{array}{lll}\text { Stufe } 1 & 95,0^{\circ} \mathrm{C} & 1 \mathrm{~min}\end{array}$

Anfangsdenaturierung

Stufe 2

Denaturierung

Annealing

Elongation

$95,0^{\circ} \mathrm{C}$

min

Stufe 3

Primer Extention

$72,0{ }^{\circ} \mathrm{C}$

$5 \mathrm{~min}$

Stufe 4

Kühlung

$4,0{ }^{\circ} \mathrm{C}$

$\infty$ 
Eine technische Ausnahme bildet der Nachweis des fucP-Gens, welcher in Form einer Multiplex-PCR erfolgte.

Die Multiplex-PCR ermöglicht den Nachweis mehrerer Gene in einem einzigen Reaktionsansatz. Eine wichtige Voraussetzung für die Anwendung der Multiplex-PCR ist die eindeutige Zuordnung der Amplifikate aufgrund unterschiedlicher Längen der PCR-Produkte. Die fucP-positiven Stämme produzieren Banden von 1,2 kb Fragmentgröße während die fucP-negativen Stämme aufgrund einer Deletion im Bereich dieses Genlocus ein Amplifikat von 446 bp Fragmentgröße aufweisen (MURAOKA und ZHANG 2011).

Tabelle 8: Ansatz für die Multiplex-PCR zum Nachweis von fucP

Die Angaben in Klammern stellen wieder die Menge für einen ganzen PCR-Ansatz dar. In der Arbeit wurde auch für den Fucose-Nachweis ein halber Ansatz verwendet.

\begin{tabular}{ll}
\hline Komponente & Menge in $\boldsymbol{\mu l}$ \\
\hline Aqua bidest & $17,3(34,5)$ \\
$10 \times$ PCR-Puffer & $2,5(5)$ \\
dNTPs (dATP, dCTP, dGTP, dTTP) & $0,5(1)$ \\
cj0486FWD & $1,0(2)$ \\
cj0486REV & $1,0(2)$ \\
rpoC & $1,0(2)$ \\
rpsL & $1,0(2)$ \\
Taq-DNS-Polymerase & $0,25(0,5)$ \\
Template DNS & 1,0 \\
Gesamtvolumen & $22,5(45)$ \\
\hline
\end{tabular}


Tabelle 9: PCR-Programm für die Multiplex-PCR

(entsprechend MURAOKA u. ZHANG 2011)

\section{Temperatur Zeit}

Stufe 1

Anfangsdenaturierung $\quad 95^{\circ} \mathrm{C} \quad 15 \mathrm{~min}$

Stufe 2

Denaturierung

Annealing

Elongation

$\left.\begin{array}{l}95{ }^{\circ} \mathrm{C} \\ 58{ }^{\circ} \mathrm{C} \\ 72{ }^{\circ} \mathrm{C}\end{array}\right\} 25 \times \quad \begin{aligned} & 45 \mathrm{sec} \\ & 45 \mathrm{sec} \\ & 90 \mathrm{sec}\end{aligned}$

Stufe 3

$72{ }^{\circ} \mathrm{C}$

$10 \min$

Primer Extention

Stufe 4

Kühlung

$4{ }^{\circ} \mathrm{C}$

$\infty$

\subsubsection{Nachweis der PCR-Produkte mittels Agarose-Gelelektrophorese}

In der vorliegenden Arbeit wurde die Agarose-Gelelektrophorese zur Darstellung der PCRProdukte (aus 2.2.1) eingesetzt.

Die Agarose-Gelelektrophorese ermöglicht die Auftrennung von DNS-Molekülen entsprechend ihrer Größe im elektrischen Feld. Grundprinzip ist die Wanderung geladener Teilchen im elektrischen Feld. Die aufgrund der Phosphatgruppen negativ geladenen DNS-Moleküle wandern im elektrischen Feld zur positiv geladenen Anode. Die Wanderungsgeschwindigkeit eines DNS-Moleküls ist abhängig von dessen Ladung und Größe, der Porengröße des Gels und der angelegten elektrischen Spannung. Kleinere DNS-Moleküle können sich schneller durch die Poren bewegen als Größere. Es entsteht eine Art „Siebeffekt“. Durch Vergleich mit Standard-DNS bekannter Fragmentlänge kann die Größe der DNS-Fragmente nach ausreichender Auftrennung bestimmt werden. Die aufzutrennende DNS wurde vor dem 
Auftragen in die Geltaschen mit Ladepuffer, welcher den Farbstoff Bromphenolblau enthält, versetzt. Dadurch wird eine Visualisierung des sonst nicht sichtbaren Gellaufs ermöglicht. Das dem Agarose-Gel zugesetzte Ethidiumbromid interkaliert mit einzelnen Basen der DNS und fluoresziert unter UV-Licht. Der Vorteil der Methode für die Studie liegt in der einfachen Herstellung der Gele, die nach individuellen Anforderungen hergestellt werden können. Allerdings ist dadurch auch ein höherer Zeitbedarf vorhanden.

\section{Versuchsdurchführung}

Zur elektrophoretischen Auftrennung der PCR - Produkte wurden $1 \%$ Agarosegele in 1× TAE-Puffer verwendet. Dafür wurden 1,6 g Agarose und $160 \mathrm{ml}$ 1×TAE-Puffer gemischt und in der Mikrowelle zu einer klaren Lösung aufgekocht. Zu dieser Lösung wurden nach Abkühlung $16 \mu 1$ Ethidiumbromid zugesetzt. Anschließend ist die Lösung in eine Gelkammer mit Kämmen zur Formung der Probetaschen gegossen worden. Nach Auspolymerisation wurden die Kämme entfernt und das Gel in die Elektrophoreseapparatur gelegt. Anschließend ist das Gel mit 1×TAE-Puffer bedeckt worden. In die Geltaschen wurde die mit Ladepuffer und Farbindikator versetzte DNS pipettiert. Zur Größenbestimmung der Fragmente wurde zudem ein geeigneter Längenstandard in die erste Spur je Reihe geladen. Bei einer konstanten Spannung von ca. $150 \mathrm{~V}$ bei einer Laufzeit von etwa 45 min erfolgte dann die Elektrophorese. Nach ausreichender Auftrennung der Fragmente wurden die Banden unter dem UV-Tisch sichtbar gemacht und das Ergebnis photographisch dokumentiert.

\subsubsection{Multilocus-Sequenz-Typing (MLST)}

MLST ist ein molekularbiologisches Verfahren zur Typisierung von Bakterienstämmen oder anderen Mikroorganismen mittels Sequenzierung von internen Fragmenten verschiedener Housekeeping-Gene (MAIDEN et al. 1998). In erster Linie wurde MLST für weltweit vergleichbare epidemiologische Studien und zur epidemiologischen Überwachung entworfen. MLST ermöglicht Laboratorien eine einfache und schnelle Typisierung von Bakterienstämmen durch die Sequenzierung der Housekeeping-Gene und deren Vergleich mit bereits MLST-typisierten Referenzstämmen (URWIN und MAIDEN 2003). 
Zur MLST-Typisierung von C. jejuni wählten DINGLE et al. (2001) nachfolgende sieben Housekeeping-Gene (Tabelle 2): aspA (Aspartat-Ammonium-Lyase), glnA (GlutaminSynthetase), gltA (Citrat-Synthetase), glyA (Serin-Hydroxy-Methyltransferase), pgm (Phosphoglycerat-Mutase), tkt (Transketolase) und uncA (ATP-Synthase).

Die untersuchten Genloci sind weitestgehend konservierte Regionen, weisen aber dennoch eine gewisse Variabilität auf. Diese Sequenzvarianten dienen zur Unterscheidung verschiedener Isolate auf Subspeziesebene und können bestimmten Sequenztypen bzw. sogenannten klonalen Komplexen (CC) zugeordnet werden. Je nach Sequenz des Gen-Abschnittes wird jedem Genlocus eine Allelnummer zugeordnet. Auf diese Weise erhält ein typisiertes Isolat gemäß der Kombination der Allelnummern der 7 Genloci einen Sequenztyp.

Auf der Onlinedatenbank: http://pubmlst.org/campylobacter, entwickelt von Keith Jolley und Man-Suen Chan, erfolgt zentral die Vergabe von Allelnummern für spezifische Sequenzen und deren Zuordnung zu spezifischen Sequenztypen.

Tabelle 10: Primer für die Sequenzierung zur $C$. jejuni-MLST-Typisierung (als Referenz diente die Publikation von DINGLE et al. 2001)

\begin{tabular}{|c|c|}
\hline Bezeichnung & Sequenz $5^{6}-3^{6}$ \\
\hline aspA-F-S & CCA ACT GCA AGA TGC TGT ACC \\
\hline $\operatorname{aspA-R-S}$ & TTA ATT TGC GGT AAT ACC ATC \\
\hline$g \ln A-F-S$ & CAT GCA ATC AAT GAA GAA AC \\
\hline$g \ln A-R-S$ & TTC CAT AAG CTC ATA TGA AC \\
\hline gltA-F-S & GTG GCT ATC CTA TAG AGT GGC \\
\hline gltA-R-S & CCA AAG CGC ACC AAT ACC TG \\
\hline$g l y A-F-S$ & AGC TAA TCA AGG TGT TTA TGC GG \\
\hline$g l y A-R-S$ & AGG TGA TTA TCC GTT CCA TCG C \\
\hline pgm-F-S & GGT TTT AGA TGT GGC TCA TG \\
\hline pgm-R-S & TCC AGA ATA GCG AAA TAA GG \\
\hline tkt-F-S & GCT TAG CAG ATA TTT TAA GTG \\
\hline$t k t-R-S$ & ACT TCT TCA CCC AAA GGT GCG \\
\hline uncA-F-S & TGT TGC AAT TGG TCA AAA GC \\
\hline uncA-R-S & TGC CTC ATC TAA ATC ACT AGC \\
\hline
\end{tabular}




\section{Ergebnisse}

\section{1 Überblick}

Im Zuge dieser Arbeit wurden 266 C. jejuni-Isolate (Tab. 13 Anhang) durch Screening auf die Präsenz von zehn Virzulenz-assoziierten Markergenen: cj1321-1326, ciaB, cdtB, fucP, cj0178/cj0755, ceuE, pldA und cstII/cstIII charakterisiert.

Bei Betrachtung der Ergebnisse lässt sich feststellen, dass ciaB in $100 \%$ der Isolate präsent und somit auch der häufigste Genmarker innerhalb der 266 Isolate ist. Gefolgt von $c d t B$ mit $99,6 \%(265$ / 266).

Den Sechs-Gen-Komplex cj1321-1326 zur Flagellin- $O$-Glykolisierung findet man in 63,9 \% (170/266 ), fucP in 57,9\% ( $154 / 266$ ), cj0178 in 76,7\% (204/ 266 ) und cj0755 in 78,2\% (208 / 266) der Isolate. Des Weiteren wurde in 87,2 \% (232 / 266) ceuE nachgewiesen und in 86,1 \% (229 / 266) pldA. Die Ergebnisse für pldA und ceuE beziehen sich hier ausschließlich auf die Nutzung von Primern basierend auf der Genomsequenz von C. jejuni NCTC 11168. In den für NCTC 11168-Primer-negativen Isolaten sind pldA und ceuE jedoch mit Primern basiernd auf der Genomsequenz von C. jejuni 81-176 detektierbar, so dass hier also nur das in NCTC 11168 vorkommende Allel erfasst wurde. Die Marker für die LipooligosaccharidSialyltransferase cstII sind in 53,4\% (142/266) und für cst III in 30,8\% (82/266) der Isolate präsent.

Abbildung 3 veranschaulicht die Ergebnisse zur Häufigkeitsverteilung der Markergene innerhalb der Isolatsammlung. Die Ergebnisse sind außerdem in Tabelle 11 dokumentiert. 


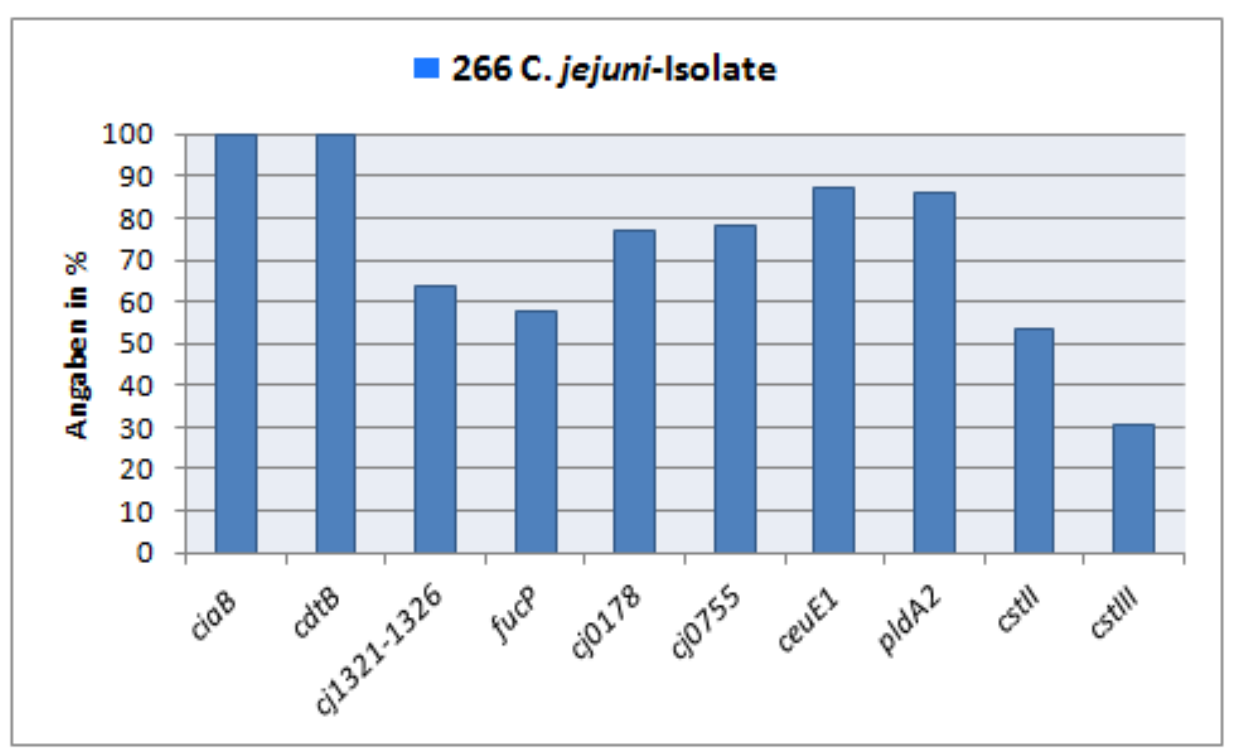

\begin{abstract}
Abb. 3: Verteilung der 10 genetischen Marker
Innerhalb aller untersuchten $266 C$. jejuni-Islolate.

$c e u E^{1}$ basierend auf der Genomsequenz von Stamm NCTC 11168

$p l d A^{2}$ basierend auf der Genomsequenz von Stamm NCTC 11168
\end{abstract}

\title{
3.2 Definition von Gruppen
}

Bereits 2011 wurde die Existenz von sechs C. jejuni-Gruppen (neun Untergruppen) durch Kombination von MLST mit sechs genetischen Markern demonstriert (ZAUTNER et al. 2011). Nach dem PCR-Test auf weitere zehn, zuvor in dieser Arbeit beschriebene, genetische Marker fällt insgesamt auf, dass zwei große $C$. jejuni-Gruppen unterschieden werden können. Vor allem die genetischen Marker cj1321-1326; fucP; cj0178 und cj0755 splitten die Testpopulation in 2 Hauptgruppen (Gruppe 1 und 2) und 7 Untergruppen.

Die erste Gruppe besteht aus Isolaten, die positiv für die Gene cj1321-1326, fucP, cj0178 und cj0755 sind. Diese vier Gene sind weitestgehend miteinander assoziiert. Diese erste große Gruppe setzt sich aus den Untergruppen $1 \mathrm{a}$ und $1 \mathrm{~b}$ zusammen. Innerhalb der Teilgruppe $1 \mathrm{~b}$ lassen sich noch 3 Untergruppen differenzieren $\left(1 b^{*}, 1 b^{* *}, 1 b^{* * *}\right)$.

Gruppe $1 b^{*}$ und $1 b^{* *}$ unterscheiden sich im Auftreten der Gene cstII und cstIII. Während $1 b^{*}$ zu 84,1\% cstIII-positive Isolate einschließt, finden sich in Gruppe $1 b^{* *}$ zu 97,4 \% nur cstIIpositive Isolate (Tabelle 11). Untergruppe $1 b^{* * *}$ zeichnet sich dadurch aus, dass im Vergleich $\mathrm{zu}$ Gruppe $1 \mathrm{~b}^{*}$ und $1 \mathrm{~b}^{* *}$ deutlich weniger Isolate PCR-positiv auf cj1321-1326 und fucP 
getestet wurden (Tab.11). Die überwiegenden MLST-CC in Gruppe 1 sind CC 21, 206 und 48. Mit 135 der gesamt 266 getesteten Isolate enthält diese Gruppe auch die größte Anzahl an Isolaten.

Die zweite große Isolatgruppe zeigt sich negativ für die Gene cj1321-1326, fucP, cj0178 und cj0755. In dieser 51 Isolate umfassenden Gruppe finden sich nur Isolate aus den MLST-CC 22, 42, 45 und 283. Allerdings überwiegt MLST-CC 45 mit 58,8 \%.

Die Gruppe kann in die Untergruppen 2a und 2b gespalten werden. Die Unterteilung ergibt sich aus der Beobachtung, dass in Gruppe 2a 94,1\% (16/17) der Isolate cstII-positiv sind, während in Gruppe 2b 86,0 \% der Isolate keine Lipooligosaccharid-Sialyltransferase besitzen. Folglich sind nur 14,0\% (5/34) der Isolate cstII-positiv und alle 34 Isolate aus Gruppe 2b cstIII-negativ.

Gruppe 3 setzt sich aus 52 Isolaten zusammen, die größtenteils den MLST-CC 61, 52, 443 und 353 angehören. Die Isolate dieser Gruppe sind mehrheitlich cstII-positiv (Tab.11). Ein Teil der Gruppe 3a-Isolate ist zwar cj1321-1326-positiv, aber im Gegensatz zu Gruppe 1 zu 90,0 \% fucP-negativ. Anhand der fucP-Präsenz erfolgt eine Untergliederung der Gruppe 3a in die Untergruppen $3 \mathrm{a}^{*}\left(\right.$ fuc $\left.P^{+}\right)$und $3 \mathrm{a}^{* *}\left(\right.$ fuc $P^{-}$, Tab.11).

Die Gruppen 4, 5 und 6 bestehen aus maximal 9 Isolaten und sind damit vergleichsweise klein (Tabelle 11). Auffallend ist, dass alle 3 Gruppen zu $100 \%$ cstIII-negativ getestet wurden. Zudem ist auch weniger als die Hälfte der Isolate (42,9 \%) cstII-positiv. Somit ist der Großteil der 21 Isolate aus Gruppe 4, 5 und 6 für die Lipooligosaccharid- Sialyltransferase-Isoenzyme II und III negativ.

Gruppe 6 imponiert innerhalb dieser 3 kleineren Gruppen dadurch, dass alle 9 Isolate (CC 257) $f u c P^{+}$getestet wurden,wohingegen nur 33,3 \% dieser Isolate für den Gencluster $c j 1321$ 1326 positiv getestet worden sind.

Zusammenfassend lassen sich alle 266 Isolate je nach An- und Abwesenheit der zehn genetischen Marker in 9 Gruppen unterteilen: $1 \mathrm{a} ; 1 \mathrm{~b} ; 2 \mathrm{a} ; 2 \mathrm{~b} ; 3 \mathrm{a} ; 3 \mathrm{~b} ; 4 ; 5$ und 6 . Das heißt sechs Hauptgruppen $(1,2,3,4,5,6)$ und neun Untergruppen $\left(1 \mathrm{a}, 1 \mathrm{~b}^{*}, 1 \mathrm{~b}^{* *}, 1 \mathrm{~b}^{* * *}, 2 \mathrm{a}, 2 \mathrm{~b}, 3 \mathrm{a}^{*}\right.$, $3 \mathrm{a}^{* *}$ und $3 \mathrm{~b}$ ). Die mit Asterisk $\left(^{*}\right)$ markierten Gruppen stellen Untergruppen dar, die aufgrund der An- oder Abwesenheit einzelner Marker eine weitere Unterteilung sinnvoll erscheinen 
lassen. Unter Einbeziehung der mit Asterisk gekennzeichneten Gruppen ergeben sich dadurch zwölf Gruppen:1a, 1b* $1 b^{* *}, 1 b^{* * *}, 2 a, 2 b, 3 a^{*}, 3 a^{* *}, 3 b, 4,5$ und 6 .

Tabelle 11 dokumentiert die Resultate der PCRs und die Verteilung der genetischen Marker, sowie LLC- und MLST-CC- Zugehörigkeit entsprechend der Gruppen. Überdies ist in der letzten Spalte der Anteil an menschlichen Isolaten innerhalb der Gruppe dargestellt.

Abbildung 4 verbildlicht mittels einer Gesamtübersicht über die Verteilung der genetischen Marker - innerhalb der definierten Gruppen - die Ergebnisse.

\begin{tabular}{|c|c|c|c|c|c|c|c|c|c|c|}
\hline $\begin{array}{l}\text { Unter- } \\
\text { gruppe }\end{array}$ & $c j 1321-1326$ & fucP & cj0178 & $c j 0755$ & $\begin{array}{l}\text { genetische } \\
\text { ceuE }^{l}\end{array}$ & $\begin{array}{r}\text { Marker } \\
\text { pldA }^{2}\end{array}$ & cstII & $c s t I I I$ & $\mathrm{CC}^{\mathrm{a}}$ & Herkunft $^{b}$ \\
\hline $1 \mathrm{a}$ & $\mathbf{x}$ & $\mathbf{X}$ & $\mathbf{x}$ & $\mathbf{X}$ & $\mathbf{x}$ & $\mathbf{x}$ & & $\mathbf{X}$ & 21 & m;h;p;r \\
\hline $1 b^{*}$ & $\mathbf{X}$ & $\mathbf{x}$ & $\mathbf{x}$ & $\mathbf{X}$ & $\mathbf{x}$ & $\mathbf{x}$ & & $\mathbf{x}$ & 21,206 & m;h;p;r \\
\hline $1 b^{* *}$ & $\mathbf{x}$ & $\mathbf{x}$ & $\mathbf{x}$ & $\mathbf{x}$ & $\mathbf{x}$ & $\mathbf{x}$ & $\mathbf{X}$ & & 48,206 & m;h;p;r \\
\hline $1 b^{* * * *}$ & & & $\mathbf{x}$ & $\mathbf{x}$ & $\mathbf{x}$ & $\mathbf{x}$ & & & 49,446 & m;p;h \\
\hline $2 a$ & & & & & & & $\mathbf{X}$ & & 22,42 & m;h;r \\
\hline $2 b$ & & & & & & & & & 45,283 & m;h;p;r \\
\hline $3 a^{*}$ & $\mathbf{X}$ & $\mathbf{x}$ & $\mathbf{x}$ & $\mathbf{X}$ & & & $\mathbf{X}$ & & $52,443,828$ & m;p;h \\
\hline $3 a^{* *}$ & $\mathbf{X}$ & & $\mathbf{x}$ & $\mathbf{x}$ & $\mathbf{x}$ & & $\mathbf{X}$ & & 353,354 & m;p;h \\
\hline $3 b$ & & & $\mathbf{X}$ & $\mathbf{X}$ & $\mathbf{X}$ & & $\mathbf{X}$ & & 61 & m;p;r \\
\hline 4 & & & & & $\mathbf{x}$ & & $\mathbf{X}$ & & 1034,1332 & m;p;h \\
\hline 5 & & & $\mathbf{x}$ & $\mathbf{x}$ & $\mathbf{x}$ & $\mathbf{x}$ & & & none & $\mathbf{m} ; \mathbf{h}$ \\
\hline 6 & & $\mathbf{X}$ & $\mathbf{x}$ & $\mathbf{X}$ & $\mathbf{x}$ & $\mathbf{x}$ & & & 257 & $m ; p ; h$ \\
\hline
\end{tabular}

\section{Abb. 4: Verteilung der genetischen Marker, MLST-CC-Zuordnung und Isolat-Herkunft}

Innerhalb der zuvor definierten sechs Haupt-und neun Untergruppen.

„X“ symbolisiert ein überdurchschnittliches Vorhandensein des genetischen Markers

${ }^{a}$ CC-klonaler Komplex, ${ }^{b}$ m-Mensch, h-Huhn, p-Pute, r-Rind

${ }^{1}$ basierend auf Primern der Genom-Sequenz von NCTC 11168

${ }^{2}$ basierend auf Primern der Genom-Sequenz von NCTC 11168

Die Gruppen 2, 3 und 4 umfassen signifikant weniger positive Isolate für die Gene pldA und ceuE, die sich mit den Primerpaaren, basierend auf der NCTC 11168-Genomsequenz, amplifizieren ließen, und sind darum nicht mit einem X gekennzeichnet.Mit Primern, basierend auf der C. jejuni-81-176-Genomsequenz, waren pldA und ceuE allerdings auch in den 11168-Primer-PCR-negativen Isolaten nachweisbar.CiaB und $c d t B$ wurden ubiquitär in allen Isolaten nachgewiesen und sind deshalb zur besseren Übersicht in Abb. 4 nicht aufgeführt . 
Tabelle 11: Verteilung der genetischen Marker, LLC und MLST-CC ${ }^{+}$

\begin{tabular}{|c|c|c|c|c|c|c|c|c|c|c|c|c|c|}
\hline Untergruppe & ciaB & vadtB & $-c j 1321-1326$ & fucP & $-c j 0178$ & $-c j 0755$ & ceuE ${ }^{1}$ & pldA ${ }^{2}$ & i cstII & I cstIII & $\sim$ LLC $^{3}$ & $-\mathbf{C C}^{4}$ & Mensch \\
\hline $1 \mathbf{a}$ & $\begin{array}{c}38 / 38 \\
(100)\end{array}$ & $\begin{array}{l}38 / 38 \\
(100)\end{array}$ & $\begin{array}{l}38 / 38^{\#} \\
(100)\end{array}$ & $\begin{array}{l}38 / 38^{\#} \\
(100)\end{array}$ & $\begin{array}{l}38 / 38^{\#} \\
(100)\end{array}$ & $\begin{array}{l}38 / 38^{\#} \\
(100)\end{array}$ & $\begin{array}{c}38 / 38^{\#} \\
(100)\end{array}$ & $\begin{array}{l}38 / 38^{\#} \\
(100)\end{array}$ & $\begin{array}{l}13 / 38^{\circ} \\
(34.2)\end{array}$ & $\begin{array}{l}33 / 38^{\#} \\
(86.4)\end{array}$ & $\mathrm{C} / \mathrm{A}$ & 21 & $16 / 38(42,1)$ \\
\hline $1 b^{*}$ & $\begin{array}{l}44 / 44 \\
(100)\end{array}$ & $\begin{array}{l}44 / 44 \\
(100)\end{array}$ & $\begin{array}{l}43 / 44^{\#} \\
(97.7)\end{array}$ & $\begin{array}{l}44 / 44^{\#} \\
(100)\end{array}$ & $\begin{array}{l}44 / 44^{\#} \\
(100)\end{array}$ & $\begin{array}{l}44 / 44^{\#} \\
(100)\end{array}$ & $\begin{array}{l}42 / 44^{\circ} \\
(95.5)\end{array}$ & $\begin{array}{l}41 / 44 \\
(93.2)\end{array}$ & $\begin{array}{l}16 / 44^{\circ} \\
(36.4)\end{array}$ & $\begin{array}{l}37 / 44^{\#} \\
(84.1)\end{array}$ & $\mathrm{C} / \mathrm{A} / \mathrm{B}$ & 21,206 & $19 / 44(42,2)$ \\
\hline $1 b^{* *}$ & $\begin{array}{l}38 / 38 \\
(100)\end{array}$ & $\begin{array}{l}38 / 38 \\
(100)\end{array}$ & $\begin{array}{l}38 / 38^{\#} \\
(100)\end{array}$ & $\begin{array}{l}36 / 38^{\#} \\
(94.7)\end{array}$ & $\begin{array}{l}37 / 38^{\#} \\
(97.4)\end{array}$ & $\begin{array}{l}38 / 38^{\#} \\
(100)\end{array}$ & $\begin{array}{l}35 / 38 \\
(92.1)\end{array}$ & $\begin{array}{l}37 / 38^{\circ} \\
(97.4)\end{array}$ & $\begin{array}{l}37 / 38^{\#} \\
(97.4)\end{array}$ & $\begin{array}{l}2 / 38^{\#} \\
(5.3)\end{array}$ & B2 & 48,206 & $19 / 38(50,0)$ \\
\hline $1 b^{* * *}$ & $\begin{array}{l}15 / 15 \\
(100)\end{array}$ & $\begin{array}{l}15 / 15 \\
(100)\end{array}$ & $\begin{array}{l}7 / 15 \\
(46.7)\end{array}$ & $\begin{array}{l}5 / 15^{\circ} \\
(33.3)\end{array}$ & $\begin{array}{l}15 / 15^{\#} \\
(100)\end{array}$ & $\begin{array}{l}15 / 15^{\#} \\
(100)\end{array}$ & $\begin{array}{l}14 / 15^{\#} \\
(93.3)\end{array}$ & $\begin{array}{l}15 / 15^{\#} \\
(100)\end{array}$ & $\begin{array}{l}6 / 15 \\
(40.0)\end{array}$ & $\begin{array}{l}0 / 15^{\#} \\
(0.0)\end{array}$ & B, D & 49,446 & $9 / 15(60)$ \\
\hline $2 a$ & $\begin{array}{l}17 / 17 \\
(100)\end{array}$ & $\begin{array}{l}17 / 17 \\
(100)\end{array}$ & $\begin{array}{l}2 / 17^{\#} \\
(11.8)\end{array}$ & $\begin{array}{l}0 / 17^{\#} \\
(0.0)\end{array}$ & $\begin{array}{l}0 / 17^{\#} \\
(0.0)\end{array}$ & $\begin{array}{c}3 / 17^{\#} \\
(17,6)\end{array}$ & $\begin{array}{l}12 / 17 \\
(70.6)\end{array}$ & $\begin{array}{l}14 / 17 \\
(82.4)\end{array}$ & $\begin{array}{l}16 / 17^{\#} \\
(94.1)\end{array}$ & $\begin{array}{l}1 / 17^{\#} \\
(5.9)\end{array}$ & $\mathrm{A} 1 / \mathrm{B}$ & 22,42 & $8 / 17(47,1$ \\
\hline $2 b$ & $\begin{array}{l}34 / 34 \\
(100)\end{array}$ & $\begin{array}{l}34 / 34 \\
(100)\end{array}$ & $\begin{array}{l}3 / 34^{\#} \\
(8.8)\end{array}$ & $\begin{array}{l}1 / 34^{\#} \\
(2.9)\end{array}$ & $\begin{array}{l}1 / 34^{\#} \\
(2.9)\end{array}$ & $\begin{array}{l}1 / 34^{\#} \\
(2.9)\end{array}$ & $\begin{array}{l}26 / 34^{\circ} \\
(76.5)\end{array}$ & $\begin{array}{l}29 / 34 \\
(85.3)\end{array}$ & $\begin{array}{l}5 / 34^{\#} \\
(14.7)\end{array}$ & $\begin{array}{l}0 / 34^{\#} \\
(0.0)\end{array}$ & $\mathrm{D} / \mathrm{E} / \mathrm{H} / \mathrm{U}$ & 45,283 & $22 / 34^{\circ}(64,7)$ \\
\hline $3 a^{*}$ & $\begin{array}{l}22 / 22 \\
(100)\end{array}$ & $\begin{array}{l}21 / 22 \\
(95.5)\end{array}$ & $\begin{array}{l}15 / 22 \\
(68.2)\end{array}$ & $\begin{array}{l}18 / 22^{\circ} \\
(81.8)\end{array}$ & $\begin{array}{l}22 / 22^{\#} \\
(100)\end{array}$ & $\begin{array}{l}22 / 22^{\#} \\
(100)\end{array}$ & $\begin{array}{l}18 / 22 \\
(81.8)\end{array}$ & $\begin{array}{l}18 / 22 \\
(81.8)\end{array}$ & $\begin{array}{l}18 / 22^{\#} \\
(81.8)\end{array}$ & $\begin{array}{l}1 / 22^{\#} \\
(4.5)\end{array}$ & - & $52,443,828$ & $15 / 22(68,2)$ \\
\hline $3 \mathbf{a}^{* *}$ & $\begin{array}{r}19 / 19 \\
(100)\end{array}$ & $\begin{array}{l}19 / 19 \\
(100)\end{array}$ & $\begin{array}{l}16 / 19^{\circ} \\
(84.2)\end{array}$ & $\begin{array}{l}2 / 19^{\#} \\
(10.5)\end{array}$ & $\begin{array}{l}19 / 19^{\#} \\
(100)\end{array}$ & $\begin{array}{l}19 / 19^{\#} \\
(100)\end{array}$ & $\begin{array}{l}18 / 19^{\#} \\
(94.7)\end{array}$ & $\begin{array}{l}11 / 19 \\
(57.9)\end{array}$ & $\begin{array}{l}12 / 19 \\
(63.2)\end{array}$ & $\begin{array}{l}7 / 19 \\
(36.8)\end{array}$ & $\mathrm{E}$ & 353,354 & $4 / 19^{\circ}(21,1)$ \\
\hline 3b & $\begin{array}{l}11 / 11 \\
(100)\end{array}$ & $\begin{array}{l}11 / 11 \\
(100)\end{array}$ & $\begin{array}{l}2 / 11^{\circ} \\
(18.2)\end{array}$ & $\begin{array}{l}0 / 11^{\#} \\
(0.0)\end{array}$ & $\begin{array}{l}11 / 11^{\#} \\
(100)\end{array}$ & $\begin{array}{l}11 / 11^{\#} \\
(100)\end{array}$ & $\begin{array}{l}10 / 11 \\
(90.9)\end{array}$ & $\begin{array}{l}8 / 11 \\
(72.7)\end{array}$ & $\begin{array}{l}10 / 11^{\circ} \\
(90.9)\end{array}$ & $\begin{array}{l}1 / 11^{\circ} \\
(9.1)\end{array}$ & - & 61 & $3 / 11(27,3)$ \\
\hline 4 & $\begin{array}{l}8 / 8 \\
(100)\end{array}$ & $\begin{array}{l}8 / 8 \\
(100)\end{array}$ & $\begin{array}{l}3 / 8 \\
(37.5)\end{array}$ & $\begin{array}{l}0 / 8^{\#} \\
(0.0)\end{array}$ & $\begin{array}{l}1 / 8^{\#} \\
(12.5)\end{array}$ & $\begin{array}{l}0 / 8^{\#} \\
(0.0)\end{array}$ & $\begin{array}{l}7 / 8 \\
(87.5)\end{array}$ & $\begin{array}{l}6 / 8 \\
(75.0)\end{array}$ & $\begin{array}{l}5 / 8 \\
(62.5)\end{array}$ & $\begin{array}{l}0 / 8^{\#} \\
(0.0)\end{array}$ & - & 1034,1332 & $2 / 8(25,0)$ \\
\hline 5 & $\begin{array}{l}4 / 4 \\
(100)\end{array}$ & $\begin{array}{l}4 / 4 \\
(100)\end{array}$ & $\begin{array}{l}0 / 4^{\#} \\
(0.0)\end{array}$ & $\begin{array}{l}1 / 4 \\
(25.0)\end{array}$ & $\begin{array}{l}4 / 4^{\#} \\
(100)\end{array}$ & $\begin{array}{l}4 / 4^{\#} \\
(100)\end{array}$ & $\begin{array}{l}4 / 4^{\#} \\
(100)\end{array}$ & $\begin{array}{l}4 / 4^{\#} \\
(100)\end{array}$ & $\begin{array}{l}2 / 4 \\
(50.0)\end{array}$ & $\begin{array}{l}0 / 4^{\#} \\
(0.0)\end{array}$ & - & none & $1 / 4(25,0)$ \\
\hline 6 & $\begin{array}{l}9 / 9 \\
(100)\end{array}$ & $\begin{array}{l}9 / 9 \\
(100)\end{array}$ & $\begin{array}{l}3 / 9 \\
(33.3)\end{array}$ & $\begin{array}{l}9 / 9^{\#} \\
(100)\end{array}$ & $\begin{array}{l}9 / 9^{\#} \\
(100)\end{array}$ & $\begin{array}{l}9 / 9^{\#} \\
(100)\end{array}$ & $\begin{array}{l}8 / 9 \\
(88.8)\end{array}$ & $\begin{array}{l}8 / 9 \\
(88.8)\end{array}$ & $\begin{array}{l}2 / 9^{\circ} \\
(22.2)\end{array}$ & $\begin{array}{l}0 / 9^{\#} \\
(0.0)\end{array}$ & $\mathrm{A} / \mathrm{D}$ & 257 & 7/9(77,8) \\
\hline alle & $\begin{array}{l}266 / 266 \\
(100)\end{array}$ & $\begin{array}{l}265 / 266 \\
(99.6)\end{array}$ & $\begin{array}{l}170 / 266 \\
(63.9)\end{array}$ & $\begin{array}{l}154 / 266 \\
(57.9)\end{array}$ & $\begin{array}{l}204 / 266 \\
(76.7)\end{array}$ & $\begin{array}{l}208 / 266 \\
(78.2)\end{array}$ & $\begin{array}{l}232 / 266 \\
(87.2)\end{array}$ & $\begin{array}{l}229 / 266 \\
(86.1)\end{array}$ & $\begin{array}{l}142 / 266 \\
(53.4)\end{array}$ & $\begin{array}{l}82 / 266 \\
(30.8)\end{array}$ & all & all & $128 / 266(48,1)$ \\
\hline
\end{tabular}

${ }^{+}$innerhalb der definierten Gruppen

${ }^{1}$ negative Isolate nachweisbar mit dem Vorwärtsprimer basierend auf der Genom-Frequenz von 81-176: 5'-GATAGAGTCGCAGGCGTTCC -3'

${ }^{2}$ negative Isolate nachweisbar mit dem Vorwärtsprimer basierend auf der Genom-Frequenz von 81-176: 5'-AAACTTATGCGTTTTT -3'

${ }^{3}$ Lipooligosaccharid Locus Klasse (LOS) entsprechend HABIB et al. 2009, HOTTER et al. 2010, REVEZ et al. 2011

${ }^{4}$ Klonale Komplexe (CC) nach MLST-Typisierung entsprechend ZAUTNER et al. 2011

$\mathrm{p}<0,05 /{ }^{\#} \mathrm{p}<0,001 \mathrm{im}$ Vergleich zu den Isolaten, die nicht zur entsprechenden Gruppe gehören

Die letzte Spalte der Tabelle gibt an, wie viele Isolate der entsprechenden Gruppe menschlichen Ursprungs sind, in Klammern Angaben in Prozent. 


\subsection{Verteilung der Marker innerhalb der definierten Gruppen}

Alle zehn geprüften genetischen Marker (Tab.1, Kapitel 2.1.2), abgesehen vom genetischen Marker $p l d A$, zeigen in ihrer Verteilung innerhalb der Gruppen signifikante Unterschiede.

Die Signifikanz innerhalb der Gruppen wurde im Vergleich zu den Isolaten, die nicht zur entsprechenden Gruppe gehören, mittels t-Test ermittelt. Innerhalb der Gruppen zeigen sich vereinzelte nicht signifikante Unterschiede, aber der Großteil der Isolate hat eine signifikante Verteilung innerhalb der Gruppen. Die ermittleten p-Werte sind in Tabelle 12 zusammengestellt.

\section{Tabelle 12 : Ergebnisse des t-Test}

Ermittelt durch einen t-Test zur Bestimmung der Signifikanz der genetischen Marker innerhalb der Gruppen im Vergleich zu den nicht zur Gruppe gehörigen Isolaten. Felder ohne farbige Markierung entsprechen $p>0,05$ (kein signifikanter Unterschied), grüne Felder $\mathrm{p}<0,05$ (signifikanter Unterschied) und hellblaue Felder $\mathrm{p}<0,001$ (hoch sugnifikanter Unterschied).

\begin{tabular}{|c|c|c|c|c|c|c|c|c|}
\hline & cj1321/26 & fuc $P$ & ceuE & pldA & cstII & cstIII & cj0178 & cj0755 \\
\hline $1 a$ & 0,00000 & 0,00000 & 0,00001 & 0,00000 & 0,00543 & 0,00000 & 0,00000 & 0,00000 \\
\hline $1 b^{*}$ & 0,00000 & 0,00000 & 0,03534 & 0,54285 & 0,00655 & 0,00000 & 0,00000 & 0,00000 \\
\hline $1 \mathrm{~b} * *$ & 0,00000 & 0,00000 & 0,92702 & 0,02655 & 0,00000 & 0,00000 & 0,00000 & 0,00000 \\
\hline $1 \mathrm{~b} * * *$ & 0,16596 & 0,05236 & 0,00001 & 0,00000 & 0,24747 & 0,00000 & 0,00000 & 0,00000 \\
\hline $2 a$ & 0,00000 & 0,00000 & 0,05814 & 0,35506 & 0,00000 & 0,00044 & 0,00000 & 0,00000 \\
\hline $2 b$ & 0,00000 & 0,00000 & 0,04455 & 0,43026 & 0,00000 & 0,00000 & 0,00000 & 0,00000 \\
\hline $3 a *$ & 0,77849 & 0,01013 & 0,00001 & 0,52005 & 0,00333 & 0,00000 & 0,00000 & 0,00000 \\
\hline $3 a * *$ & 0,03673 & 0,00000 & 0,00001 & 0,09266 & 0,47935 & 0,58713 & 0,00000 & 0,00000 \\
\hline $3 b$ & 0,00229 & 0,00000 & 0,86244 & 0,20851 & 0,00208 & 0,03485 & 0,00000 & 0,00000 \\
\hline 4 & 0,16230 & 0,00000 & 0,69549 & 0,34952 & 0,69902 & 0,00000 & 0,00098 & 0,00000 \\
\hline 5 & 0,00000 & 0,26132 & 0,00001 & 0,00000 & 0,86546 & 0,00000 & 0,00000 & 0,00000 \\
\hline 6 & 0,08327 & 0,00000 & 0,74875 & 0,00000 & 0,04971 & 0,00000 & 0,00000 & 0,00000 \\
\hline
\end{tabular}

Nachfolgend wird die Verteilung der genetischen Marker ciaB, cdtB, cj1321-1326, fucP, cj0178, cj0755, ceuE, pldA und cstII/cstIII innerhalb der definierten Gruppen detaillierter dargestellt. 


\subsubsection{Campylobacter-Invasions-Antigen und Zytolethales distendierendes Toxin}

Die Gene $c i a B$ und $c d t B$ werden innerhalb der Testpoulation als ubiquitär betrachtet.

Während $c i a B$ in allen Subpopulationen gefunden wurde, fehlte $c d t B$ nur in einem einzigen Isolat der Gruppe $3 \mathrm{a}^{*}$. Demzufolge sind $100 \%$ der 266 Isolate ciaB-positiv und 99,6\% der Isolate $c d t B$-positiv.

\subsubsection{Gencluster zur Flagellin- $O$-Glykolisierung}

Der Gencluster zur Flagellin-O-Glykolisierung konnte in der Mehrzahl der Isolate der Gruppen 1a, 1b und 3a detektiert werden.

Jedoch sind in der 15 Isolate umfassenden Untergruppe $1 \mathrm{~b}^{* * *}$ (CC 49 und 446) nur 7 von 15 Isolaten (46,7 \%) positiv für diesen Marker. Darüber hinaus ist ein Teil der Isolate aus Gruppe $4(37,5 \%, 3 / 8)$ und aus Guppe $6(33,3 \%, 3 / 9)$ cj1321-1326 PCR-positiv.

In Gruppe 5 sind alle vier zugehörigen Isolate negativ für diesen Gencluster. Insgesamt konnte der Marker in den Gruppen 2a, 2b, 3b und 5 signifikant seltener eruiert werden als in den Gruppen 1a, $1 \mathrm{~b}$ und 3a. Lediglich in den Gruppen $1 \mathrm{~b}^{* * *} ; 3 \mathrm{a}^{*} ; 4$ und 6 sind die Unterschiede nicht signifikant ( $p>0,05$, Abb.5).

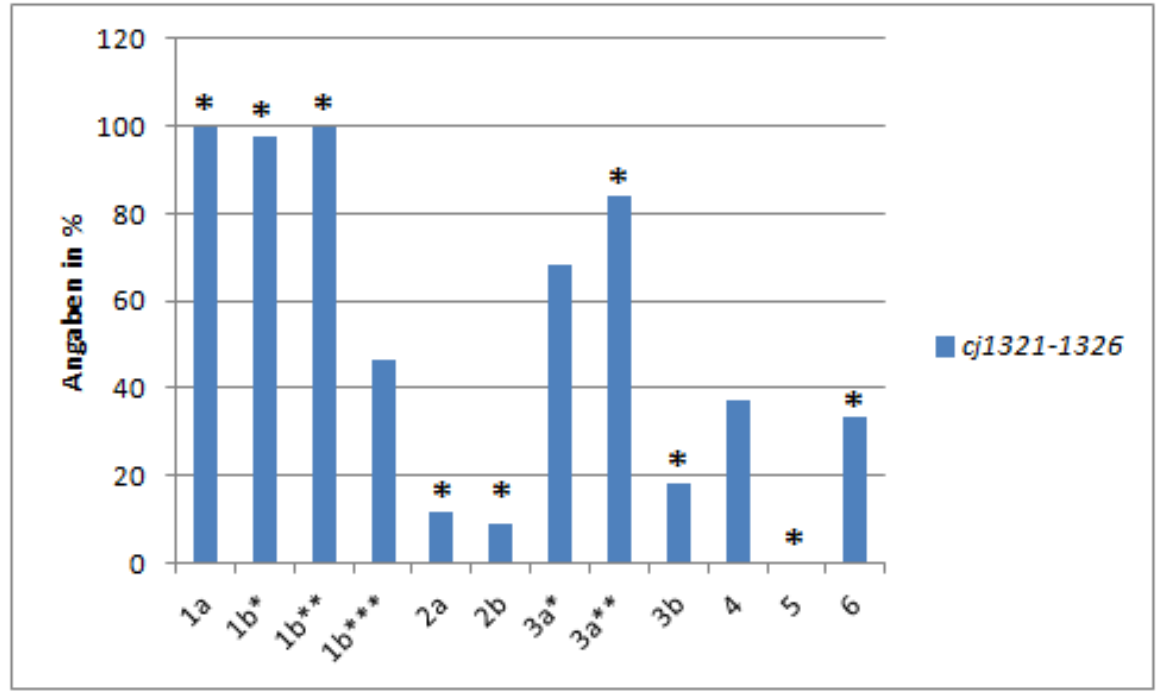

Abb. 5: Verteilung des genetischen Markers cj1321-1326 innerhalb der definierten Gruppen, ${ }^{*}$ Ergebnis signifikant $(p<0,05)$ 


\subsubsection{L-Fucose-Permease}

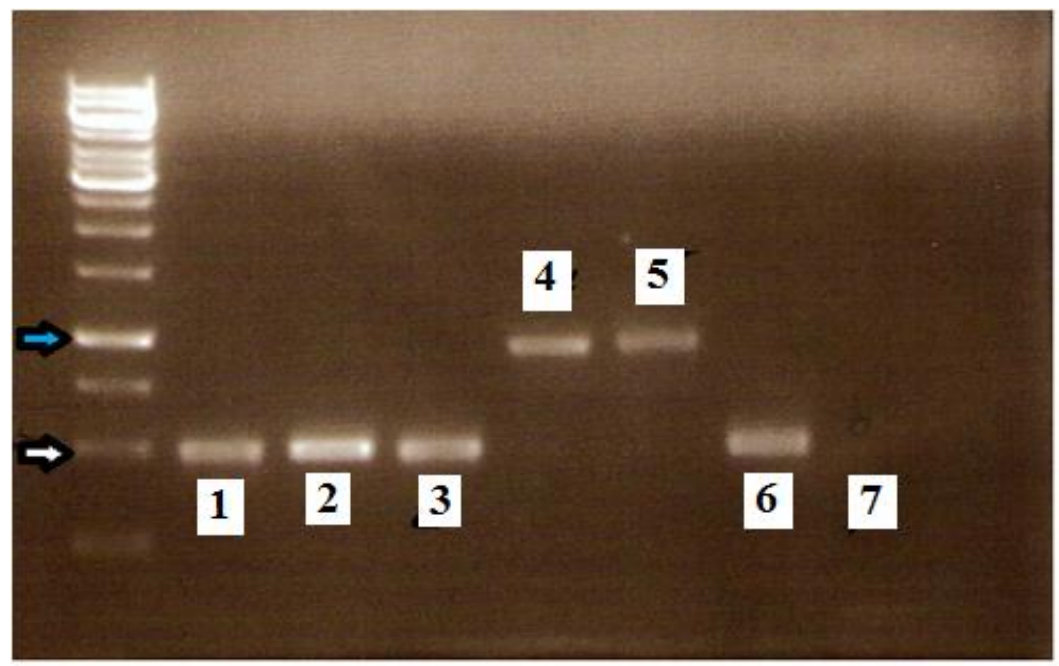

\section{Abb. 6: Photographische Dokumentation einer Gel-Elektrophorese}

Darstellung der Multiplex-PCR-Produkte einer Testreihe. Auf der linken Seite der Abbildung sieht man die Auftrennung des Nukleinsäuren-Längenstandards (“GenRulerTM 1kb Plus DNA Ladder”). Der weiße Pfeil markiert eine Fragmentgröße von $500 \mathrm{bp}$ und der blaue Pfeil von 1000bp. Die Zahlen markieren die aufgetrennte DNS verschiedener Isolate: 1- BfR3551, 2- bovC246, 3-BfR3885, 4-bovC539, 5bovC405, 6-A28, 7-negativ Kontrolle (Isolate entsprechend ihrer Bezeichnung in Tabelle 12; siehe Anhang). Da zum Nachweis des fucP-Gens eine Multiplex-PCR eingesetzt wurde, weisen die Banden unterschiedlich große, aber eindeutig zuordenbare, Amplifikatlängen auf. Die $f u c P$-positiven Stämme produzieren Banden von $1,2 \mathrm{~kb}$ Fragmentgröße, während die $f u c P$-negativen Stämme, entsprechend einer Deletion des Genclusters, Amplifikte von 446bp aufweisen (MURAOKA und ZHANG 2011). Demzufolge ist die aufgetrennte DNS der Isolate 4 und 5 auf der Abbildung fucPpositiv (Banden oberhalb einer Höhe von 1000bp) und die anderen fucP-negativ.

Für das L-Fucose-Permease-Gen fucP konnte ein vergleichbares Verteilungsmuster unter den Subgruppen wie für den Marker zur Flagellin-O-Glykolisierung aufgezeigt werden (Abb.7). Die Isolate der Gruppen 1a, 1b ${ }^{*}$ und 6 sind zu $100 \%$ positiv für fucP. Nur in Gruppe 6 sind $100 \%$ der Isolate für fucP positiv, aber lediglich 33,3 \% für cj1321-1326 (wie zuvor beschrieben). In der Gruppe $1 b^{* *}$ sind 94,7\% (36/38) positiv für fucP, d.h. nur 2 der 38 Isolate sind im PCR-Test fucP-negativ. Die kleine Untergruppe $1 \mathrm{~b}^{* * *}$, bestehend aus CC 49und CC 446- Isolaten, bildet auch hier eine Ausnahme. Lediglich 5 der 15 Isolate (33,3\%) dieser Gruppe sind fucP-positiv. Zudem fehlt das Gen fast durchgängig in den Gruppen 2a/b, $3 a^{* *}(2 / 19) ; 3 b ; 4$ und 5. 


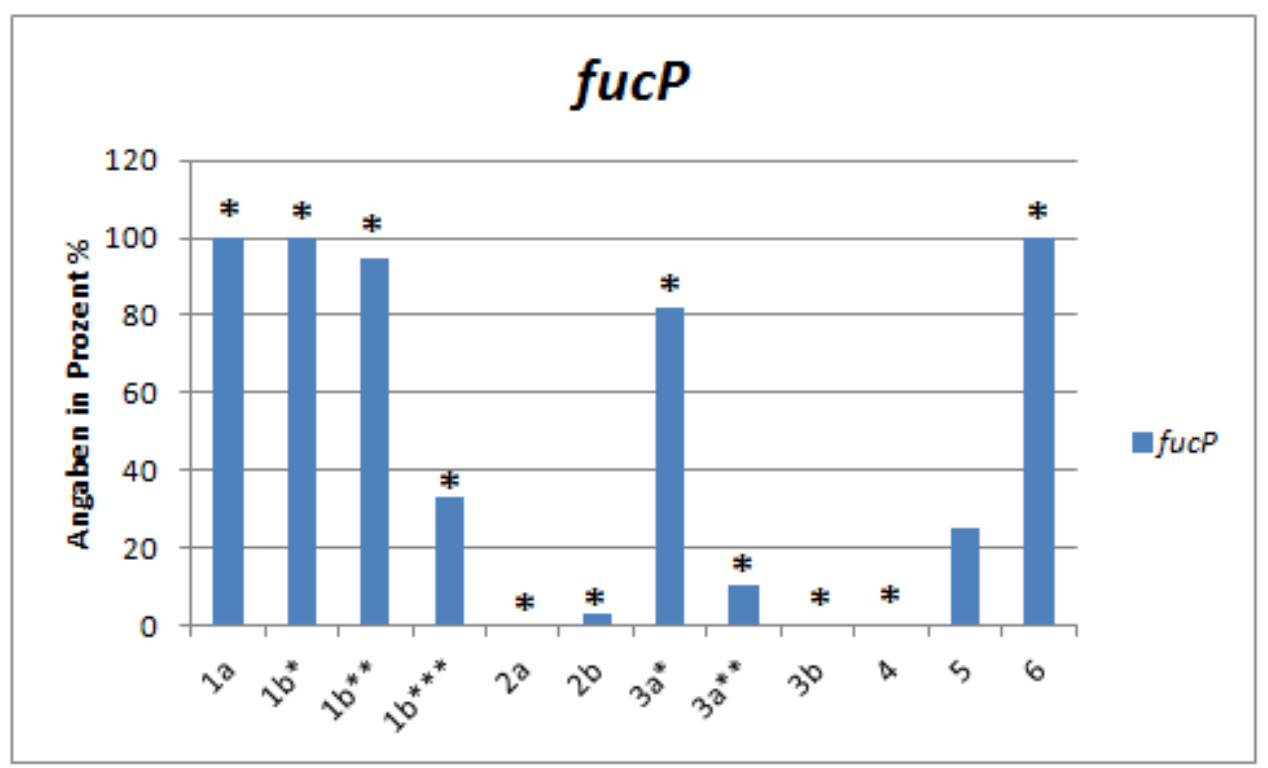

Abb. 7: Darstellung der Verteilung des L-Fucose-Permease-Gens fucP

innerhalb der C. jejuni-Gruppen, ${ }^{*}$ Ergebnis signifikant $(\mathrm{p}<0,05)$

\subsubsection{Enterochelin-Aufnahmeprotein und Phospholipase A der äußeren Membran}

Ebenfalls wurde in der Arbeit die Präsenz der Gene ceuE und pldA mittels Polymerasenkettenraktion überprüft. Zunächst wurden die Isolate mit ceuE-Primern und pldA-Primern, basierend auf der C. jejuni-NCTC 11168 Genomsequenz, wie in der Arbeit von FEODOROFF et al. (2010) dargestellt, untersucht (siehe 2.1.2, Tab. 1).

In den Subpopulationen 1a und 5 waren jeweils $100 \%$ der Isolate ceuE-positiv und in den Gruppen $1 \mathrm{~b}^{* * *}, 3 \mathrm{a}^{* *}, 3 \mathrm{~b}, 4$ und 6 wurde die $100 \%$ ceuE-Positivitätsrate aufgrund jeweils einzelner $c e u E$-negativer Isolate verfehlt. Nur in Gruppe 2 waren signifikant deutlich mehr Isolate negativ für ceuE, bei ausschließlicher Nutzung des Primerpaares basierend auf der NCTC 11168-Genomsequenz..

In der Subpopulation 2a waren 70,6 \% (12/17) der Isolate für diesen Marker positiv. In Gruppe $2 b$ fand sich eine ähnliche Verteilung mit 76,5\% positiven Isolaten (26/34). In Gruppe $3 \mathrm{a}^{*}$ waren mehr Isolate positiv als in Gruppe 2 (18/22). Dennoch fanden sich hier mit $81,8 \%$ weniger ceuE-positive Isolate als in den Gruppen 1, 3a ${ }^{* *}, 3 \mathrm{~b}, 4,5$ und 6 . 
Für das Markergen pldA konnten nur in den Gruppen 1a, 1b ${ }^{* * *}$ und in Gruppe $5 \mathrm{zu} 100 \%$ positive Isolate nachgewiesen werden. In den anderen Subpopulationen blieben immer einige Isolate mit den vom NCTC 11168-Genom abgeleiteten Primern negativ (Tabelle 11).

Die mit den von NCTC 11168-abgeleiteten Primern ceuE- und pldA-negativen Isloate wurden zusätzlich mit den jeweiligen Primerpaaren basierend auf dem C. jejuni 81-176-Genom untersucht. In allen diesen Isolaten, die i.d.R. eine phylogenetisch größere Nähe zu $C$. jejuni 81-176 aufweisen als zu C. jejuni NCTC 11168, konnten unter Nutzung dieser Methode beide Markergene nachgewiesen werden.

D. h. unter ausschließlichem Gebrauch der NCTC 11168-Primer konnte nur für die Gruppe 2Isolate eine signifikant $(24,0 \%, \mathrm{p}<0,002)$ geringere Präsenz des NCTC-11168-ceuE-Allels festgestellt werden.

Allerdings konnten keine signifikanten Unterschiede zwischen den verschiedenen IsolateGruppen bezüglich der pldA-Allele festgestellt werden.

\subsubsection{Eisenaufnahmesysteme}

Des Weiteren wurde die Präsenz der Markergene cj0178 (kodiert einen Siderophore-Rezeptor der äußeren Membran) und cj0755 (ein Eisenaufnahmeprotein) in der Testpopulation untersucht.

Grundsätzlich konnten beide Gene in mehr als $76 \%$ der Isolate nachgewiesen werden, meist in Assoziation miteinander. In den Gruppen 1a, 1b* $3 \mathrm{a}^{*}, 3 \mathrm{a}^{* *}, 3 \mathrm{~b}, 5$ und 6 waren $100 \%$ der Isolate für beide Gene positiv. Ähnliches gilt für die Gruppe $1 b^{*}$, in der nur ein Isolat von 38 Isolaten für cj0178 negativ war, während für cj0755 38 von 38 Isolaten (100\%) positiv getestet worden.

In Gruppe 2a sind alle Isolate für den Marker cj0178 negativ, während 3 von 17 Isolaten cj0755-positiv waren. In Gruppe $2 \mathrm{~b}$ sind bis auf ein $c j 0178^{+} / c j 0755^{+}$-Isolat alle Isolate negativ auf beide genetischen Marker.

Ähnlich ist die Verteilung in Gruppe 4. Dort ist lediglich ein Isolat (von insgesamt acht) cj0178-positiv, wobei alle Gruppe 4-Isolate negativ für cj0755 sind.

In den Gruppen 2a, 2b und 4 wurden die Eisenaufnahme-Marker nur vereinzelt gefunden. Allerdings waren etwa $100 \%$ der Isolate der übrigen Gruppen positiv für beide Gene. 


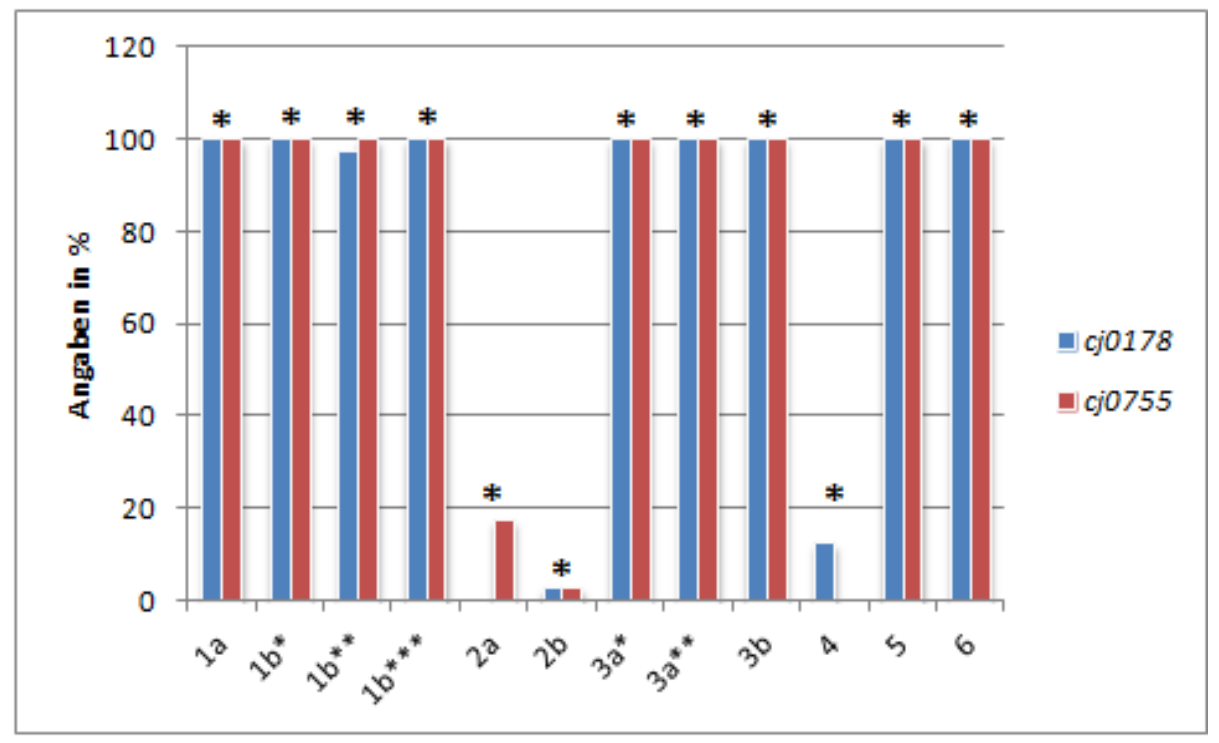

Abb. 8: Verteilung der Marker $c j 0178$ und $c j 0755$

innerhalb der C. jejuni-Gruppen, ${ }^{*}$ Ergebnis signifikant $(\mathrm{p}<0,05)$

\subsubsection{Marker für die Lipooligosaccharid-Sialyltransferase}

Vor dem Hintergrund Isolate mit sialyliertem LOS von solchen ohne sialyliertem LOS zu unterscheiden, wurden die Gene cstII und cstIII in das Markergenpanel eingeschlossen. Es gibt bereits detaillierte Studien (HABIB et al. 2009, HOTTER et al. 2010, REVEZ et al. 2011) die MLST-CC mit verschiedenen LOS-Klassen assoziieren. Dass ermöglicht eine Verbindung zwischen einer bestimmten Isolat-Gruppe mit einer spezifischen LOS-Klasse, allein basierend auf MLST-CC und der Information über die Ab- oder Anwesenheit von cstII und cstIII (Gruppe und zugeordnetes LLC finden sich in Tabelle 11) zu ziehen.

Isolate der Gruppe $1 \mathrm{a}$ und $1 \mathrm{~b}^{*}$ konnten mehrheitlich positiv auf cstIII getestet werden, aber auch $c s t I I-$ positve Isolate finden sich in den beiden Gruppen. Die Untergruppe $1 b^{* *}$, die CC 48 und CC 206 Isolate beinhaltet, ist fast ausschließlich cstII-positiv (37/38). Lediglich 2 von 38 Isolaten dieser Gruppe sind cstIII-positiv.In der kleinen Untergruppe $1 b^{* * * *}$ (beinhaltet 15 Isolate der klonalen Komplexe CC 44 und CC 446) finden wir zu 40 \% cstII-positive aber durchgängig cstIII-negative Isolate. Unter den Gruppe 3-Isolaten befinden sich mehr cstIIpositive als cst III-positive Isolate.

Die Gruppen 4, 5 und 6 sind zum größten Teil für beide Marker negativ getestet worden. 
23 Isolate der ingesamt 266 Isolate umfassenden Testpopulation konnten auf beide genetischen Marker positiv getestet werden. Die Mehrheit der doppelt-positiven Isolate befindet sich in Gruppe $1(15 \%, 20 / 135)$ und gehört dem klonalen Komplex CC 21 an.

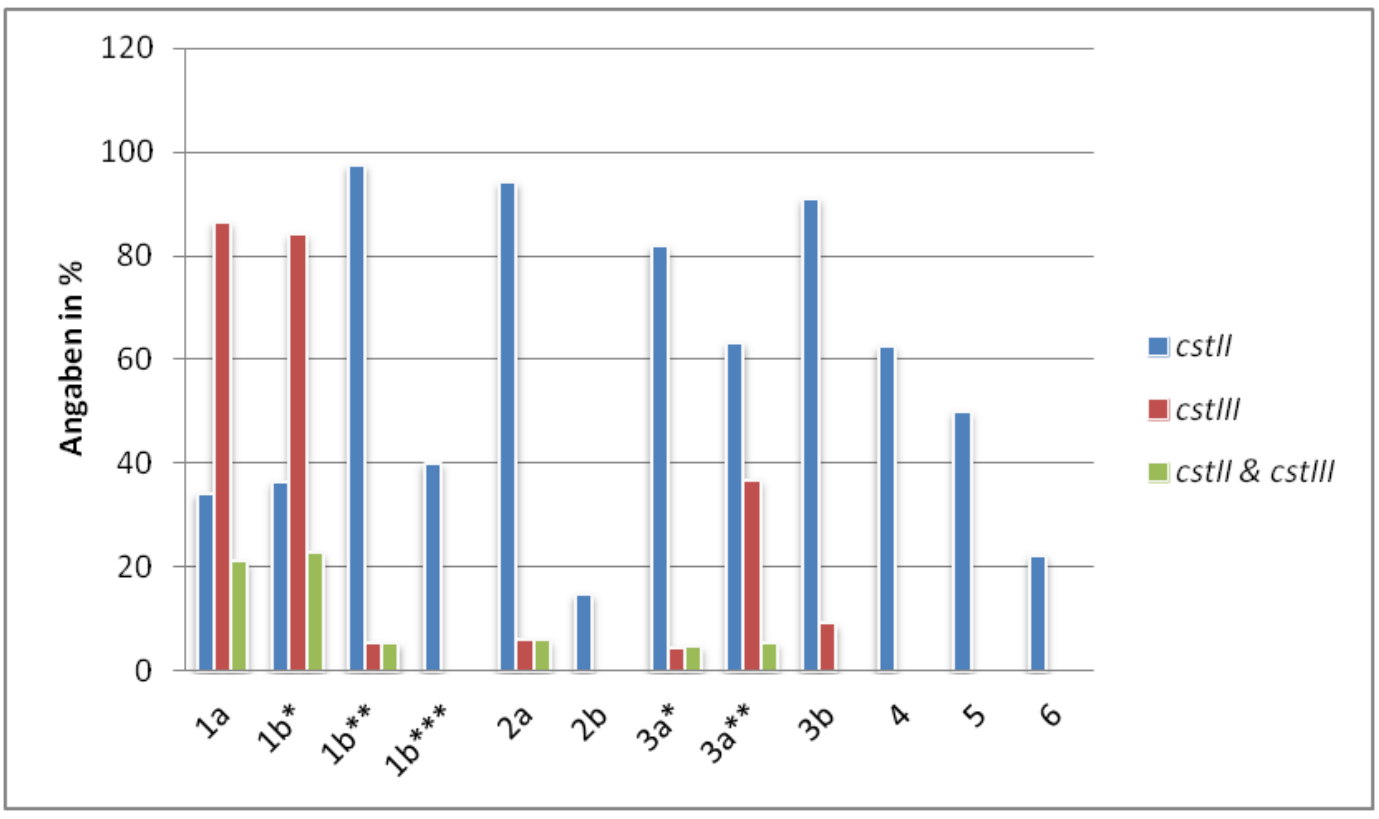

Abb. 9: Verteilung von cstII, cstIII \& cstII/cstIII innerhalb der Gruppen

Häufigkeitsverteilung unter den verschiedenen $C$. jejuni-Isolate-Gruppen. 


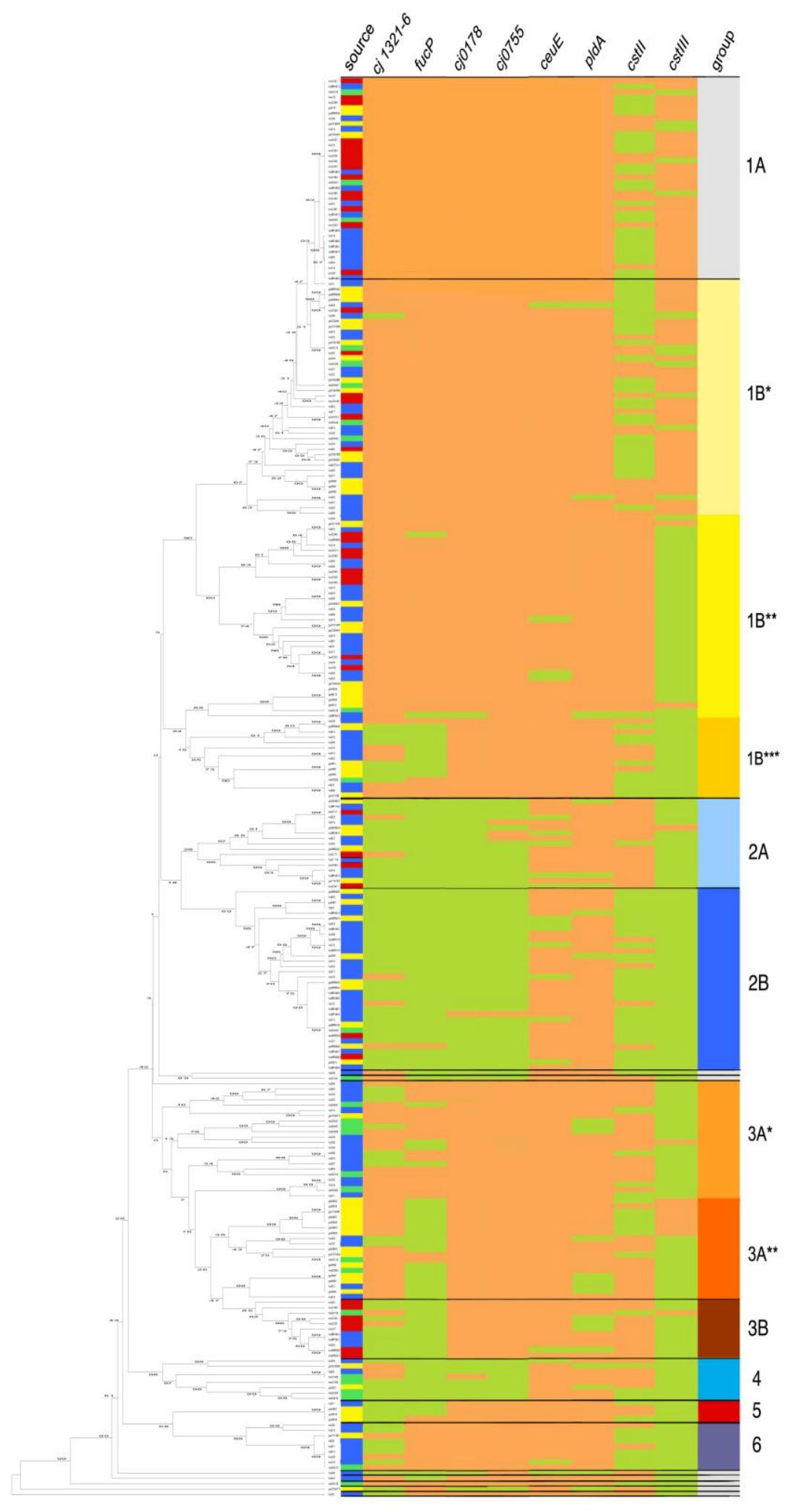

Abb. 10: MLST-sequenzbasierter UPGMA-Baum (Erläuterung Folgeseite kursiv) 
Verteilung der acht Markergene innerhalb der sechs festgelegten Gruppen (zwölf Untergruppen).

Auf der linken Seite wird der MLST-sequenzbasierte UPGMA-Baum der 266 Isolate abgebildet. Die Nummern an den Zweigen des Baumes geben die phylogenetische Verwandschaft an. Auf der rechten Seite der Tabelle sind alle Isolate entsprechend IsolatQuelle, An- oder Abwesenheit des genetischen Markers und Zugehörigkeit zu einer der definierten Gruppen dargestellt.

Quelle (eng. source): Isolate vom Mensch sind blau markiert; Hühner-Isolate gelb; Rinder rot und Puten-Isolate grün. Markergene: Die Anwesenheit des genetischen Markers ist mit hellroten Schattierungen markiert und die Abwesenheit des Markers mit hellgrünen Schattierungen. Die Marker von rechts nach links sind: cj1321-6, fucP, cj0178, cj0755(cfrA), ceuE, pldA, cstII und cstIII.

Die letzte Spalte gibt die Gruppen-Zugehörigkeit entsprechend Tabelle 11 wieder: hellgrau(1A), hellgelb $\left(1 b^{*}\right)$, intensives gelb $\left(1 b^{* *}\right)$, ockergelb $\left(1 b^{* * *}\right)$, hellblau $(2 a)$, dunkelblau (2b), orange $\left(3 a^{*}\right)$, orangerot $\left(3 a^{* *}\right)$, rostrot (3b), türkis (4), rot (5), kobaltblau (6), weiß (vereinzelte, nicht zuordenbare Isolate) 


\subsection{Verteilung der Markergene nach Isolat-Ursprung}

Fortführend wurden die Isolate innerhalb der 9 Gruppen in Hinblick auf ihren Ursprung (Menschen, Hühner, Puten und Rinder) ausgewertet und in Relation zur Gesamtanzahl innerhalb der 266 Gesamt-Isolate gesetzt.

Beim Vergleich der 9 Gruppen zeigt sich, dass humane Isolate als einzige in allen Gruppen vertreten sind. In den Gruppen 2 und 6 sind Menschen-Isolate, im Gegensatz zu den Isolaten anderen Ursprungs, am häufigsten existent. Humane Isolate machen mit 48,5 \% den Großteil der 266 Isolate aus, gefolgt von Hühner-Isolaten (25,2\%), bovinen Isolaten (16,2\%) und letztlich Puten-Isolaten mit einem Anteil von 10,2 \% an der Gesamtzahl von 266 Isolaten.

Bei genauerer Betrachtung der 2 großen C. jejuni-Isolatgruppen 1 und 2 fällt auf, dass in Gruppe 1 mit 69,8\% am häufigsten bovine Isolate vertreten sind, wenngleich die humanen Isolate mit 48,8 \% als zweites folgen. Insgesamt gesehen stellen aber in Gruppe 1 Isolate tierischen Ursprungs (Huhn, Rind, Pute) im Vergleich zu den menschlichen Isolaten den größeren Anteil (72/135 Isolaten). Der Anteil an bovinen Isolaten ist in Gruppe 1a mit 34,9 \% (15/43) fast dreimal so hoch wie der Anteil menschlicher Isolate 12,4 \%(16/129).

In der 51 Isolate umfassenden Gruppe 2 treten Menschen-Isolate prozentual am zahlreichsten auf 23,3\% (30/129). Gruppe 2b umfasst deutlich mehr humane Isolate 17,1 \% (22/129) wie Hühner-Isolate 13,4 \% (9/67), die anteilig als zweites folgen. Ähnlich verhält sich Gruppe 6, hier sind 7 der 9 Isolate menschlicher Herkunft.

Puten-Isolate sind Spitzenreiter in Gruppe 3 und 4. Gruppe 5 enthält fast ausschließlich Hühner-Isolate 75\% (3/4). Rinder-Isolate fehlen gänzlich in den Gruppen 4, 5 und 6.

Eine graphische Darstellung der Isolatverteilung, gemäß ihrem Ursprung innerhalb der 9 Gruppen, bietet Abbildung 11. 


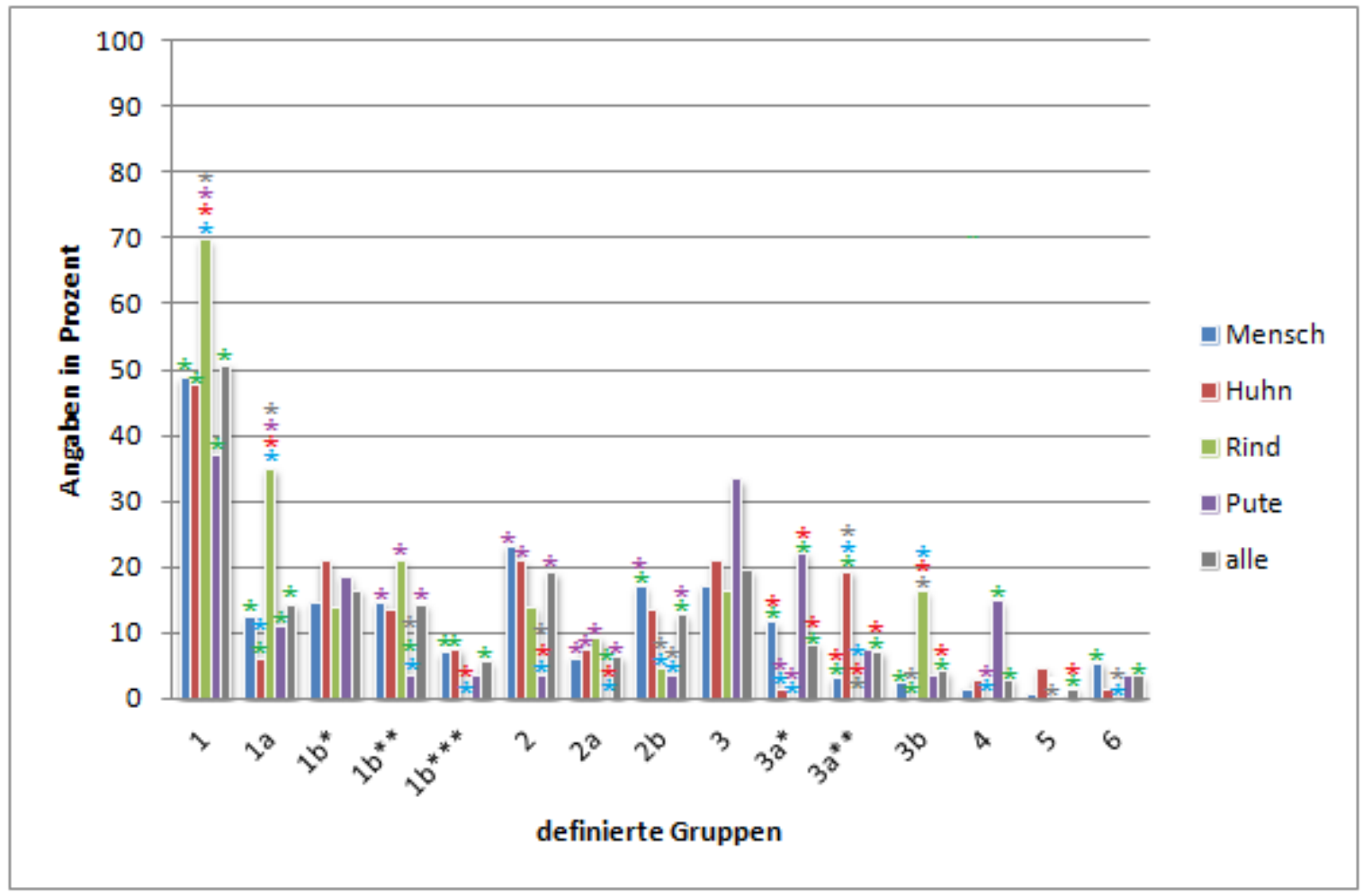

\section{Abb. 11: Relative Häufigkeit der C. jejuni-Isolat-Ursprünge in Isolatgruppen}

Relative Verteilung der Isolate nach Isolat-Ursprung innerhalb der neun, entsprechend der MarkergenVerteilung definierten Gruppen. Signifikant unterschiedliche Werte $(\mathrm{p}<0,05)$ sind durch einen Asterisk in der Farbe des Vergleichswertes markiert (z.B. roter Asterisk beim Vergleich mit der von Hühnern isolierten Subpopulation). Bei fehlendem Asterisk liegen demnach keine signifikanten $(\mathrm{p}>0,05)$ Unterschiede vor.

\subsection{Verteilung der Marker innerhalb der Spezies}

In die Untersuchung wurde außerdem die Korrelation zwischen genetischem Marker und Isolat-Ursprung einbezogen.Von den 266 Isolaten der Testpopulation sind 129 humanen Ursprungs, 67 stammen von Hühnern, 43 haben bovinen Ursprung und 27 Isolate wurden aus Puten isoliert.

Der sechs Gene umfassende Cluster zur Flagellin- $O$-Glykolisierung cj1321-1326 wurde in $63,9 \%(174 / 266)$ der Isolate detektiert. Der Gencluster ist in Isolaten menschlichen Ursprungs am schwächsten vertreten (59,7\%), jedoch in der überwiegenden Mehrheit der Puten- $(77,8 \%)$ und Rinder-Isolate $(74,4 \%) \mathrm{zu}$ finden. Ein ähnliches Verteilungsmuster präsentiert das L-Fucose-Permease-Gen $f u c P$. Es konnte in 59,0 \% der Isolate nachgewiesen 
werden, primär in Rinder- und Puten-Isolaten. Allerdings ist diese heterogene Verteilung zwischen den verschiedenen Wirtsarten nicht signifikant, wie in Abbildung 12 veranschaulicht.

Bezüglich der Lipooligosaccharid-Sialyltransferase-Gene cstII und cstIII konnte festgestellt werden, dass cstII in der Mehrzahl der 266 Isolate auftritt (55,3\%), cstIII hingegen nur in $30,8 \%$ der Isolate. Begutachtet man vorzugsweise die Isolate menschlichen Ursprungs fällt auf, dass 55,0 \% cstII ${ }^{+}$sind (71/129) und nur 24,8 \% (32/129) der Isolate cstIII $^{+}$. Insgesamt identifiziert man cstII mit $69,8 \%$ am häufigsten in Rinder-Isolaten und cstIII am zahlreichsten in Hühner-Isolaten 40,3 \% (27/67). 23 Isolate sind sowohl für cstII als auch für cstIII positiv. Die Kombination aus beiden tritt am häufigsten in bovinen Isolaten (14,0 \%) auf. Abbildung 12 dokumentiert die relative Häufigkeit der Markergene nach Wirtsspezies.

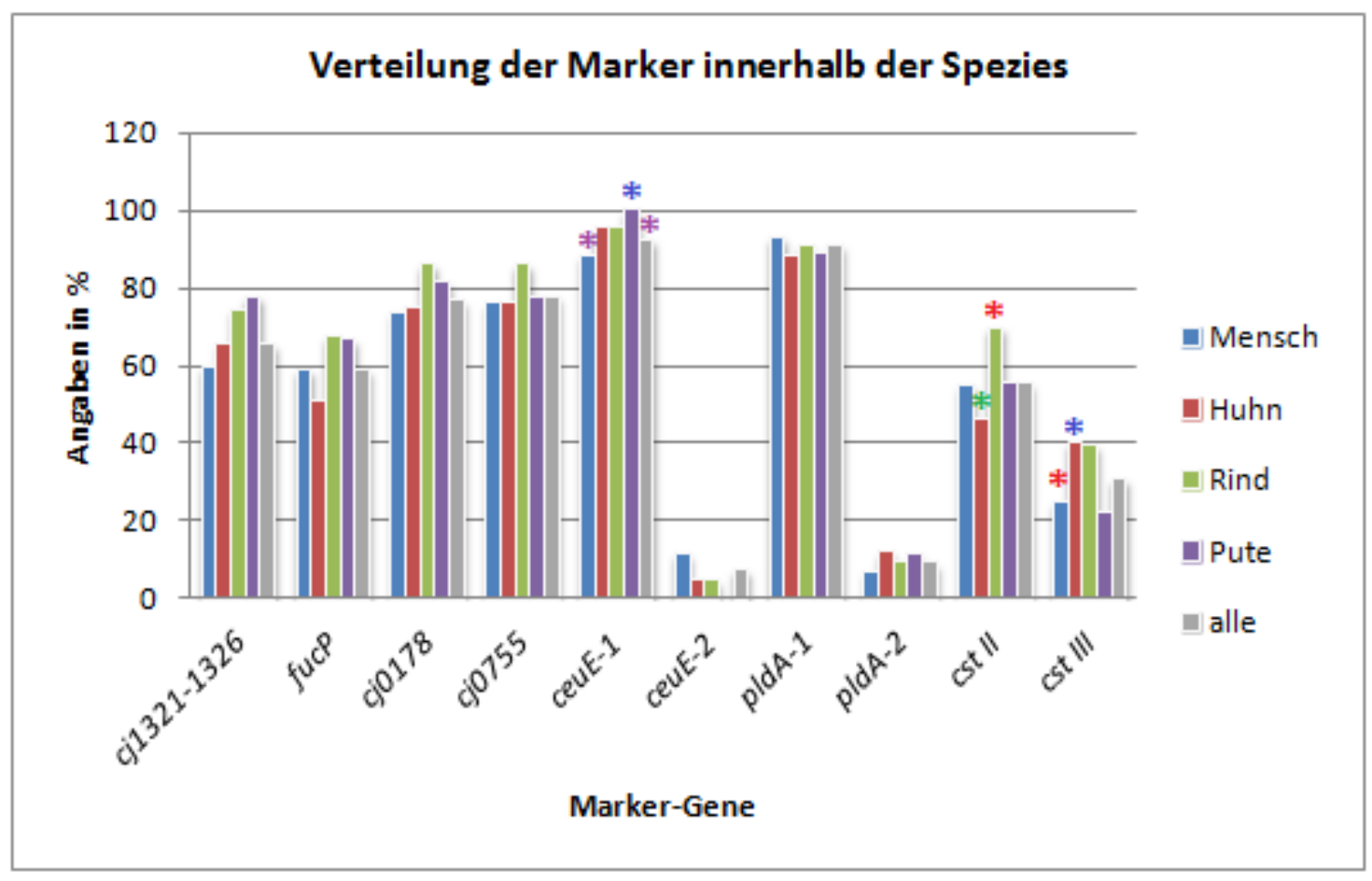

Abb. 12 : Relative Häufigkeit der Markergene nach Wirtsspezies

Signifikante Unterschiede $(\mathrm{p}<0,05)$ sind durch Asteriske in den Farben des Vergleichswert (z.B. roter Asterisk, wenn mit Huhn verglichen) markiert. Fehlende Asteriske markieren nicht signifikante $(\mathrm{p}>0,05)$ Unterschiede.

\footnotetext{
${ }^{1}$ Ergebnisse basieren auf dem NCTC 11168-abgeleiteten Primern

${ }^{2}$ Ergebnisse basieren auf den 81-176-abgeleiteten Primern
} 
In den Kreis der Betrachtungen wurden außerdem einige Markergen-Kombinationen: cj132126 / fucP; cj0178/cj0755; cj1321-26 / fucP/cj0178/cj0755 mit einbezogen.

Die Gene $c j 1321-1326$ und fucP sind in 140 der 266 Isolate (d.h. 52,6 \%) miteinander assoziiert. Die genetischen Marker cj0178 und cj0755 treten in 76,0 \% (202/266) der Isolate zusammen auf. Betrachtet man die Verknüpfung zwischen allen vier Genen (cj132126/fucP/cj0178/cj0755), erkennt man, dass etwa die Hälfte der Isolate(132/266) positv für alle vier Gene getestet wurde.

Diese „4-Gen-Kombination“ findet sich innerhalb der Rinder-Isolate (67,4 \%) am häufigsten. Vergleichsweise sind nur 49,6 \% der Menschen-Isolate sind positiv für alle vier Gene.

Die Assoziation der Gene cj1321-1326 und fucP dominiert mit 67,4 \% in den RinderIsolaten. Jedoch waren die meisten dieser Verteilungsunterschiede innerhalb der Menschen-, Hühner, Rinder und Puten-Isolate nicht signifikant, Abbildung 13.

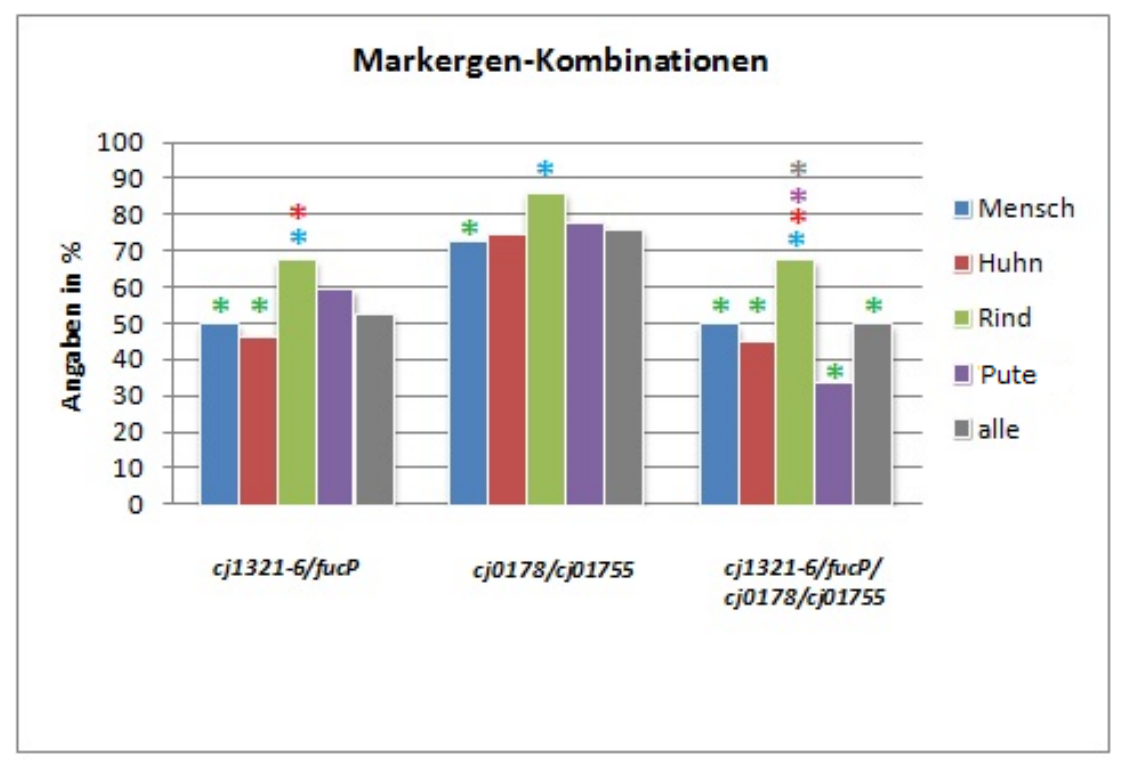

\section{Abb. 13 : Verteilung der Markergen-Kombinationen}

Innerhalb der verschiedenen C. jejuni-Gruppen gemäß Isolat-Ursprung.

Vergleich der Markergen-Kombinationen cj1321-1326/ fucP; cj0178/cj01755 und cj1321-26/fucP/cj0178/cj01755 nach Isolat-Ursprung (Mensch, Huhn, Rind,Pute). Signifikant unterschiedliche Werte $(\mathrm{p}<0,05)$ sind durch Asteriske in den Farben des Vergleichswerts markiert. Fehlende Asteriske markieren nicht signifikante $(\mathrm{p}>0,05)$ Unterschiede. 


\subsection{Hospitalisierung und blutiger Stuhl}

Zuletzt wurden die klinischen Parameter: (I) Hospitalisierung und (II) Blut im Stuhl innerhalb der menschlichen Isolate in die Überlegungen einbezogen. Etwa die Hälfte (129 Isolate) der 266 untersuchten Isolate stammen vom Menschen. Die relative Häufigkeit humaner Isolate liefert daher Aussagen über die klinische Relevanz einer bestimmten Isolat-Gruppe.

Von 104 der 129 untersuchten humanen Isolate liegen Informationen über die klinischen Parameter Hospitalisierung und Blut im Stuhl vor (Tabelle 13 Anhang).

Zwischen den verschiedenen Isolatgruppen konnten wenige signifikante Unterschiede bezüglich der beiden untersuchten klinischen Parameter ermittelt werden. Nur die Isolate der Gruppe $1 b^{* *}$ besaßen im Vergleich $\mathrm{zu}$ den nicht $1 b^{* *}$-Isolaten eine signifikant geringere Hospitalisierungs-Rate $(p=0,01374)$, während in Gruppe 6 signifikant $(p=0,01215)$ mehr Hospitalisierungen zu verzeichnen waren.

Signifikant $(\mathrm{p}=0,00020)$ weniger Blut im Stuhl konnte für die Isolate der Gruppe 3a* demonstriert werden.

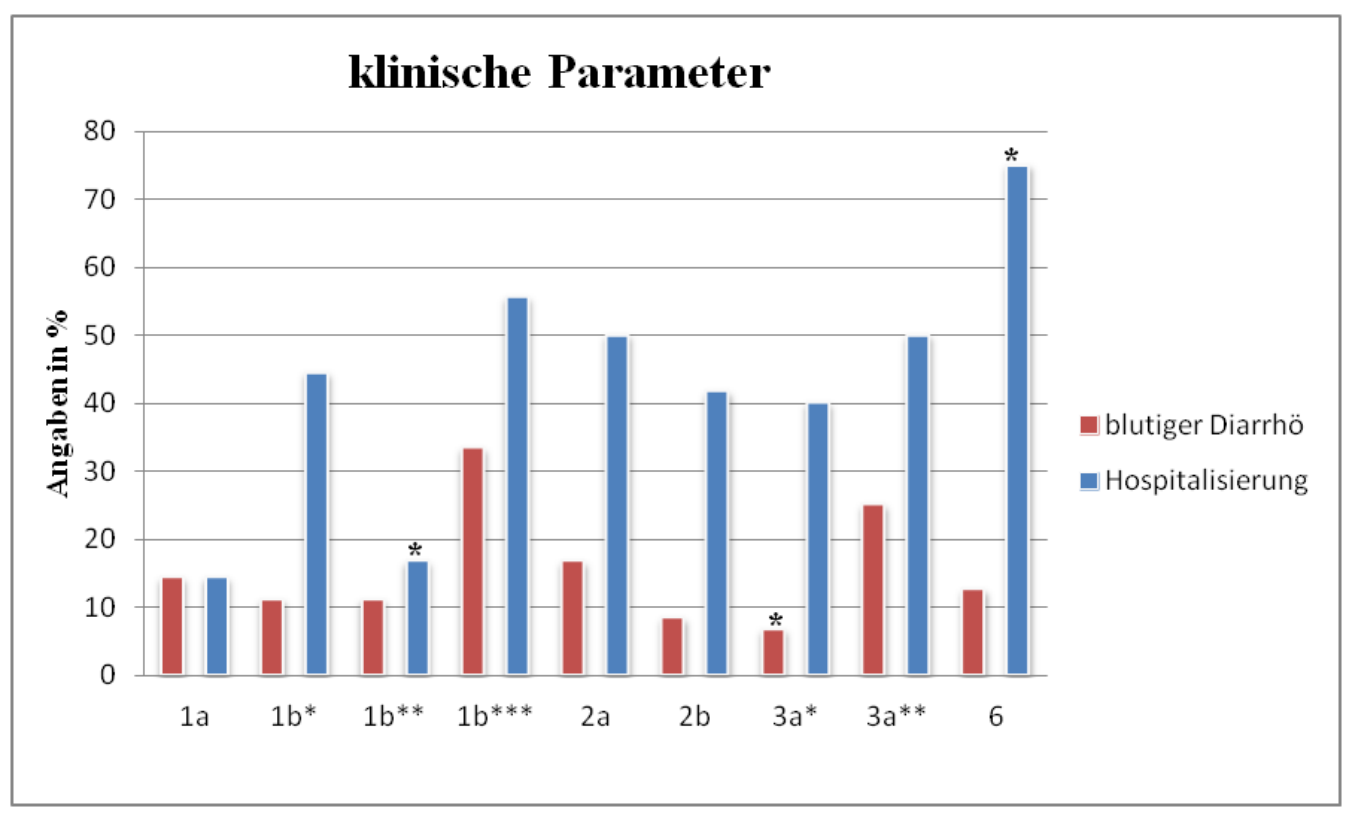

\section{Abb. 14 : Relative Häufigkeit von klinischen Parametern in Isolatgruppen}

Relative Verteilung von blutiger Diarrhö und Hospitalisierung nach Isolat-Ursprung innerhalb der signifikanten Gruppen. Signifikanzen wurden im Vergleich zu den nicht zur Gruppe gehörigen humanen Isolaten ermittelt. Signifikante Werte $(\mathrm{p}<0,05)$ sind durch einen Asterisk gekennzeichnet. Gruppe 4, 5 \& 6 fehlen wegen mangelnder Aussagekraft in der Statistik (jeweils nur ein Isolat mit klinischer Information). 


\section{Diskussion}

C. jejuni-Infektionen gehören weltweit $\mathrm{zu}$ den häufigsten bakteriellen Ursachen für Gastroenteritis (SCHMIDT-OTT et al. 2006). Allein 2012 wurden dem RKI bis zur 49. Kalenderwoche 60.390 durch Campylobacter ssp. verursachte Enteriden gemeldet (RKI 2012).

Haupinfektionsquelle ist der Verzehr von kontaminiertem Geflügelfleisch und die Zubereitung kreuzkontaminierter Nahrung. Aber auch der Konsum von Rindfleisch und das Trinken unpasteurisierter Milch können zur Infektion führen (FRIEDMAN et al. 2000). Klinische Symptome der Gastroenteritis reichen von milden, nicht entzündlichen, selbst limitierenden Durchfällen bis zu schwereren, entzündlichen, blutigen Durchfällen (WASSENAAR und BLASER 1999). Postinfektiöse Komplikationen wie GBS oder reaktive Arthritis können in seltenen Fällen auftreten (BUTZLER 2004). Daraus wird die Bedeutung von Campylobacter als zunehmendes Problem der öffentlichen Gesundheit deutlich.

Im Zuge dieser Arbeit wurden 266 Isolate verschiedener Herkunft (Mensch, Huhn, Rind, Pute) mittels PCR auf das Vorhandensein von zehn Virulenz-assoziierten Markern überprüft, um die Stämme mit dem höchsten gesundheitsgefährdenden Potential zu ermitteln.

\subsection{Gencluster zur Flagellin-O-Glykolisierung}

Auf der Suche nach Möglichkeiten, Stämme von verschiedenen Ursprungsquellen zu unterscheiden, identifizierten CHAMPION et al. 2005 einen Cluster von sechs Genen, cj1321cj1326, zur Flagellin-O-Glykolisierung. Der Cluster kommt vorwiegend in Stämmen aus Nutztierbeständen vor (PARKHILL et al. 2000).

Die Autoren der Studie fanden heraus, dass die Mehrheit (55,7\%) ihrer untersuchten klinischen Isolate nicht zu den Stämmen gehört, die von Nutztieren stammen, d.h. sie waren negativ für den Gencluster cj1321-1326. Die cj1321-6-negativen Stämme sind überwiegend bei asymptomatischen Trägern isoliert worden oder es handelte sich um Umweltisolate. Diese Untersuchungsergebnisse führten zu der Hypothese, dass die meisten Campylobacteriosen durch „Umweltquellen“ und nicht durch den Verzehr von Nutztierfleisch hervorgerufen werden (CHAMPION et al. 2005). 
Der Gencluster zur Flagellin-O-Glykolisierung könnte ebenfalls eine Rolle in der Wirtsbesiedlung und Zellinvasion spielen und das Überleben im humanen Wirt von $C$. jejuni durch Umgehung des Immunsystems verbessern (CHAMPION et al. 2005).

Das Vorkommen des Sechs-Gen-Clusters in 63, 9 \% (170/266) der untersuchten Isolate legt einen Isolat-Ursprung in Nutztierbeständen für diese Subpopulation nahe.

Wie schon bei CHAMPION et al. 2005 konnte der Marker am geringsten in klinischen Isolaten nachgewiesen werden. Die Mehrheit der Positivproben des Markers cj1321-1326 stammt von Puten (77,8 \%) und Rindern (74,4\%) (entsprechend Abb. 12).

Prüft man die Verteilung des genetischen Markers innerhalb der definierten Gruppen, erkennt man, dass Gruppe 1 mehrheitlich positiv für den Gencluster zur Flagellin- $O$-Glykolisierung getestet wurde, Gruppe 2-Isolate dagegen fast ausschließlich negativ für diesen Marker. Diese Ergebnisse bedeuten gemäß der Studie von CHAMPION et al. (2005), dass Gruppe 2 vornehmlich nicht aus Nutztierbestands-Stämmen zusammengesetzt ist und die 53-Isolateumfassende Gruppe 1 zum größten Teil aus Nutztier-assoziierten Stämmen.

Die Umwelt-adaptierte Gruppe 2b (cj1321-1326 ) ist signifikant öfter mit Isolaten humaner Herkunft assoziiert $(64,7 \%$, 22/34). Somit besitzen die Stämme der Gruppe 2 statistisch ein deutlich größeres pathogenes Potenzial für den Menschen als Isolate, die positiv für den mit Nutztierbeständen-assoziierten Marker cj1321-1326 getestet worden.

\subsection{Fucose-Verstoffwechselung}

Aufgrund der Abwesenheit der Phosphofruktokinase ist $C$. jejuni nicht in der Lage, exogene Glukose zu verwerten (PARKHILL et al. 2000, VELAYUDHAN und KELLY 2002). Indes konnten MURAOKA und ZHANG (2011) eine Genregion identifizieren, welche einigen $C$. jejuni-Stämmen die Fucose-Nutzung ermöglicht und ihre Anpassung an nährstoffarme Umgebungen verbessert.

Nach den vorliegenden Ergebnissen der Multiplex-PCR über An-oder Abwesenheit des fucPGens, dessen Expression durch Fucose induziert wird (MURAOKA und ZHANG 2010), sind über die Hälfte $(57,9 \%)$ der insgesamt 266 untersuchten Isolate fucP-positiv und dementsprechend in der Lage, L-Fucose zu verstoffwechseln. 
Bei der statistischen Auswertung zum Verteilungsmuster des Virulenz-asoziierten Markers fucP konnten signifikante Unterschiede innerhalb der definierten Gruppen ermittelt werden. So fehlt das Gen fucP in den Isolaten der Gruppe 2. Folglich sind Gruppe 2-Isolate nicht in der Lage, Fucose zum Wachstum zu nutzen. Zur Energiegewinnung metabolisieren sie hauptsächlich Carbonsäuren wie Fumarat und Crotonat (KELLY 2001). Demgegenüber konnte im Großteil der Gruppe 1-Isolate und in allen Isolaten aus Gruppe 6 fucP signifikant bewiesen werden, infolgedessen die Isolate dieser Gruppen Fucose verstoffwechseln können und besser an Fucose-haltige Umgebungen angepasst sind. Allerdings kann die Mehrheit der Gruppe 2-Isolate zusätzlich einen erweiterten Aminosäurestoffwechsel $\left(g g t^{+}\right.$, ans $\left.B^{+}\right)$und einen alternativen aneroben Stoffwechselweg $\left(d m s A^{+}\right)$zur Energiegewinnung heranziehen (HOFREUTER et al. 2006 und 2008).

Es wurde gezeigt, dass fucP ausschließlich in $\gamma$-Glutamyl-Transpeptidase $(g g t)$-negativen Isolaten auftritt (MURAOKA und ZHANG 2011). Das periplasmatische Enzym ggt kommt sowohl in Prokaryonten als auch in Eukaryonten vor und hat eine wichtige Funktion im Abbau von Glutamin und Gluthation im Gamma-Glutamat-Zyklus. Der Zyklus reguliert die Aufnahme von Aminosäuren in die Zellen (TATE und MEISTER 1981, HOFREUTER et al. 2008). Die in einigen C. jejuni-Stämmen vorkommende GGT ermöglicht die Metabolisation von Glutamin und Glutathion. Außerdem wird durch die Expression der $\gamma$-Glutamyl-Transpeptidase die Fähigkeit zur Kolonisation des murinen Intestinums verbessert (HOFREUTER et al. 2008).

Die in dieser Arbeit überprüfte Testpopulation wurde auf das Vorhandensein von ggt überprüft. Dabei wurde ersichtlich, dass die hauptsächlich aus CC 22 und CC 45 bestehende Isolat-Gruppe $2 g g t^{+}$ist (ZAUTNER et al. 2011).

Die Ergebnisse stehen zusammen mit den aktuellen Testergebnissen zum Vorhandensein von fucP im Einkang mit Erkenntnissen von MURAOKA und ZHANG (2011).

Gruppe 2 ist fucP-negativ, aber $g g t$-positiv. In Gruppe 1 hingegen (v.a. Stämme vom Typ CC 21) sind die meisten Isolate $f u c P^{+}$, aber für ggt- negativ getestet worden (Übersicht in Abbildung 15). Interessanterweise sind die Isolate der Gruppe 6 alle in der Lage, L-Fucose zu verstoffwechseln ( $f u c P$-positv), aber auch positiv für die mit ggt-assoziierten Marker ansB und $d m s A$, allerdings nicht für $g g t$. 
Das Verteilungsmuster von $f u c P$ ähnelt dem in Nutztierbeständen prominenten Marker cj1321-1326 und der Serin-Protease cj1365 (ZAUTNER et al. 2011). Somit hat die FucosePermease ebenfalls eine bedeutende Rolle in der Besiedlung der Darmmukosa, indem sie es ermöglicht, Fucose aus der intestinalen Flora als Substrat zu nutzen.

\subsection{Eisenverwertung}

Die Fähigkeit, Eisen zu erwerben, ist eine wesentliche Voraussetzung zur bakteriellen Replikation und damit, v.a. in eisenarmen Umgebungen, ein wichtiger Virulenz-assoziierter Faktor (PICKET et al. 1992, van VLIET et al. 2002).

Es konnte eine Subpopulation von $C$. jejuni-Isolaten identifiziert werden, die mit höheren Raten von blutigen Stühlen und Hospitalisierungen einhergeht. Diese Isolat-Gruppe ist ggtpositiv. Aber ceuE, welches ein bindendes Protein zur Enterochelin-Aufnahme kodiert, konnte bei ausschließlicher Nutzung des Primers, basierend auf der Genomsequenz vom Stamm NCTC 11168, nicht nachgewiesen werden (FEODOROFF et al. 2010).

Die von den Autoren beschriebene Subpopulation korreliert mit Gruppe 2 der vorliegenden Arbeit. Tabelle 11 verdeutlicht, dass in dieser Gruppe überdurchschnittlich viele Isolate signifikant weniger das NCTC 11168-ceuE-Allel besitzen als in den anderen definierten Gruppen. Hier konnte jedoch das 81-176-ceuE-Allel nachgewiesen werden. In der Isolat-Gruppe 2 konnten die Komponenten zur Eisenaufnahme cj0178 und $c f r A$ kaum nachgewiesen werden (Tabelle 11). Die beiden von FEODOROFF et al. (2010) identifizierten Gruppen, die zum einen duch signifikant mehr blutige Stühle bei vorhandenem ggt und zum anderen mit höheren Hospitalisierungsraten bei ceuE ${ }_{11168}$-Negativität charakterisiert waren, stimmen dem Markergenprofil zufolge mit Gruppe $2 b$ der vorliegenden Arbeit überein.

Es besteht eine Umkehrbeziehung zwischen der Anzahl an funktionsfähigen EisenAufnahme-Systemen und einer erhöhten Wahrscheinlichkeit von blutigen Durchfällen. Neben ceuE und $g g t$ sind die Komponenten zur Eisenaufnahme $c j 0178$ und $c f r A / 0755$ somit auch als Marker für klinische Verläufe nützlich. 


\subsection{Zusammensetzung des Lipooligosaccharids}

Sialylierte LOS sind an der Entstehung der beiden Neuropathien GBS und MFS beteiligt.

Diese Autoimmunerkrankungen können infolge einer Campylobacteriose durch molekulare Mimikry zwischen $C$. jejuni-LOS und humanen Gangliosiden entstehen. Am häufigsten lassen sich bei GBS-Patienten Antikörper gegen das gleichfalls sialylierte GM1-Gangliosid, nachweisen (GODSCHALK et al. 2004, YUKI et al. 2004). Das Schlüsselenzym der Sialylierung ist die Sialin- oder Neuraminsäuresynthase neuBCA (VIMR et al. 1989).

In Anlehnung an die Organisation des LOS-Locus wurden von PARKER et al. (2005 und 2008) verschiedene LOS-Locus-Klassen (LLC) definiert. Die LLC A, B, C, M und R enthalten die Sialinsäuresynthase $п е u B C A$ und mindestens eine von zwei klassen-spezifischen Sialintransferasen, die zum einen vom cstII-Gen, welches man verstärkt in LLC A, B, M und $\mathrm{R}$ findet, und zum anderen vom cstIII-Gen, das überwiegend in LLC C vorkommt, kodiert werden (PARKER et al. 2005 und 2008). Die aufgeführten LOS-Klassen verschlüsseln Enzyme um ein sialyliertes LOS zu synthetisieren. Den LOS-Klassen D-H fehlt eine Sialintransferase (PARKER et al. 2008).

In dieser Arbeit wurden nur die Schlüsselenzyme zur LOS-Sialyllierung cstII und cstIII untersucht. Da bereits detaillierte Studien (HABIB et al. 2009, HOTTER et al. 2010, REVEZ et al. 2011) über den Zusammenhang von MLST-CC und LLC existieren, kann basierend auf der Kenntnis von MLST-CC und der An- oder Abwesenheit von cstII/cstIII, die spezifische LLC abgeleitet werden. Das Gen cstIII (orf7c) findet sich verstärkt in LLC C (PARKER et al. 2005), cstII (orf7ab) dagegen in LLC A und B (PARKER et al. 2005).

Abgesehen von 23 doppelt-positiven Isolaten, überwiegend in Gruppe 1, konnten die meisten Isolate der Studien-Population entweder cstII- oder cstIII- positiv getestet werden.

In den Gruppen 1a und $1 b^{*}$ befinden sich überdurchschnittlich viele cstIII-positve Isolate $\left(86,4 \%\right.$ in Gruppe $1 \mathrm{a}$ und $84,1 \%$ in Gruppe $\left.1 b^{*}\right)$. Gruppe $1 \mathrm{a}$ und $1 \mathrm{~b}^{*}$ bestehen aus Isolaten, die zum CC 21 gehören. Diese Ergebnisse stimmen mit denen von HABIB et al. überein, da CC 21 Stämme entweder der LLC C oder LLC A angehören (HABIB et al. 2009).

Die Untergruppe $1 b^{* *}$, setzt sich aus CC 206 und CC 48 Isolaten zusammen, und ist fast ausschließlich cstII-positiv (97,4\%), nur 2 der 38 Isolate dieser Gruppe sind cstIII-positiv. 
Demzufolge sind die $1 \mathrm{~b}^{* *}$-Isolate der LLC B zugehörig (HABIB et al. 2009, HOTTER et al. 2010).

Ein Teil der CC 49- und CC 446-Isolate -beinhaltenden Gruppe $1 b^{* * *}$ ist cstII-positv (6/15), während die verbleibenden 60,0\% sowohl cstII- als auch cstIII-negativ sind. Demnach setzt sich die Isolatgruppe $1 \mathrm{~b}^{* * *}$ aus LLC B und D Isolaten zusammen (HABIB et al. 2009).

Die 94,1 \% (16/17) der Isolate aus Gruppe 2a wurden positiv auf cstII getestet. Nur ein Isolat war cstIII-positiv. Dieses Ergebnis korreliert mit LLC A1 und B (HABIB et al. 2009, REVEZ et al. 2011). Im Kontrast dazu ist der Großteil der Isolate aus Gruppe $2 \mathrm{~b}$ cstII- und cstIIInegativ und gehört damit LLC D und E(H) an (HABIB et al. 2009).

Die Mehrheit der Isolate aus Gruppe 3 besitzt cstII. Nur einige Isolate der Untergruppe $3 \mathrm{a}^{* *}$ konnten positiv für cstIII getestet werden. Diese 7 von 19 cstIII $^{+}$-Isolate aus $3 \mathrm{a}^{* *}$ gehören zum CC 353 und zur LLC C. Da alle Isolate aus Gruppe 4, 5 und 6 cstIII- und auch größtenteils cstII-negativ sind, besitzen diese Isolate Lipooligosaccharide, die nichtsialylisiert sind.

Von HOTTER et al. wurden LLC D und E-Isolate, welche den Gruppe 2b-Isolaten der gegenwärtigen Studie entsprechen, mit einer erhöhten Hospitalisierungsrate in Zusammenhang gebracht (HOTTER et al. 2010). Diese Beobachtung passt zu den

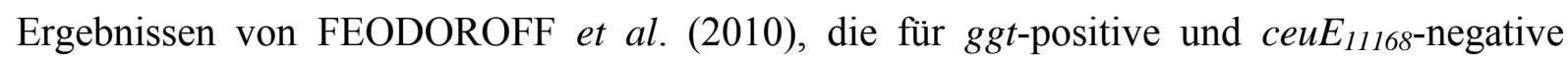
Gruppen erhöhte Hospitalisierungs-Raten feststellten. Auch die Prävalenzraten der Isolate menschlichen Ursprungs aus der gegenwärtigen Studie stützen dieses Ergebnis.

HOTTER et al. (2010) assoziierten LLC B und C mit mehr blutigen Stühlen. LLC B und C korrelieren in dieser Analyse mit dem größten Teil von Gruppe 1-Isolaten, aber auch mit einem Teil von Gruppe 2a-Isolaten. In diesen Gruppen konnten jedoch nur nicht signifikant mehr blutige Stühle innerhalb der klinischen Isolate festgestellt werden (Punkt 3.5 im Ergebnisteil).

\subsection{Campylobacter-Invasions-Antigen B}

Aktuellen Studien zufolge spielt das ciaB-Genprodukt eine ausschlaggebende Rolle bei der Wirtszellinvasion. Demzufolge stellt es einen bedeutenden Faktor für C. jejuni-induzierte Darmentzündungen dar (KONKEL et al. 1999, RIVERA-AMILL et al. 2001). 
Alle 266 Isolate dieser Studie sind positiv für ciaB getestet worden. Dieses Ergebniss deckt sich mit den Berichten vorangegangener Studien (FEODOROFF et al. 2010, DATTA et al. 2003, TALUKDER et al. 2008).

\subsection{Zytolethales Distendierendes Toxin (CDT)}

Ähnlich wie bei $c i a B$ wurde auch für das Zytoxin $c d t$ das ubiquitäre Vorkommen innerhalb der Testpopulation nachgewiesen. Unabhängig von dem ubiquitären Vorkommen der $c d t A B C$-Gene konnten jedoch Unterschiede in der Genexpression, d.h. der Toxinproduktion auf dem phänotypischen Level in einem auf CHO-K1-Zellen basierenden in vitro-Modell demonstriert werden (HÄNEL et al. 2007).

Demzufolge läßt sich mit dem molekularbiologischen Nachweis der ubiquitären Gene ciaB und $c d t B$ kein Rückschluss auf die unterschiedliche Virulenz der einzelnen $C$. jejuni-Isolate oder Isolat-Gruppen ziehen.

\subsection{Phospholipase A der äußeren Membran}

Phospholipase A besitzt eine zell-assoziierte hämolytische Aktivität und hat damit eine Bedeutung als Virulenzfaktor. Ähnlich wie schon bei ceuE ist ein Teil der Isolate unter ausschließlicher Nutzung eines Primers basierend auf der Genomsequenz von C. jejuni NCTC 11168 negativ für diesen Marker. Anders als bei ceuE waren die Ergebnisse nach Nutzung eines Vorwärts-Primers basierend auf der Genomsequenz von 811-76 aber nicht signifikant.

\subsection{Schlussfolgerungen bezüglich der Marker-Verteilung}

Die Anordnung der zehn Virulenz-assoziierten Marker konkretisiert und ergänzt die vorherige Definition der Subgruppen anhand von Metabolismus-assoziierten genetischen Markern durch ZAUTNER et al. 2011 (kurz zusammengefasst unter Punkt 1.5).

Abbildung 15 bietet eine Gesamtübersicht über die Verteilung der Metabolismus- sowie der Virulenz-assoziierten genetischen Marker, die in der vorliegenden Arbeit betrachtet wurden. Dadurch lässt sich die Konkretisierung und Ergänzung der vorherigen Gruppendefinition besser veranschaulichen. 


\begin{tabular}{|c|c|c|c|c|c|c|c|c|c|c|c|c|c|c|c|c|c|}
\hline Gruppe $^{\text {a }}$ & cj1321-1326 & fucP & cj0178 & cj0755 & $c e u E^{1}$ & pldA ${ }^{2}$ & cstII & cstIII & Gruppe $^{\text {b }}$ & cij1367/71 & $c j 1585 c$ & dTLP7 & $d m s A$ & ans $B$ & ggt & $\mathrm{CC}$ & LLC \\
\hline $1 \mathrm{a}$ & $\mathrm{X}$ & $\mathrm{X}$ & $\mathrm{X}$ & $\mathrm{X}$ & $\mathrm{X}$ & $\mathrm{X}$ & & $\mathrm{X}$ & 1a & $X$ & $\mathrm{X}$ & $X$ & & & & 21 & $C, A$ \\
\hline $1 b^{*}$ & $X$ & $X$ & $\mathrm{X}$ & $\mathrm{X}$ & $X$ & $\mathrm{X}$ & & $\mathrm{X}$ & & & & & & & & 21,206 & $C, A, B$ \\
\hline $1 b^{* *}$ & $\mathrm{X}$ & $X$ & $\mathrm{X}$ & $\mathrm{X}$ & $\mathrm{X}$ & $\mathrm{X}$ & $\mathrm{X}$ & & $1 \mathrm{~b}$ & $\mathrm{X}$ & $\mathrm{X}$ & & & & & 48,206 & $B 2$ \\
\hline $1 b^{* * * *}$ & & & $\mathrm{X}$ & $\mathrm{X}$ & $\mathrm{X}$ & $\mathrm{X}$ & & & & & & & & & & 49,446 & $B, D$ \\
\hline $2 a$ & & & & & & & $\mathrm{X}$ & & $2 \mathrm{a}$ & $\mathrm{X}$ & & & $\mathrm{X}$ & $\mathrm{X}$ & $\mathrm{X}$ & 22,42 & $A 1, B$ \\
\hline $2 b$ & & & & & & & & & $2 b$ & & & & $\mathrm{X}$ & $\mathrm{X}$ & $\mathrm{X}$ & 45,283 & $D, E, H, U$ \\
\hline $3 a^{*}$ & $X$ & $X$ & $\mathrm{X}$ & $\mathrm{X}$ & & & $\mathrm{X}$ & & $3 a$ & $\mathrm{X}$ & $\mathrm{X}$ & & & & & $52,443,828$ & \\
\hline $3 a^{* *}$ & $X$ & & $\mathrm{X}$ & $\mathrm{X}$ & $\mathrm{X}$ & & $\mathrm{X}$ & & & & & & & & & 353,354 & E \\
\hline $3 \mathbf{b}$ & & & $\mathrm{X}$ & $X$ & $\mathrm{X}$ & & $\mathrm{X}$ & & $3 b$ & $\mathrm{X}$ & $X$ & $\mathrm{X}$ & & & & 61 & \\
\hline 4 & & & & & $\mathrm{X}$ & & $\mathrm{X}$ & & 4 & & & & $X$ & & & 1034,1332 & \\
\hline 5 & & & $X$ & $X$ & $\mathrm{X}$ & $\mathrm{X}$ & & & 5 & $\mathrm{X}$ & $\mathrm{X}$ & & & & & none & \\
\hline 6 & & $X$ & $X$ & $X$ & $X$ & $\mathrm{X}$ & & & 6 & $X$ & & & X & $\mathrm{X}$ & & 257 & $A, D$ \\
\hline
\end{tabular}

\section{Abb. 15 : Überblick zur Verteilung der genetischen Marker}

Auf der linken Seite der Abbildung unter Gruppe ${ }^{a}$ finden sich die Ergebnisse der aktuellen Arbeit zu den Virulenz-assoziierten Markern: $c j 1321$ 1326, fucP, cj0178, cj0755 sowie cstII/cstIII, entsprechend der aktualisierten Gruppendefinition. CiaB und $c d t B$ sind ubiquitär und deshalb zur besseren Übersicht in der Abb. nicht aufgeführt.

Auf der rechten Seite unter Gruppe ${ }^{\mathrm{b}}$ finden sich die Ergebnisse der Arbeit von ZAUTNER et al. 2011 für die Metabolismus-assoziierten Marker: cjj1367, cjj811-76-1367/71(cj1365c) kodiert eine Serin-Protease, $c j 1585 c$ (Oxidoreduktase), $t l p 7_{m+c}$ (transducer-like Protein heterodimere Form vs. monomere Form), dmsA (kodiert eine Untereinheit der Dimethylsulfoxid-Oxidoreduktase A), ansB (eine periplasmatische Asparaginase) und ggt ( $\gamma$ Glutamyl-Transpeptidase).

CC-klonaler Komplex , LLC-zugehörige LOS-Klasse 
Betrachtet man alle detektierten Virulenz-assoziierten Faktoren der vorliegenden Studie sowie die Metabolimus-assoziierten Markergene, können 2 Hauptgruppen von Markergenkombinationen, repräsentiert durch Gruppe 1a und 2b, beschrieben werden. Alle anderen Gruppen stellen einen sukzessiven evolutionären Übergang an Markergen-Kombinationen zwischen Gruppe 1a und 2b dar. Der Hauptfokus der Betrachtungen richtet sich daher an diese beiden Gruppen.

Eine herausstechende Population wird von den Gruppen 1a und 1b sowie von Gruppe 3a geformt. Die Isolate dieser Subgruppen sind in der Lage, L-Fucose zu verwerten. Zudem scheinen diese Stämme aufgrund der Anwesenheit von cj1321-cj1326 besonders an Nutztiere angepasst zu sein. Überdies sind diese Gruppen positiv für die Marker cj1365c (ZAUTNER et al. 2011) und cstII/cstIII, außerdem besitzen die Untergruppen alle 5 Eisentransportsysteme. Das sialylisierte LOS (da cstII u./o. cstIII positiv) in Kombination mit cj1321-1326 fördert eine effizientere Wirtsepithelzellinvasion und besitzt das Potential, GBS zu induzieren. Die Stämme der drei aufgeführten Gruppen verfügen nicht über die Gene des erweiterten Aminosäure-Metabolismus, ansB und ggt. Auch die Gene des alternativen aneroben Stoffwechselweges (dmsA-negativ) sind nicht nachweisbar. Aufgrund ihrer Adaptation zu Nutztierbeständen sind diese Stämme mit weniger schweren Campylobacteriosen assoziiert.

Im Gegensatz dazu besitzen die Isolate der Gruppe 2 einen erweiterten AminosäureMetabolismus basierend auf dem Vorhandensein von ansB, und ggt sowie einen alternativen anaeroben Stoffwechselweg (dmsA-positiv) (ZAUTNER et al. 2011, entsprechend Abb.15). Alle Isolate der Gruppe 2 besitzen kein $f u c P$ und sind damit nicht in der Lage, L-Fucose zu metabolisieren. Daneben verfügen die Isolate nur über 3 der insgesamt 5 Eisenaufnahmesysteme.

Die Gruppe 2 teilt sich in 2 Untergruppen: 2a und 2b. Die Untergruppe $2 b$ ist negativ für die Marker cj1365c, cj1321-1326 sowie cstII/cstIII und demzufolge stärker Umwelt-adaptiert. Im Gegensatz dazu ist Gruppe 2a positiv für cj1365c und cstII, während cj1321-1326 gleichermaßen nicht nachweisbar ist. Zusätzlich wird die Untergruppe 2a durch die Präsenz des vom Flagellum ausgeschiedenen nicht-flagellaren Proteins A1 FSPA1 charakterisiert (DE HAAN et al. 2010). 100 \% der ST-22-Stämme, welche in Gruppe 2a vorkommen, wurden positiv für $f_{s p A l}$ getestet (DE HAAN et al. 2010). FspAl schützt nach Auseinandersetzung mit heterologen Stämmen vor einer Erkrankung (BAQAR et al. 2008). 
Die übrigen Gruppen zeigen eher einen sukzessiven evolutionären Übergang an MarkergenKombinationen verglichen mit 1a und 2b. In dieser Hinsicht scheint Gruppe 6 bemerkenswert. Die entsprechenden Isolate sind, wie es für Gruppe 2-Isolate typisch ist, positiv auf ans $B$ und dmsA sowie positiv für fucP, cj0178, cj0755 und $c j 1365 c$, typisch für Gruppe 1-Isolate. Allerdings ist der Großteil der Isolate negativ für ggt und cj1321-1326. Dazu besitzt nur die Hälfte der Isolate aus Gruppe 6 ein sialyliertes LOS.

In der hochvirulenten Isolat-Gruppe von MORTENSEN et al. werden LLC D und E mit einer höheren Hospitalisierungsrate in Verbindung gebracht (MORTENSEN et al. 2009). In der Untersuchung von FEODOROFF et al. (2010) werden schwerere Campylobacteriosen und blutige Durchfälle mit ggt-positiven und $c e u E_{11168}$-negativen $C$. jejuni-Isolaten assoziiert.

Überträgt man diese Ergebnisse auf die Gruppen der vorliegenden Studie, besitzt Gruppe 2 das höchste krankheitserregende Potential, d.h. die höchste Virulenz für den Menschen, denn Gruppe 2 beinhaltet Isolate vom Typ LLC D und E, zudem finden sich in dieser Gruppe die meisten $c e u E_{11168}-$ negativen Isolate (vgl. Tab.11). Die nicht mit Nutztieren assoziierten Stämme, d.h. Umweltisolate nach CHAMPION et al. (2005), und Stämme mit nichtsialylisiertem LOS dominieren diese höher virulente Gruppe 2.

Die $t l p 7_{m+c}$ Gene, kodierend für einen Ameisensäurerezeptor, assoziieren stark mit bovinem Isolat-Ursprung und können damit als Indikator für bovinen Ursprung dienen (ZAUTNER et al. 2011). In unserer aktuellen Studie können keine signifikanten Unterschiede in der Verteilung der zehn Genmarker nach Isolat-Ursprung ermittelt werden.

Beim Vergleich der 9 Untergruppen nach Isolat-Herkunft sind die Unterschiede signifikanter. Betrachtet man die beiden hauptfokussierten Gruppen 1a und 2b kann festgestellt werden, dass Gruppe 1a signifikant $(\mathrm{p}=0,00625)$ mehr Isolate vom Rind als vom Mensch aufweist. Und Gruppe $2 b$ signifikant $(p=0,00861)$ mehr humane Isolate $(17,1 \%)$ als Isolate vom Rind $(3,7 \%)$. 


\subsection{Saisonalität}

Humane Campylobacteriosen zeigen eine auffällige Saisonalität mit Häufung in den Sommermonaten (LOUIS et al. 2005). Die Faktoren für diese jahreszeitlichen Unterschiede sind noch wenig verstanden. So unterscheidet sich auch die jahreszeitliche Prävalenz von CC 21- und CC 45 -Komplexen, den beiden häufigsten MLST-CC bei C. jejuni-Isolaten vom Menschen (DINGLE et al. 2002, SOPWITH et al. 2006).

Von HABIB et al. (2010) wurden unter den zu MLST- CC 21- und CC 45- gehörigen Isolaten unterschiedliche Stressreaktionen beobachtet. Während CC 21- Stämme toleranter gegenüber extremen Temperaturen sind, zeigen CC 45- Stämme höhere Überlebensraten unter oxidativem Stress und Temperaturen unter dem Gefrierpunkt. CC 45- Stämme sind stärker daran angepasst, auch außerhalb des Wirts zu überleben als andere CC-Typen (SOPWITH et al. 2008).

Diese Beobachtung wird durch die Festellung gestützt, das Campylobacteriose-Fälle durch CC 21- bzw. CC 45-Stämme unterschiedliche Peaks in ihrer jahreszeitlichen Verteilung aufweisen, Campylobacteriosen, die durch Typ CC 45-Stämme ausgelöst werden, zeigen einen jahreszeitlichen Peak im Frühsommer (ca.17.-38. Kalenderwoche) und sind auch der prävalenteste $C$. jejuni-Typ in Oberflächenwasserproben. In den Kalenderwochen vor und nach dem Frühsommer sind CC 45-Stämme eher schwach vertreten. Isolate mit dem Sequenztyp 45 finden sich in der $g g t^{+}-$und $f u c P^{-}$-Gruppe $2 b$. Diese ist auch für den Nutztierbestandmarker cj1321-1326 negativ. Die mit schweren Campylobacteriosen in Zusammenhang gebrachte Gruppe $2 b$ ist demnach v.a. im Frühsommer nachweisbar.

Eine zweite von SOPWITH et al. (2008) beschriebene Gruppe mit CC 21-Isolaten entspricht in der vorliegenden Arbeit der Untergruppe 1a. Campylobacteriosen durch CC 21-Stämme werden stetig das ganze Jahr über gemeldet, mit einer Häufung im Spätsommer (SOPWITH et al. 2008). Die Subgruppe 1a ist in der Lage, L-Fucose zu verstoffwechseln. Die Isolate dieser Gruppe exprimieren den Nutztier-assoziierten-Marker cj1321-1326. Krankheitsfälle durch infizierte Rinder stehen im klarem Zusammenhang mit CC 21- Stämmen (CLARK et al. 2003 und 2005). Die Gruppe 1a enthält mit 34,9 \% (15/43) Rinder-Isolaten sogar fast dreimal so viele bovine wie humane Isolate (nur 12,4\%, 16/129). 


\section{$5 \quad$ Zusammenfassung}

Thermophile $C$. jejuni gehören weltweit zu den häufigsten Erregern bakterieller Gastroenteritiden beim Menschen. Der Erreger wird hauptsächlich durch kreuzkontaminierte Lebensmittel, zumeist ausgehend von Geflügelprodukten, übertragen. C. jejuni zeigt außerdem eine hohe genetische Vielfalt unter seinen Isolaten.

Mit dem Ziel herauszufinden, ob das Auftreten gewisser Markergene mit bestimmten klonalen Komplexen von C. jejuni korreliert, wurden im Rahmen dieser Arbeit 266 C. jejuniIsolate unterschiedlicher Herkunft (Mensch, Rind, Huhn, Pute) molekularbiologisch auf das Vorhandensein von zehn Virulenz-assoziierten Faktoren: cj1321-1326 (Sechs-Gen-Komplex zur Flagellin-O-Glykolisierung), ciaB (Campylobacter-Invasions-Antigen B), cdtB (cytolethal distending toxin, CDT) Untereinheit B, fucP (L-Fucose-Permease Gen), cj0178/cj0755 (Eisentransporter), ceuE (ein bindendes Protein zur Enterochelin-Aufnahme), pldA (Phospholipase A der äußeren Membran) und cstII/cstIII (Lipooligosaccharid-Sialyltransferase) überprüft.

In einer vorrangegangen Studie von ZAUTNER et al. 2011 wurden bereits 266 C. jejuniIsolate durch Kombination von MLST und den sechs genetischen Metabolismus-assoziierten Markern: $a n s B$ (periplasmatische Asparaginase), $d m s A$ (eine Untereinheit der Dimethylsulfoxid-Oxidoreduktase), ggt ( $\gamma$-Glutamyl-Transpeptidase), cj1585c (Oxidoreduktase), cjj811-76-1367/71 (Serin-Protease) und $t l p 7_{m+c}$ (transducer-like Protein, zusammengesetzt aus $c j 0951 c$ und $c j 0952 c$ ) in sechs Gruppen unterteilt.

Zur Konkretisierung dieser bestehenden Gruppendefinition und Kennzeichnung der Gruppen mit dem höchsten gesundheitsgefährdenden Potential wurden dieselben 266 Isolate nun weiter charakterisiert.

Vor allem die genetischen Marker cj1321-1326; fucP; cj0178 und cj0755 sind weitestgehend miteinander assoziiert und splitten die Testpopulation in 2 Hauptgruppen und 7 Untergruppen und stützen damit die alte Gruppendefinition.

Abgesehen vom Virulenz-assoziierten Marker pldA zeigen alle ermittelten genetischen Marker signifikante Unterschiede unter den verschiedenen MLST-basierten Gruppen. 
Basierend auf den Daten der Arbeit konnte ein Biotyp von C. jejuni-Isolaten, der durch die Präsenz von ansB, dmsA, ggt und die Absenz von cj1321-1326; fucP; cj0178, cj0755, cj1365c, cj1585c sowie cstII/cstIII charakterisiert ist, bestimmt werden. Isolate dieser Gruppe gehören hauptsächlich den MLST-CC 22, 42, 45, 283 an und sind eher an eine Persistenz in der Umwelt-adaptiert. Zum Wachstum nutzen die Stämme dieser Gruppe einen erweiterten Aminosäurestoffwechsel sowie einen alternativen anaeroben Stoffwechselweg (dmsApositiv). Hingegen kann aufgrund des fehlenden fucP keine L-Fucose verstoffwechselt werden. Außerdem sind die Stämme dieser Gruppe toleranter gegen oxidativen Stress und besser frostbeständig. Die jahreszeitliche Prävalenz ist am stärksten im Frühsommer.

Dieser Umwelt- aber schlechter Wirts-adaptierte Biotyp wird mit mehr Campylobacteriosen beim Menschen in Verbindung gebracht, äußert sich mit mehr blutigen Stühlen und Hospitalisierungen und ist somit hochgradiger virulent für den Menschen.

Im Gegensatz dazu ist die zweite Hauptgruppe stärker an tierische Wirte adaptiert und in der Lage, L-Fucose aus Mucosa oder Milch zu metabolisieren. Isolate dieses Biotyps tolerieren für C. jejuni extreme Temperaturen besser und zeigen eine relativ gleichmäßige Prävalenz im Jahresverlauf. Alle fünf bekannten $C$. jejuni-Eisentransportsysteme sind detektierbar, ebenso die Marker cj1321-1326, cj1365c, cj1585c und cstII und/oder cstIII. Die vorherrschenden MLST-CC sind CC 21, 48, 61 und 20. Dieser besser Wirt-sadaptierte Biotyp wird mit weniger schweren Campylobacteriosen in Zusammenhang gebracht.

Alle anderen Gruppen stellen einen sukzessiven evolutionären Übergang an MarkergenKombinationen zwischen diesen beiden Hauptgruppen dar. 


\section{Tabellenverzeichnis}

Tabelle 1: $\quad$ Primer für die Amplifikation der Markergene .............................................. 20

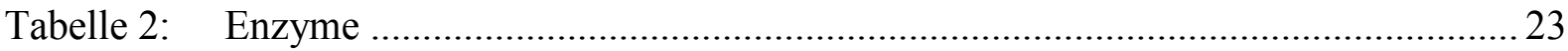

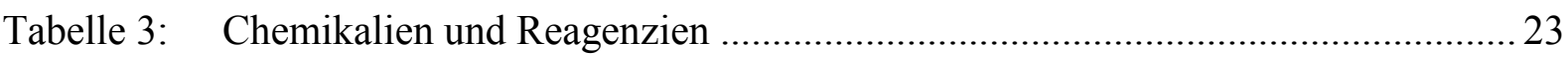

Tabelle 4: Verwendete Verbrauchsmaterialien ................................................................ 24

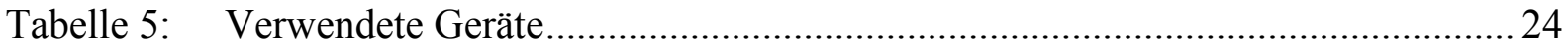

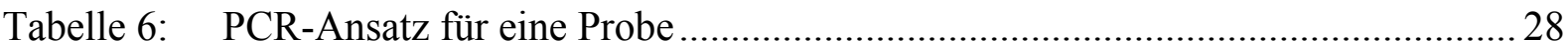

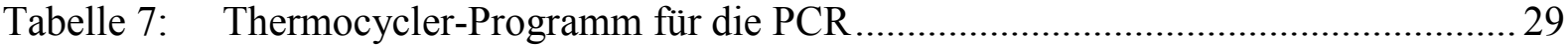

Tabelle 8: Ansatz für die Multiplex-PCR zum Nachweis von fucP …............................. 30

Tabelle 9: PCR-Programm für die Multiplex-PCR .............................................................. 31

Tabelle 10: Primer für die Sequenzierung zur C. jejuni-MLST-Typisierung ........................ 33

Tabelle 11: Verteilung der genetischen Marker, LLC und MLST-CC ${ }^{+}$............................... 38

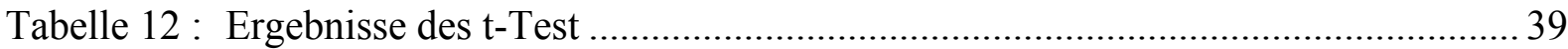

Tabelle 13: Bezeichnung, Herkunft und sonstige Charakteristika ...................................... 68 


\section{$7 \quad$ Abbildungsverzeichnis}

Abb. 1: Elektronenmikroskopische Darstellung von Campylobacter jejuni ........................ 1

Abb. 2: Verteilung gentischer $C$. jejuni-Marker, MLST-CC und Isolat-Herkunft............ 15

Abb. 3: Verteilung der 10 genetischen Marker .................................................................. 35

Abb. 4: Verteilung der genetischen Marker, MLST-CC-Zuordnung und Isolat-Herkunft 37

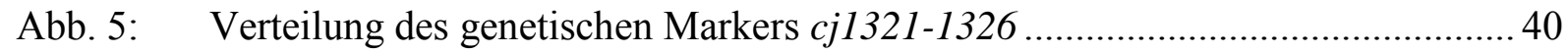

Abb. 6: Photographische Dokumentation einer Gel-Elektrophorese .................................. 41

Abb. 7: Darstellung der Verteilung des L-Fucose-Permease-Gens fucP .......................... 42

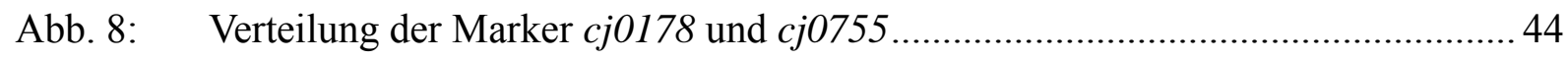

Abb. 9: Verteilung von cstII, cstIII \& cstII/cstIII innerhalb der Gruppen......................... 45

Abb. 10: MLST-sequenzbasierter UPGMA-Baum ........................................................... 46

Abb. 11: Relative Häufigkeit $\operatorname{der} C$. jejuni-Isolat-Ursprünge in Isolatgruppen .................... 49

Abb. 12 : Relative Häufigkeit der Markergene nach Wirtsspezies ....................................... 50

Abb. 13 : Verteilung der Markergen-Kombinationen ............................................................ 51

Abb. 14 : Relative Häufigkeit von klinischen Parametern in Isolatgruppen.......................... 52

Abb. 15 : ̈berblick zur Verteilung der genetischen Marker ............................................... 60 


\section{$8 \quad$ Anhang}

\subsection{Verwendete $C$. jejuni-Stämme}

\section{Tabelle 13: Bezeichnung, Herkunft und sonstige Charakteristika}

Die Tabelle sortiert die in dieser Arbeit verwendeten C. jejuni- Isolate nach ihrem Ursprung. Für die Isolate menschlicher Herkunft gibt die letzte Spalte Auskunft über die Parameter Hospitalisierung und blutiger Stuhl. CiaB und $c d t B$ sind ubiquitär in allen Isolaten und deshalb nicht aufgeführt. Kürzel: human-Mensch, cow-Rind, chicken-Huhn, turkey-Pute, MLST-ST-Sequenztyp, MLST-CC-klonaler Komplex ceuE und pldA beziehen sich auf Primer basierend auf dem Genom von NCTC 11168; durch zusätzliche Nutzung von Primern basierend auf der Sequenz von 81-176 konnten aber auch die negativen Isolate positiv für ceuE und pldA getestet werden.

\begin{tabular}{|c|c|c|c|c|c|c|c|c|c|c|c|c|c|c|c|}
\hline Nr. & Name & Her- & MLST-ST & MLST-CC & cj1321-6 & Fucose & cj0178 & cj0755 & ceuE & pldA & cstll & cstIII & Gruppe & blutiger/wäss- & Hospitali- \\
\hline & & kunft & & & & & & & & & & & & riger Stuhl & sierung \\
\hline & & & & & & & & & & & & & & & \\
\hline 1 & huBfR3943 & human & 60 & 61 & 0 & 0 & 1 & 1 & 1 & 1 & 1 & 0 & $3 B$ & no data & no data \\
\hline 2 & huBfR3947 & human & 60 & 61 & 0 & 0 & 1 & 1 & 1 & 1 & 1 & 0 & $3 B$ & no data & no data \\
\hline 5 & huE04 & human & 48 & 48 & 1 & 1 & 1 & 1 & 1 & 1 & 1 & 0 & $1 \mathrm{~B}^{* *}$ & 0 & 1 \\
\hline 6 & huB18 & human & 122 & 206 & 1 & 1 & 1 & 1 & 1 & 1 & 1 & 0 & $1 \mathrm{~B}^{* *}$ & 0 & 0 \\
\hline 7 & huB24 & human & 4639 & 21 & 1 & 1 & 1 & 1 & 1 & 1 & 0 & 1 & $1 \mathrm{~B}^{*}$ & 0 & 0 \\
\hline 8 & huB14 & human & 4635 & 21 & 1 & 1 & 1 & 1 & 1 & 1 & 1 & 0 & $1 \mathrm{~B}^{*}$ & 0 & 1 \\
\hline 9 & huC02 & human & 760 & 21 & 1 & 1 & 1 & 1 & 1 & 1 & 1 & 1 & $1 \mathrm{~B}^{*}$ & 0 & 1 \\
\hline 10 & huB10 & human & 48 & 48 & 1 & 1 & 1 & 1 & 1 & 1 & 1 & 0 & $1 \mathrm{~B}^{\star *}$ & 0 & 0 \\
\hline 11 & huC14 & human & 4645 & 48 & 1 & 1 & 1 & 1 & 1 & 1 & 1 & 0 & $1 \mathrm{~B}^{\star *}$ & 0 & 0 \\
\hline 12 & huE05 & human & 4591 & 48 & 1 & 1 & 1 & 1 & 1 & 1 & 1 & 0 & $1 \mathrm{~B}^{* *}$ & 0 & 1 \\
\hline 13 & huE06 & human & 4591 & 48 & 1 & 1 & 1 & 1 & 1 & 1 & 1 & 0 & $1 \mathrm{~B}^{* *}$ & 1 & 0 \\
\hline 14 & huA10 & human & 122 & 206 & 1 & 1 & 1 & 1 & 1 & 1 & 1 & 0 & $1 \mathrm{~B}^{\star *}$ & 0 & 0 \\
\hline 15 & huA28 & human & 122 & 206 & 1 & 1 & 1 & 1 & 1 & 1 & 1 & 0 & $1 \mathrm{~B}^{\star \star}$ & 1 & 0 \\
\hline 16 & huA35 & human & 122 & 206 & 1 & 1 & 1 & 1 & 1 & 1 & 1 & 0 & $1 \mathrm{~B}^{* *}$ & 0 & 0 \\
\hline
\end{tabular}




\begin{tabular}{|c|c|c|c|c|c|c|c|c|c|c|c|c|c|c|c|}
\hline Nr. & Name & Her- & MLST-ST & MLST-CC & cj1321-6 & Fucose & cj0178 & cj0755 & ceuE & pldA & cstll & cstIII & Gruppe & blutiger/wäss- & Hospitali- \\
\hline & & kunft & & & & & & & & & & & & riger Stuhl & sierung \\
\hline 17 & huB08 & human & 4633 & 206 & 1 & 1 & 1 & 1 & 1 & 1 & 1 & 0 & $1 \mathrm{~B}^{* *}$ & 0 & 0 \\
\hline 18 & huA13 & human & 3188 & 206 & 1 & 1 & 1 & 1 & 0 & 1 & 1 & 0 & $1 \mathrm{~B}^{* *}$ & 0 & 0 \\
\hline 19 & huE16 & human & 4654 & none & 1 & 1 & 1 & 1 & 1 & 1 & 1 & 0 & $1 \mathrm{~B}^{\star *}$ & 0 & 0 \\
\hline 20 & huE13 & human & 4652 & 206 & 1 & 1 & 1 & 1 & 1 & 1 & 1 & 0 & $1 \mathrm{~B}^{\star *}$ & 0 & 0 \\
\hline 21 & huC17 & human & 4647 & 48 & 1 & 1 & 1 & 1 & 1 & 1 & 1 & 0 & $1 \mathrm{~B}^{* *}$ & 0 & 0 \\
\hline 22 & huA34 & human & 572 & 206 & 1 & 1 & 1 & 1 & 1 & 1 & 1 & 0 & $1 \mathrm{~B}^{\star *}$ & 0 & 0 \\
\hline 23 & huA26 & human & 572 & 206 & 1 & 1 & 1 & 1 & 0 & 1 & 1 & 0 & $1 \mathrm{~B}^{* *}$ & 0 & 0 \\
\hline 24 & huA20 & human & 572 & 206 & 1 & 1 & 1 & 1 & 0 & 1 & 1 & 0 & $1 \mathrm{~B}^{\star *}$ & 0 & 0 \\
\hline 25 & huC11 & human & 2845 & 21 & 1 & 1 & 1 & 1 & 1 & 1 & 0 & 1 & $1 \mathrm{~B}^{*}$ & 0 & 0 \\
\hline 26 & huA24 & human & 19 & 21 & 1 & 1 & 1 & 1 & 0 & 0 & 0 & 1 & $1 \mathrm{~B}^{*}$ & 0 & 1 \\
\hline 27 & huC06 & human & 50 & 21 & 1 & 1 & 1 & 1 & 1 & 1 & 0 & 1 & $1 \mathrm{~B}^{*}$ & 0 & 0 \\
\hline 28 & huB15 & human & 50 & 21 & 1 & 1 & 1 & 1 & 1 & 1 & 0 & 1 & $1 \mathrm{~B}^{*}$ & 0 & 0 \\
\hline 29 & huC23 & human & 50 & 21 & 1 & 1 & 1 & 1 & 1 & 1 & 1 & 1 & $1 \mathrm{~B}^{\star}$ & 0 & 0 \\
\hline 30 & huA31 & human & 50 & 21 & 1 & 1 & 1 & 1 & 1 & 1 & 1 & 1 & $1 \mathrm{~B}^{*}$ & 1 & 1 \\
\hline 31 & huC01 & human & 50 & 21 & 1 & 1 & 1 & 1 & 1 & 1 & 1 & 1 & $1 \mathrm{~B}^{*}$ & 1 & 1 \\
\hline 32 & huB17 & human & 1823 & 21 & 1 & 1 & 1 & 1 & 1 & 1 & 1 & 1 & $1 \mathrm{~B}^{*}$ & 0 & 0 \\
\hline 33 & huC03 & human & 4640 & 21 & 1 & 1 & 1 & 1 & 1 & 1 & 0 & 1 & $1 \mathrm{~B}^{*}$ & 0 & 1 \\
\hline 34 & huNCTC11168 & human & 43 & 21 & 1 & 1 & 1 & 1 & 1 & 1 & 0 & 1 & $1 \mathrm{~B}^{*}$ & no data & no data \\
\hline 35 & huA05 & human & 507 & 21 & 1 & 1 & 1 & 1 & 1 & 1 & 0 & 1 & $1 \mathrm{~B}^{*}$ & 0 & 0 \\
\hline 36 & huA17 & human & 221 & 206 & 1 & 1 & 1 & 1 & 1 & 1 & 0 & 1 & $1 \mathrm{~B}^{*}$ & 0 & 0 \\
\hline 37 & huA02 & human & 4588 & 21 & 1 & 1 & 1 & 1 & 1 & 0 & 1 & 0 & $1 \mathrm{~B}^{*}$ & 0 & 1 \\
\hline 38 & huA21 & human & 4588 & 21 & 1 & 1 & 1 & 1 & 1 & 1 & 1 & 1 & $1 \mathrm{~B}^{*}$ & 0 & 0 \\
\hline 39 & huA03 & human & 1519 & 21 & 1 & 1 & 1 & 1 & 1 & 0 & 0 & 1 & $1 \mathrm{~B}^{*}$ & 0 & 0 \\
\hline 40 & huB09 & human & 4286 & 21 & 1 & 1 & 1 & 1 & 1 & 1 & 1 & 1 & $1 \mathrm{~B}^{*}$ & 0 & 1 \\
\hline 41 & huBfR4012 & human & 21 & 21 & 1 & 1 & 1 & 1 & 1 & 1 & 0 & 1 & $1 \mathrm{~A}$ & data & no data \\
\hline 42 & huC26 & human & 21 & 21 & 1 & 1 & 1 & 1 & 0 & 1 & 1 & 1 & $1 \mathrm{~A}$ & 0 & 0 \\
\hline 43 & huA18 & human & 21 & 21 & 1 & 1 & 1 & 0 & 1 & 1 & 1 & 0 & $1 \mathrm{~A}$ & 0 & 1 \\
\hline 44 & huBfR3883 & human & 21 & 21 & 1 & 1 & 1 & 1 & 1 & 1 & 0 & 1 & $1 \mathrm{~A}$ & no data & no data \\
\hline 45 & huBfR3869 & human & 21 & 21 & 1 & 1 & 1 & 1 & 1 & 1 & 0 & 1 & $1 \mathrm{~A}$ & no data & no data \\
\hline 46 & huE01 & human & 21 & 21 & 1 & 1 & 1 & 1 & 1 & 1 & 0 & 1 & $1 \mathrm{~A}$ & 0 & 0 \\
\hline 47 & huBfR3872 & human & 21 & 21 & 1 & 1 & 1 & 1 & 1 & 1 & 0 & 1 & $1 \mathrm{~A}$ & no data & no data \\
\hline 48 & huBfR3898 & human & 21 & 21 & 1 & 1 & 1 & 1 & 1 & 1 & 0 & 1 & $1 \mathrm{~A}$ & no data & no data \\
\hline
\end{tabular}




\begin{tabular}{|c|c|c|c|c|c|c|c|c|c|c|c|c|c|c|c|}
\hline Nr. & Name & Her- & MLST-ST & MLST-CC & cj1321-6 & Fucose & cj0178 & cj0755 & ceuE & pldA & cstll & cstIII & Gruppe & blutiger/wäss- & Hospitali- \\
\hline & & kunft & & & & & & & & & & & & riger Stuhl & sierung \\
\hline 49 & huC19 & human & 4648 & 21 & 1 & 1 & 1 & 1 & 1 & 1 & 0 & 1 & $1 \mathrm{~A}$ & 1 & 0 \\
\hline 50 & huBfR3866 & human & 53 & 21 & 1 & 1 & 1 & 1 & 1 & 1 & 0 & 1 & $1 \mathrm{~A}$ & no data & no data \\
\hline 51 & huBfR3881 & human & 53 & 21 & 1 & 1 & 1 & 1 & 1 & 1 & 0 & 1 & $1 \mathrm{~A}$ & no data & no data \\
\hline 52 & huBfR3876 & human & 53 & 21 & 1 & 1 & 1 & 1 & 1 & 1 & 0 & 1 & $1 \mathrm{~A}$ & no data & no data \\
\hline 53 & huB02 & human & 53 & 21 & 1 & 1 & 1 & 1 & 1 & 1 & 0 & 1 & $1 \mathrm{~A}$ & 0 & 0 \\
\hline 54 & huB25 & human & 53 & 21 & 1 & 1 & 1 & 1 & 1 & 1 & 0 & 1 & $1 \mathrm{~A}$ & 0 & 0 \\
\hline 55 & huBfR3865 & human & 53 & 21 & 1 & 1 & 1 & 1 & 1 & 1 & 0 & 1 & $1 \mathrm{~A}$ & no data & no data \\
\hline 56 & huC10 & human & 4644 & none & 1 & 1 & 1 & 1 & 1 & 1 & 0 & 0 & $3 A^{*}$ & 0 & 1 \\
\hline 57 & huC04 & human & 4641 & 607 & 1 & 1 & 1 & 1 & 1 & 1 & 1 & 0 & $3 A^{*}$ & 0 & 0 \\
\hline 58 & huB03 & human & 535 & 460 & 1 & 1 & 1 & 1 & 1 & 1 & 1 & 0 & $3 A^{*}$ & 0 & 1 \\
\hline 59 & huC20 & human & 51 & 443 & 1 & 1 & 1 & 1 & 1 & 1 & 1 & 0 & $3 A^{*}$ & 0 & 0 \\
\hline 60 & huC24 & human & 51 & 443 & 1 & 1 & 1 & 1 & 1 & 1 & 0 & 0 & $3 A^{*}$ & 0 & 1 \\
\hline 61 & huA11 & human & 2034 & 443 & 1 & 1 & 1 & 1 & 1 & 1 & 0 & 0 & $3 A^{*}$ & 0 & 0 \\
\hline 62 & huE02 & human & 49 & 49 & 1 & 1 & 1 & 1 & 1 & 1 & 1 & 0 & $1 \mathrm{~B}^{\star \star \star}$ & 0 & 0 \\
\hline 63 & huE12 & human & 450 & 446 & 1 & 1 & 1 & 1 & 1 & 1 & 0 & 0 & $1 \mathrm{~B}^{\star \star \star}$ & 1 & 0 \\
\hline 64 & huB06 & human & 4631 & 446 & 1 & 1 & 1 & 1 & 1 & 1 & 0 & 0 & $1 \mathrm{~B}^{\star \star \star *}$ & 0 & 0 \\
\hline 65 & huB07 & human & 4632 & 206 & 1 & 1 & 1 & 1 & 1 & 1 & 1 & 0 & $1 \mathrm{~B}^{\star *}$ & 0 & 1 \\
\hline 66 & huC18 & human & 53 & 21 & 1 & 1 & 1 & 1 & 1 & 1 & 1 & 1 & $1 \mathrm{~A}$ & 0 & 0 \\
\hline 67 & huB04 & human & 475 & 48 & 1 & 1 & 1 & 1 & 1 & 1 & 1 & 0 & $3 A^{*}$ & 0 & 1 \\
\hline 68 & huC28 & human & 257 & 257 & 1 & 1 & 1 & 1 & 1 & 1 & 0 & 0 & 6 & 0 & 1 \\
\hline 69 & huA16 & human & 257 & 257 & 0 & 1 & 1 & 1 & 0 & 1 & 0 & 0 & 6 & 1 & 1 \\
\hline 70 & huB20 & human & 4637 & 52 & 0 & 1 & 1 & 1 & 1 & 1 & 1 & 0 & $3 A^{*}$ & 0 & 0 \\
\hline 71 & huC25 & human & 775 & 52 & 0 & 1 & 1 & 1 & 1 & 1 & 1 & 0 & $3 A^{*}$ & 0 & 0 \\
\hline 72 & huA22 & human & 4630 & 52 & 0 & 1 & 1 & 1 & 1 & 1 & 1 & 0 & $3 A^{*}$ & 0 & 1 \\
\hline 73 & huA09 & human & 354 & 354 & 0 & 1 & 1 & 1 & 1 & 1 & 0 & 0 & $3 A^{*}$ & 0 & 0 \\
\hline 74 & huB16 & human & 354 & 354 & 0 & 1 & 1 & 1 & 1 & 1 & 1 & 0 & $3 A^{*}$ & 0 & 0 \\
\hline 75 & huC21 & human & 4649 & 354 & 0 & 1 & 1 & 1 & 1 & 1 & 1 & 0 & singleton & 0 & 1 \\
\hline 76 & huC22 & human & 584 & 257 & 0 & 1 & 1 & 1 & 1 & 1 & 1 & 0 & 6 & 0 & 1 \\
\hline 77 & huE15 & human & 4571 & 257 & 0 & 1 & 1 & 1 & 1 & 1 & 0 & 0 & 6 & 0 & 1 \\
\hline 78 & huE23 & human & 257 & 257 & 0 & 1 & 1 & 1 & 1 & 1 & 0 & 0 & 6 & 0 & 1 \\
\hline 79 & huB11 & human & 257 & 257 & 0 & 1 & 1 & 1 & 1 & 1 & 1 & 0 & 6 & 0 & 1 \\
\hline 80 & huB13 & human & 257 & 257 & 0 & 1 & 1 & 1 & 1 & 1 & 0 & 0 & 6 & 0 & 0 \\
\hline
\end{tabular}




\begin{tabular}{|c|c|c|c|c|c|c|c|c|c|c|c|c|c|c|c|}
\hline Nr. & Name & Her- & MLST-ST & MLST-CC & cj1321-6 & Fucose & cj0178 & cj0755 & ceuE & pldA & cstll & cstllI & Gruppe & blutiger/wäss- & Hospitali- \\
\hline & & kunft & & & & & & & & & & & & riger Stuhl & sierung \\
\hline 81 & huB19 & human & 4636 & none & 1 & 0 & 1 & 1 & 1 & 1 & 1 & 0 & $3 A^{* *}$ & 1 & 1 \\
\hline 82 & huA27 & human & 464 & none & 1 & 0 & 1 & 1 & 1 & 0 & 1 & 0 & $3 A^{* *}$ & 0 & 0 \\
\hline 83 & huC05 & human & 4642 & 353 & 1 & 0 & 1 & 1 & 1 & 1 & 1 & 1 & $3 A^{*}$ & 0 & 0 \\
\hline 84 & huC16 & human & 4646 & 460 & 1 & 0 & 1 & 1 & 1 & 1 & 1 & 0 & $1 \mathrm{~B}^{\star \star \star}$ & 1 & 1 \\
\hline 85 & huA14 & human & 380 & none & 1 & 0 & 1 & 1 & 1 & 1 & 1 & 0 & $1 \mathrm{~B}^{\star \star \star}$ & 0 & 1 \\
\hline 86 & huB22 & human & 380 & none & 1 & 0 & 1 & 1 & 1 & 1 & 1 & 0 & $1 \mathrm{~B}^{\star \star \star}$ & 0 & 1 \\
\hline 87 & huA25 & human & 4589 & 52 & 1 & 0 & 1 & 1 & 1 & 1 & 1 & 0 & singleton & 0 & 0 \\
\hline 88 & huC09 & human & 1287 & 1287 & 1 & 0 & 1 & 1 & 1 & 1 & 1 & 0 & $3 A^{*}$ & 0 & 1 \\
\hline 89 & huE03 & human & 61 & 61 & 0 & 0 & 1 & 1 & 1 & 1 & 1 & 0 & $3 B$ & 1 & 0 \\
\hline 90 & huA29 & human & 658 & 658 & 0 & 0 & 1 & 1 & 1 & 0 & 1 & 0 & $3 A^{* *}$ & 0 & 1 \\
\hline 91 & huC07 & human & 4643 & 658 & 0 & 0 & 1 & 1 & 1 & 1 & 1 & 0 & $3 A^{* *}$ & 0 & 0 \\
\hline 92 & huE07 & human & 4650 & 354 & 0 & 0 & 1 & 1 & 1 & 1 & 1 & 0 & $3 A^{*}$ & 0 & 0 \\
\hline 93 & huB12 & human & 4634 & 49 & 0 & 0 & 1 & 1 & 1 & 1 & 1 & 0 & $1 \mathrm{~B}^{\star \star * *}$ & 1 & 1 \\
\hline 94 & huA33 & human & 4590 & 49 & 0 & 0 & 1 & 1 & 1 & 1 & 0 & 0 & $1 \mathrm{~B}^{\star \star \star}$ & 0 & 0 \\
\hline 95 & huA06 & human & 4587 & 49 & 0 & 0 & 1 & 1 & 1 & 1 & 0 & 0 & $1 \mathrm{~B}^{\star \star \star}$ & 0 & 1 \\
\hline 96 & huE11 & human & 4651 & none & 0 & 0 & 1 & 1 & 1 & 1 & 0 & 0 & 5 & 0 & 1 \\
\hline 97 & huBfR3895 & human & 45 & 45 & 0 & 0 & 1 & 1 & 1 & 1 & 0 & 0 & $2 B$ & no data & no data \\
\hline 98 & huBfR3933 & human & 563 & 177 & 1 & 0 & 0 & 1 & 1 & 0 & 0 & 0 & $1 \mathrm{~B}^{* *}$ & no data & no data \\
\hline 99 & huE19 & human & 22 & 22 & 0 & 0 & 0 & 1 & 1 & 1 & 1 & 0 & $2 A$ & 0 & 0 \\
\hline 100 & huB21 & human & 4638 & 22 & 0 & 0 & 0 & 1 & 1 & 1 & 1 & 0 & $2 A$ & 0 & 0 \\
\hline 101 & huA08 & human & 677 & 677 & 0 & 0 & 0 & 1 & 0 & 0 & 1 & 0 & singleton & 0 & 0 \\
\hline 102 & huB23 & human & 22 & 22 & 1 & 0 & 0 & 0 & 0 & 1 & 1 & 0 & $2 A$ & 0 & 1 \\
\hline 103 & huA19 & human & 11 & 45 & 1 & 0 & 0 & 0 & 0 & 1 & 0 & 0 & $2 B$ & 0 & 0 \\
\hline 104 & huE08 & human & 4625 & none & 1 & 0 & 0 & 0 & 1 & 1 & 0 & 0 & singleton & 0 & 0 \\
\hline 105 & huC12 & human & 45 & 45 & 1 & 0 & 0 & 0 & 1 & 1 & 1 & 0 & $2 \mathrm{~B}$ & 0 & 0 \\
\hline 106 & huE22 & human & 696 & 1332 & 1 & 0 & 0 & 0 & 1 & 1 & 1 & 0 & 4 & 0 & 0 \\
\hline 107 & huE14 & human & 4653 & 45 & 0 & 0 & 0 & 0 & 1 & 1 & 0 & 0 & $2 B$ & 0 & 1 \\
\hline 108 & hu81-176 & human & 913 & 42 & 0 & 0 & 0 & 0 & 1 & 1 & 1 & 0 & $2 A$ & 1 & 1 \\
\hline 109 & huBfR3918 & human & 42 & 42 & 0 & 0 & 0 & 0 & 0 & 0 & 1 & 0 & $2 \mathrm{~A}$ & no data & no data \\
\hline 110 & huE17 & human & 4655 & 45 & 0 & 0 & 0 & 0 & 1 & 1 & 0 & 0 & $2 B$ & 0 & 0 \\
\hline 111 & huA30 & human & 447 & 42 & 0 & 0 & 0 & 0 & 0 & 1 & 0 & 0 & $2 A$ & 0 & 1 \\
\hline 112 & huE18 & human & 4592 & 42 & 0 & 0 & 0 & 0 & 1 & 1 & 1 & 0 & $2 \mathrm{~A}$ & 0 & 0 \\
\hline
\end{tabular}




\begin{tabular}{|c|c|c|c|c|c|c|c|c|c|c|c|c|c|c|c|}
\hline Nr. & Name & Her- & MLST-ST & MLST-CC & cj1321-6 & Fucose & cj0178 & cj0755 & ceuE & pldA & cstII & cstIII & Gruppe & blutiger/wäss- & Hospitali- \\
\hline & & kunft & & & & & & & & & & & & riger Stuhl & sierung \\
\hline 113 & huB05 & human & 137 & 45 & 0 & 0 & 0 & 0 & 1 & 1 & 0 & 0 & $2 \mathrm{~B}$ & 0 & 0 \\
\hline 114 & huE21 & human & 137 & 45 & 0 & 0 & 0 & 0 & 1 & 0 & 0 & 0 & $2 B$ & 0 & 0 \\
\hline 115 & huA23 & human & 267 & 283 & 0 & 0 & 0 & 0 & 0 & 1 & 0 & 0 & $2 \mathrm{~B}$ & 0 & 0 \\
\hline 116 & huBfR3907 & human & 267 & 283 & 0 & 0 & 0 & 0 & 0 & 1 & 0 & 0 & $2 \mathrm{~B}$ & no data & no data \\
\hline 117 & huC08 & human & 383 & 283 & 0 & 0 & 0 & 0 & 1 & 1 & 0 & 0 & $2 B$ & 0 & 1 \\
\hline 118 & huBfR1780 & human & 583 & 45 & 0 & 0 & 0 & 0 & 1 & 1 & 1 & 0 & $2 B$ & no data & no data \\
\hline 119 & huBfR1781 & human & 583 & 45 & 0 & 0 & 0 & 0 & 1 & 1 & 1 & 0 & $2 B$ & no data & no data \\
\hline 120 & huA32 & human & 538 & 45 & 0 & 0 & 0 & 0 & 1 & 1 & 1 & 0 & $2 B$ & 1 & 1 \\
\hline 121 & huBfR3868 & human & 45 & 45 & 0 & 0 & 0 & 0 & 1 & 1 & 0 & 0 & $2 B$ & no data & no data \\
\hline 122 & huBfR3880 & human & 45 & 45 & 0 & 0 & 0 & 0 & 1 & 1 & 0 & 0 & $2 B$ & no data & no data \\
\hline 123 & huBfR3867 & human & 45 & 45 & 0 & 0 & 0 & 0 & 1 & 1 & 0 & 0 & $2 B$ & no data & no data \\
\hline 124 & huC27 & human & 45 & 45 & 0 & 0 & 0 & 0 & 1 & 1 & 0 & 0 & $2 B$ & 0 & 1 \\
\hline 125 & huBfR4007 & human & 45 & 45 & 0 & 0 & 0 & 0 & 1 & 1 & 0 & 0 & $2 B$ & no data & no data \\
\hline 126 & huBfR1764 & human & 22 & 22 & 0 & 0 & 0 & 0 & 1 & 1 & 1 & 0 & $2 A$ & no data & no data \\
\hline 127 & huBfR4010 & human & 483 & 45 & 0 & 0 & 0 & 0 & 1 & 1 & 0 & 0 & $2 B$ & no data & no data \\
\hline 128 & huC15 & human & 45 & 45 & 0 & 0 & 0 & 0 & 0 & 1 & 0 & 0 & $2 B$ & 0 & 1 \\
\hline 129 & huC13 & human & 583 & 45 & 0 & 0 & 0 & 0 & 0 & 1 & 0 & 0 & $2 B$ & 0 & 0 \\
\hline 130 & huBfR3894 & human & 45 & 45 & 0 & 0 & 0 & 0 & 1 & 1 & 0 & 0 & $2 B$ & no data & no data \\
\hline 131 & huA04 & human & 4626 & 1034 & 0 & 0 & 0 & 0 & 0 & 1 & 1 & 0 & 4 & 0 & 0 \\
\hline 132 & bovC486 & cow & 21 & 21 & 1 & 1 & 1 & 1 & 1 & 1 & 1 & 1 & $1 \mathrm{~A}$ & & \\
\hline 133 & bovC397 & cow & 21 & 21 & 1 & 1 & 1 & 1 & 1 & 1 & 1 & 1 & $1 \mathrm{~A}$ & & \\
\hline 134 & bovBfR3885 & cow & 48 & 48 & 1 & 1 & 1 & 1 & 1 & 1 & 1 & 0 & $1 \mathrm{~B}^{\star \star}$ & & \\
\hline 135 & bovC 0111 & cow & 3158 & 48 & 1 & 1 & 1 & 1 & 1 & 1 & 1 & 0 & $1 \mathrm{~B}^{\star *}$ & & \\
\hline 136 & bovC090 & cow & 3203 & 48 & 1 & 1 & 1 & 1 & 1 & 1 & 1 & 0 & $1 \mathrm{~B}^{\star \star}$ & & \\
\hline 137 & bovC539 & cow & 38 & 48 & 1 & 1 & 1 & 1 & 1 & 1 & 1 & 0 & $1 \mathrm{~B}^{\star \star}$ & & \\
\hline 138 & bovC405 & cow & 38 & 48 & 1 & 1 & 1 & 1 & 1 & 1 & 1 & 0 & $1 \mathrm{~B}^{\star \star}$ & & \\
\hline 139 & bovC323 & cow & 4647 & 48 & 1 & 1 & 1 & 1 & 1 & 1 & 1 & 0 & $1 \mathrm{~B}^{\star *}$ & & \\
\hline 140 & bov159 & cow & 572 & 206 & 1 & 1 & 1 & 1 & 1 & 1 & 1 & 0 & $1 \mathrm{~B}^{\star *}$ & & \\
\hline 141 & bovC508 & cow & 19 & 21 & 1 & 1 & 1 & 1 & 1 & 1 & 0 & 1 & $1 \mathrm{~B}^{*}$ & & \\
\hline 142 & bov55 & cow & 50 & 21 & 1 & 1 & 1 & 1 & 1 & 1 & 1 & 0 & $1 \mathrm{~B}^{*}$ & & \\
\hline 143 & bov127 & cow & 262 & 21 & 1 & 1 & 1 & 1 & 1 & 1 & 1 & 0 & $1 \mathrm{~B}^{*}$ & & \\
\hline 144 & bovC 0148 & cow & 1704 & 21 & 1 & 1 & 1 & 1 & 1 & 1 & 0 & 1 & $1 \mathrm{~B}^{*}$ & & \\
\hline
\end{tabular}




\begin{tabular}{|c|c|c|c|c|c|c|c|c|c|c|c|c|c|c|c|}
\hline Nr. & Name & Her- & MLST-ST & MLST-CC & cj1321-6 & Fucose & cj0178 & cj0755 & ceuE & pldA & cstII & cstIII & Gruppe & blutiger/wäss- & Hospitali- \\
\hline & & kunft & & & & & & & & & & & & riger Stuhl & sierung \\
\hline 145 & bovC 0172 & cow & 1823 & 21 & 1 & 1 & 1 & 1 & 1 & 1 & 0 & 1 & $1 \mathrm{~B}^{*}$ & & \\
\hline 146 & bov66 & cow & 4664 & 21 & 1 & 1 & 1 & 1 & 1 & 1 & 0 & 1 & $1 \mathrm{~B}^{*}$ & & \\
\hline 147 & bov137 & cow & 21 & 21 & 1 & 1 & 1 & 1 & 1 & 1 & 0 & 1 & $1 \mathrm{~A}$ & & \\
\hline 148 & bovC086 & cow & 21 & 21 & 1 & 1 & 1 & 1 & 1 & 1 & 0 & 1 & $1 \mathrm{~A}$ & & \\
\hline 149 & bovC567 & cow & 21 & 21 & 1 & 1 & 1 & 1 & 1 & 1 & 0 & 1 & $1 \mathrm{~A}$ & & \\
\hline 150 & bov79 & cow & 21 & 21 & 1 & 1 & 1 & 1 & 1 & 1 & 0 & 1 & $1 \mathrm{~A}$ & & \\
\hline 151 & bovC404 & cow & 21 & 21 & 1 & 1 & 1 & 1 & 1 & 1 & 0 & 1 & $1 \mathrm{~A}$ & & \\
\hline 152 & bovC536 & cow & 21 & 21 & 1 & 1 & 1 & 1 & 1 & 1 & 1 & 1 & $1 \mathrm{~A}$ & & \\
\hline 153 & bovC403 & cow & 4667 & 21 & 1 & 1 & 1 & 1 & 1 & 1 & 0 & 1 & $1 \mathrm{~A}$ & & \\
\hline 154 & bov207 & cow & 53 & 21 & 1 & 1 & 1 & 1 & 1 & 1 & 0 & 1 & $1 \mathrm{~A}$ & & \\
\hline 155 & bovC248 & cow & 21 & 21 & 1 & 1 & 1 & 1 & 1 & 1 & 1 & 0 & $1 \mathrm{~A}$ & & \\
\hline 156 & bovC399 & cow & 21 & 21 & 1 & 1 & 1 & 1 & 1 & 1 & 1 & 0 & $1 \mathrm{~A}$ & & \\
\hline 157 & bovC540 & cow & 38 & 48 & 1 & 1 & 1 & 1 & 1 & 1 & 1 & 0 & $1 \mathrm{~B}^{* *}$ & & \\
\hline 158 & bovC401 & cow & 21 & 21 & 1 & 1 & 1 & 1 & 1 & 1 & 1 & 1 & $1 \mathrm{~A}$ & & \\
\hline 159 & bovC402 & cow & 21 & 21 & 1 & 1 & 1 & 1 & 1 & 1 & 1 & 1 & $1 \mathrm{~A}$ & & \\
\hline 160 & bovC250 & cow & 21 & 21 & 1 & 1 & 1 & 1 & 1 & 1 & 1 & 1 & $1 \mathrm{~A}$ & & \\
\hline 161 & bovC246 & cow & 48 & 48 & 1 & 0 & 1 & 1 & 1 & 1 & 1 & 0 & $1 \mathrm{~B}^{* *}$ & & \\
\hline 162 & bovC325 & cow & 628 & 61 & 1 & 0 & 1 & 1 & 1 & 0 & 1 & 0 & $3 B$ & & \\
\hline 163 & bov60 & cow & 4665 & 61 & 0 & 0 & 1 & 1 & 1 & 1 & 1 & 0 & 3B & & \\
\hline 164 & bovC406 & cow & 4668 & 61 & 0 & 0 & 1 & 1 & 1 & 1 & 1 & 0 & $3 B$ & & \\
\hline 165 & bovC535 & cow & 4666 & 61 & 0 & 0 & 1 & 1 & 1 & 0 & 1 & 0 & 3B & & \\
\hline 166 & bov277 & cow & 352 & 61 & 0 & 0 & 1 & 1 & 1 & 0 & 1 & 0 & $3 B$ & & \\
\hline 167 & bovBfR3889 & cow & 61 & 61 & 0 & 0 & 1 & 1 & 0 & 1 & 1 & 0 & $3 B$ & & \\
\hline 168 & bovBfR3912 & cow & 61 & 61 & 0 & 0 & 1 & 1 & 1 & 1 & 1 & 0 & 3B & & \\
\hline 169 & bovC171 & cow & 4669 & none & 1 & 0 & 0 & 0 & 1 & 1 & 1 & 0 & $2 \mathrm{~A}$ & & \\
\hline 170 & bovC537 & cow & 42 & 42 & 0 & 0 & 0 & 0 & 0 & 0 & 1 & 0 & $2 A$ & & \\
\hline 171 & bovC117 & cow & 22 & 22 & 0 & 0 & 0 & 0 & 1 & 1 & 1 & 0 & $2 \mathrm{~A}$ & & \\
\hline 172 & bovC084 & cow & 4670 & 42 & 0 & 0 & 0 & 0 & 1 & 1 & 1 & 0 & $2 A$ & & \\
\hline 173 & bovBfR3929 & cow & 45 & 45 & 0 & 0 & 0 & 0 & 1 & 1 & 0 & 0 & $2 B$ & & \\
\hline 174 & bovBfR3899 & cow & 45 & 45 & 0 & 0 & 0 & 0 & 1 & 1 & 0 & 0 & $2 B$ & & \\
\hline 175 & gal245 & chicken & 50 & 21 & 1 & 1 & 1 & 1 & 1 & 1 & 0 & 1 & $1 \mathrm{~B}^{*}$ & & \\
\hline 176 & gal7073HE & chicken & 48 & 48 & 1 & 1 & 1 & 1 & 1 & 1 & 1 & 1 & $1 \mathrm{~B}^{\star *}$ & & \\
\hline
\end{tabular}




\begin{tabular}{|c|c|c|c|c|c|c|c|c|c|c|c|c|c|c|c|}
\hline $\mathrm{Nr}$. & Name & Her- & MLST-ST & MLST-CC & cj1321-6 & Fucose & cj0178 & cj0755 & ceuE & pldA & cstll & cstIII & Gruppe & blutiger/wäss- & Hospitali- \\
\hline & & kunft & & & & & & & & & & & & riger Stuhl & sierung \\
\hline 177 & galZH0097 & chicken & 122 & 206 & 1 & 1 & 1 & 1 & 1 & 1 & 1 & 0 & $1 \mathrm{~B}^{\star *}$ & & \\
\hline 178 & gal7275RP & chicken & 4662 & 48 & 1 & 1 & 1 & 1 & 1 & 1 & 1 & 0 & $1 \mathrm{~B}^{* *}$ & & \\
\hline 179 & gal7289BY & chicken & 4662 & 48 & 1 & 1 & 1 & 1 & 1 & 1 & 1 & 0 & $1 \mathrm{~B}^{\star *}$ & & \\
\hline 180 & gal7060SN & chicken & 572 & 206 & 1 & 1 & 1 & 1 & 1 & 1 & 1 & 0 & $1 \mathrm{~B}^{\star *}$ & & \\
\hline 181 & galHS06 & chicken & 4657 & none & 1 & 1 & 1 & 1 & 1 & 1 & 1 & 0 & $1 \mathrm{~B}^{* *}$ & & \\
\hline 182 & galHS13 & chicken & 3529 & none & 1 & 1 & 1 & 1 & 1 & 1 & 1 & 0 & $1 \mathrm{~B}^{\star *}$ & & \\
\hline 183 & galHS04 & chicken & 3529 & none & 1 & 1 & 1 & 1 & 1 & 1 & 1 & 0 & $1 \mathrm{~B}^{\star *}$ & & \\
\hline 184 & galHS12 & chicken & 3529 & none & 1 & 1 & 1 & 1 & 1 & 1 & 1 & 1 & $1 \mathrm{~B}^{\star *}$ & & \\
\hline 185 & galBfR3922 & chicken & 46 & 206 & 1 & 1 & 1 & 1 & 1 & 1 & 0 & 1 & $1 \mathrm{~B}^{*}$ & & \\
\hline 186 & galBfR3926 & chicken & 46 & 206 & 1 & 1 & 1 & 1 & 1 & 1 & 0 & 1 & $1 \mathrm{~B}^{*}$ & & \\
\hline 187 & galBfR3951 & chicken & 46 & 206 & 1 & 1 & 1 & 1 & 1 & 1 & 0 & 1 & $1 \mathrm{~B}^{*}$ & & \\
\hline 188 & gal7252NI & chicken & 50 & 21 & 1 & 1 & 1 & 1 & 1 & 1 & 0 & 1 & $1 \mathrm{~B}^{*}$ & & \\
\hline 189 & gal7278BB & chicken & 50 & 21 & 1 & 1 & 1 & 1 & 1 & 1 & 0 & 1 & $1 \mathrm{~B}^{*}$ & & \\
\hline 190 & gal7297BB & chicken & 50 & 21 & 1 & 1 & 1 & 1 & 1 & 1 & 0 & 1 & $1 \mathrm{~B}^{*}$ & & \\
\hline 191 & gal7292BB & chicken & 50 & 21 & 1 & 1 & 1 & 1 & 1 & 1 & 0 & 1 & $1 \mathrm{~B}^{*}$ & & \\
\hline 192 & gal7240BW & chicken & 4660 & 21 & 1 & 1 & 1 & 1 & 1 & 1 & 0 & 1 & $1 \mathrm{~B}^{*}$ & & \\
\hline 193 & gal7267BB & chicken & 4661 & 21 & 1 & 1 & 1 & 1 & 1 & 1 & 0 & 1 & $1 \mathrm{~B}^{*}$ & & \\
\hline 194 & gal7280BY & chicken & 4663 & 21 & 1 & 1 & 1 & 1 & 1 & 1 & 0 & 1 & $1 \mathrm{~B}^{*}$ & & \\
\hline 195 & galHW6 & chicken & 2192 & 206 & 1 & 1 & 1 & 1 & 1 & 1 & 1 & 1 & $1 \mathrm{~B}^{*}$ & & \\
\hline 196 & galHW1 & chicken & 2192 & 206 & 1 & 1 & 1 & 1 & 1 & 1 & 1 & 1 & $1 \mathrm{~B}^{*}$ & & \\
\hline 197 & galHW5 & chicken & 2192 & 206 & 1 & 1 & 1 & 1 & 1 & 1 & 1 & 1 & $1 \mathrm{~B}^{*}$ & & \\
\hline 198 & gal518 & chicken & 21 & 21 & 1 & 1 & 1 & 1 & 1 & 1 & 0 & 1 & $1 \mathrm{~A}$ & & \\
\hline 199 & galBfR3935 & chicken & 21 & 21 & 1 & 1 & 1 & 1 & 1 & 1 & 0 & 1 & $1 \mathrm{~A}$ & & \\
\hline 200 & gal7089RP & chicken & 21 & 21 & 1 & 1 & 1 & 1 & 1 & 1 & 1 & 0 & $1 \mathrm{~A}$ & & \\
\hline 201 & gal7255BY & chicken & 21 & 21 & 1 & 1 & 1 & 1 & 1 & 1 & 0 & 1 & $1 \mathrm{~A}$ & & \\
\hline 202 & gal7090TH & chicken & 2274 & none & 1 & 1 & 1 & 1 & 1 & 1 & 1 & 0 & $3 A^{*}$ & & \\
\hline 203 & gal4116NI & chicken & 450 & 446 & 1 & 1 & 1 & 1 & 1 & 1 & 0 & 0 & $1 \mathrm{~B}^{\star \star *}$ & & \\
\hline 204 & gal7111BY & chicken & 990 & 257 & 1 & 1 & 1 & 1 & 1 & 1 & 0 & 0 & 6 & & \\
\hline 205 & gal7270BW & chicken & 2288 & 354 & 0 & 1 & 1 & 1 & 1 & 1 & 0 & 0 & $3 A^{* *}$ & & \\
\hline 206 & galHS16 & chicken & 4659 & none & 0 & 1 & 1 & 1 & 1 & 1 & 0 & 0 & 5 & & \\
\hline 207 & galHS03 & chicken & 4656 & 353 & 1 & 0 & 1 & 1 & 1 & 1 & 0 & 1 & $3 A^{* *}$ & & \\
\hline 208 & galHS02 & chicken & 353 & 353 & 1 & 0 & 1 & 1 & 1 & 1 & 0 & 1 & $3 A^{* *}$ & & \\
\hline
\end{tabular}




\begin{tabular}{|c|c|c|c|c|c|c|c|c|c|c|c|c|c|c|c|}
\hline Nr. & Name & Her- & MLST-ST & MLST-CC & cj1321-6 & Fucose & cj0178 & cj0755 & ceuE & pldA & cstII & cstIII & Gruppe & blutiger/wäss- & Hospitali- \\
\hline & & kunft & & & & & & & & & & & & riger Stuhl & sierung \\
\hline 209 & galHS14 & chicken & 353 & 353 & 1 & 0 & 1 & 1 & 1 & 1 & 1 & 1 & $3 A^{* *}$ & & \\
\hline 210 & gal7126RP & chicken & 353 & 353 & 1 & 0 & 1 & 1 & 1 & 1 & 0 & 1 & $3 A^{* *}$ & & \\
\hline 211 & galHS07 & chicken & 353 & 353 & 1 & 0 & 1 & 1 & 1 & 1 & 0 & 1 & $3 A^{* *}$ & & \\
\hline 212 & galHS09 & chicken & 353 & 353 & 1 & 0 & 1 & 1 & 1 & 1 & 0 & 1 & $3 A^{* *}$ & & \\
\hline 213 & galHS08 & chicken & 4658 & 353 & 1 & 0 & 1 & 1 & 1 & 1 & 0 & 1 & $3 A^{* *}$ & & \\
\hline 214 & galHS05 & chicken & 1900 & 658 & 1 & 0 & 1 & 1 & 1 & 1 & 1 & 0 & $3 A^{* *}$ & & \\
\hline 215 & galHW4 & chicken & 464 & none & 1 & 0 & 1 & 1 & 1 & 1 & 1 & 0 & $3 A^{* *}$ & & \\
\hline 216 & galHW7 & chicken & 464 & none & 1 & 0 & 1 & 1 & 1 & 0 & 1 & 0 & $3 A^{* *}$ & & \\
\hline 217 & galHW3 & chicken & 464 & none & 1 & 0 & 1 & 1 & 1 & 0 & 1 & 0 & $3 A^{* *}$ & & \\
\hline 218 & galHW2 & chicken & 464 & none & 1 & 0 & 1 & 1 & 1 & 0 & 1 & 0 & $3 A^{* *}$ & & \\
\hline 219 & galHS10 & chicken & 877 & none & 0 & 0 & 1 & 1 & 1 & 1 & 1 & 0 & 5 & & \\
\hline 220 & galBfR3948 & chicken & 49 & 49 & 0 & 0 & 1 & 1 & 1 & 1 & 0 & 0 & $1 \mathrm{~B}^{\star \star \star *}$ & & \\
\hline 221 & galHR1 & chicken & 2897 & none & 0 & 0 & 1 & 1 & 1 & 1 & 0 & 0 & $1 \mathrm{~B}^{* * *}$ & & \\
\hline 222 & galHR5 & chicken & 2897 & none & 0 & 0 & 1 & 1 & 1 & 1 & 1 & 0 & $1 \mathrm{~B}^{\star \star * *}$ & & \\
\hline 223 & galHR4 & chicken & 2897 & none & 0 & 0 & 1 & 1 & 1 & 1 & 0 & 0 & $1 \mathrm{~B}^{\star \star *}$ & & \\
\hline 224 & galHS01 & chicken & 877 & none & 0 & 0 & 1 & 1 & 1 & 1 & 1 & 0 & 5 & & \\
\hline 225 & galBfR3874 & chicken & 1739 & 22 & 0 & 0 & 0 & 1 & 0 & 1 & 1 & 0 & $2 A$ & & \\
\hline 226 & galBfR3949 & chicken & 45 & 45 & 1 & 1 & 0 & 0 & 1 & 1 & 1 & 0 & $2 B$ & & \\
\hline 227 & gal7258TH & chicken & 4676 & none & 0 & 1 & 0 & 0 & 1 & 0 & 1 & 0 & singleton & & \\
\hline 228 & gal7085NW & chicken & 2367 & none & 1 & 0 & 0 & 0 & 1 & 0 & 0 & 0 & 4 & & \\
\hline 229 & gal08B5018 & chicken & 22 & 22 & 0 & 0 & 0 & 0 & 1 & 0 & 1 & 0 & $2 A$ & & \\
\hline 230 & gal356 & chicken & 230 & 45 & 0 & 0 & 0 & 0 & 1 & 0 & 0 & 0 & $2 B$ & & \\
\hline 231 & galHS11 & chicken & 45 & 45 & 0 & 0 & 0 & 0 & 0 & 1 & 0 & 0 & $2 B$ & & \\
\hline 232 & gal08B5020 & chicken & 22 & 22 & 0 & 0 & 0 & 0 & 1 & 1 & 1 & 1 & $2 A$ & & \\
\hline 233 & gal7107BY & chicken & 42 & 42 & 0 & 0 & 0 & 0 & 1 & 1 & 1 & 0 & $2 \mathrm{~A}$ & & \\
\hline 234 & galBfR3950 & chicken & 564 & 283 & 0 & 0 & 0 & 0 & 1 & 1 & 0 & 0 & $2 B$ & & \\
\hline 235 & galHB7 & chicken & 4593 & 45 & 0 & 0 & 0 & 0 & 1 & 1 & 0 & 0 & $2 B$ & & \\
\hline 236 & galBfR3914 & chicken & 295 & 45 & 0 & 0 & 0 & 0 & 0 & 1 & 0 & 0 & $2 B$ & & \\
\hline 237 & galBfR4009 & chicken & 3036 & 45 & 0 & 0 & 0 & 0 & 1 & 1 & 0 & 0 & $2 B$ & & \\
\hline 238 & galBfR4232 & chicken & 45 & 45 & 0 & 0 & 0 & 0 & 1 & 1 & 0 & 0 & $2 B$ & & \\
\hline 239 & galBfR3944 & chicken & 45 & 45 & 0 & 0 & 0 & 0 & 1 & 1 & 0 & 0 & $2 B$ & & \\
\hline 240 & galBfR4327 & chicken & 1003 & 45 & 0 & 0 & 0 & 0 & 1 & 1 & 1 & 0 & $2 \mathrm{~A}$ & & \\
\hline
\end{tabular}




\begin{tabular}{|c|c|c|c|c|c|c|c|c|c|c|c|c|c|c|c|}
\hline Nr. & Name & Her- & MLST-ST & MLST-CC & cj1321-6 & Fucose & cj0178 & cj0755 & ceuE & pldA & cstll & cstIII & Gruppe & blutiger/wäss- & Hospitali- \\
\hline & & kunft & & & & & & & & & & & & riger Stuhl & sierung \\
\hline 241 & gal509 & chicken & 977 & 1034 & 0 & 0 & 0 & 0 & 1 & 0 & 1 & 0 & 4 & & \\
\hline 242 & meC0128 & turkey & 2175 & none & 1 & 1 & 1 & 1 & 1 & 1 & 1 & 0 & $1 \mathrm{~B}^{\star *}$ & & \\
\hline 243 & meC0133 & turkey & 50 & 21 & 1 & 1 & 1 & 1 & 1 & 1 & 1 & 0 & $1 \mathrm{~B}^{*}$ & & \\
\hline 244 & $\operatorname{meC} 0340$ & turkey & 50 & 21 & 1 & 1 & 1 & 1 & 1 & 1 & 1 & 0 & $1 \mathrm{~B}^{*}$ & & \\
\hline 245 & meC0999 & turkey & 4673 & 21 & 1 & 1 & 1 & 1 & 1 & 1 & 0 & 1 & $1 \mathrm{~B}^{*}$ & & \\
\hline 246 & meC0318 & turkey & 21 & 21 & 1 & 1 & 1 & 1 & 1 & 1 & 1 & 0 & $1 \mathrm{~A}$ & & \\
\hline 247 & meC0287 & turkey & 21 & 21 & 1 & 1 & 1 & 1 & 1 & 1 & 0 & 1 & $1 \mathrm{~A}$ & & \\
\hline 248 & meC0130 & turkey & 2288 & 354 & 1 & 1 & 1 & 1 & 1 & 1 & 1 & 0 & $3 A^{* *}$ & & \\
\hline 249 & meC0374 & turkey & 824 & 257 & 1 & 1 & 1 & 1 & 1 & 1 & 1 & 0 & $3 A^{*}$ & & \\
\hline 250 & meC0149 & turkey & 4675 & 443 & 1 & 1 & 1 & 1 & 1 & 1 & 0 & 0 & singleton & & \\
\hline 251 & $\mathrm{meC} 0438$ & turkey & 1823 & 21 & 1 & 1 & 1 & 1 & 1 & 1 & 0 & 1 & $1 \mathrm{~B}^{*}$ & & \\
\hline 252 & meC0450 & turkey & 4672 & 21 & 1 & 1 & 1 & 1 & 1 & 1 & 0 & 1 & $1 \mathrm{~B}^{*}$ & & \\
\hline 253 & meC0001-1 & turkey & 21 & 21 & 1 & 1 & 1 & 1 & 1 & 1 & 0 & 1 & $1 \mathrm{~A}$ & & \\
\hline 254 & meC0281 & turkey & 828 & 828 & 1 & 1 & 1 & 1 & 1 & 0 & 1 & 0 & $3 A^{*}$ & & \\
\hline 255 & meC0280 & turkey & 828 & 828 & 1 & 1 & 1 & 1 & 1 & 0 & 1 & 0 & $3 A^{*}$ & & \\
\hline 256 & $\operatorname{meC} 0475$ & turkey & 257 & 257 & 1 & 1 & 1 & 1 & 1 & 1 & 0 & 0 & 6 & & \\
\hline 257 & meC0283 & turkey & 443 & 443 & 1 & 1 & 1 & 1 & 1 & 1 & 1 & 0 & $3 A^{*}$ & & \\
\hline 258 & meC0467 & turkey & 828 & 828 & 0 & 1 & 1 & 1 & 1 & 0 & 1 & 0 & $3 A^{*}$ & & \\
\hline 259 & meC0282 & turkey & 450 & 446 & 0 & 1 & 1 & 1 & 1 & 1 & 0 & 0 & $1 \mathrm{~B}^{* \star \star}$ & & \\
\hline 260 & meC0129 & turkey & 1348 & 61 & 1 & 0 & 1 & 1 & 1 & 1 & 0 & 1 & $3 B$ & & \\
\hline 261 & meC0680 & turkey & 464 & none & 1 & 0 & 1 & 1 & 1 & 1 & 1 & 0 & $3 A^{* *}$ & & \\
\hline 262 & meC0847 & turkey & 2091 & 52 & 1 & 0 & 1 & 1 & 1 & 1 & 1 & 0 & $3 A^{*}$ & & \\
\hline 263 & $\operatorname{meC} 1466$ & turkey & 696 & 1332 & 1 & 0 & 1 & 0 & 1 & 1 & 1 & 0 & 4 & & \\
\hline 264 & $\operatorname{meC} 1541$ & turkey & 4430 & none & 1 & 0 & 0 & 0 & 1 & 1 & 1 & 0 & singleton & & \\
\hline 265 & meC0306 & turkey & 4671 & 1034 & 0 & 0 & 0 & 0 & 1 & 1 & 0 & 0 & 4 & & \\
\hline 266 & $\mathrm{meC} 0408$ & turkey & 45 & 45 & 0 & 0 & 0 & 0 & 1 & 1 & 0 & 0 & $2 B$ & & \\
\hline 267 & $\operatorname{meC} 1496$ & turkey & 4674 & 1034 & 0 & 0 & 0 & 0 & 1 & 1 & 1 & 0 & 4 & & \\
\hline 268 & $\mathrm{meC} 0816$ & turkey & 1709 & 1034 & 0 & 0 & 0 & 0 & 1 & 1 & 0 & 0 & 4 & & \\
\hline
\end{tabular}




\subsection{Bisherige Veröffentlichungen der Ergebnisse}

Zautner AE, Ohk C, Tareen AM, Lugert R, Groß U (2012): Epidemiological association of Campylobacter jejuni groups with pathogenicity-associated genetic markers. BMC Microbiol. $\underline{12 ;} 171$ 


\section{Literaturverzeichnis}

Acke E, McGill K, Golden O, Jones BR, Fanning S, Whyte P (2009): Prevalence of thermophilic Campylobacter species in household cats and dogs in Ireland. Vet Rec 164, 4447

Allos BM (2001): Campylobacter jejuni Infections: update on emerging issues and trends. Clin Infect Des $\underline{32}, 201-206$

Altekruse SF, Stern NJ, Fields PI, und Swerdlow DL (1999): Campylobacter jejuni-an emerging foodborne pathogen. Emerg Infect Dis $\underline{5}, 28-35$

Anonymus (2006): Aktuelle Statistik meldepflichtiger Infektionskrankheiten.

Epidemiologisches Bulletin Nr. 3. Robert Koch-Institut

Anonymus (2012): Aktuelle Statistik meldepflichtiger Infektionskrankheiten.

Epidemiologisches Bulletin Nr. 50. Robert Koch-Institut

Ansorg R, Rein R, Spies A, von Recklinghausen G (1993): Cell-associated hemolytic activity of Helicobacter pylori. Eur J Clin Microbiol Infect Dis 12, 98-104

Baqar S, Applebee LA, Gilliland TC, Lee Jr. LE,Porter CK,Guerry P. 2008. Immunogenicity and protective efficacy of recombinant Campylobacter jejuni flagellum-secreted proteins in mice. Infect Immun $\underline{76}, 3170-3175$

Bereswill S, Plickert R, Fischer A, K hl AA, Loddenkemper C, Batra A, Siegmund B, Göbel UB, Heimesaat MM (2011): What you eat is what you get: Novel Campylobacter models in the quadrangle relationship between nutrition, obesity, microbiota and susceptibility to infection. European Journal of Microbiology and Immunology 1, 237-248 
Black RE, Levine MM, Clements ML, Hughes TP, Blaser MJ (1988): Experimental Campylobacter jejuni infection in humans. J Infect Dis $\underline{157}, 472-479$

Butzler JP (2004): Campylobacter, from obscurity to celebrity.Clin Microbiol Infect 10, 868876

Champion OL, Gaunt MW, Gundogdu O, Elmi A, Witney AA, Hinds J, Dorrell N, Wren BW (2005): Comparative phylogenomics of the food-borne pathogen Campylobacter jejuni reveals genetic markers predictive of infection source. Proc. Natl. Acad. Sci. USA $\underline{102}$, $16043-16048$

Chiba A, Kusunoki S, Obata H, Machinami R, Kanazawa I (1993): Serum anti-GQ1b IgG antibody is associated with ophthalmoplegia in Miller Fisher syndrome and Guillain-Barre' syndrome: clinical and immunohistochemical studies. Neurology $\underline{43}, 1911-1917$

Clark CG, Price L, Ahmed R, Woodward DL, Melito PL, Rodgers FG, Jamieson F, Ciebin B, Li A, Ellis A (2003): Characterization of waterborne outbreak-associated Campylobacter jejuni, Walkerton, Ontario. Emerg Infect Dis $\underline{9}, 1232-41$

Clark CG, Bryden L, Cuff WR, Johnson PL, Jamieson F, Ciebin B, Wang G (2005): Use of the Oxford Multilocus Sequence Typing Protocol and Sequencing of the Flagellin Short Variable Region To Characterize Isolates from a Large Outbreak of Waterborne Campylobacter sp. Strains in Walkerton, Ontario, Canada. J Clin Microbiol 43, 2080-2091

Dasti JI, Tareen AM, Lugert R, Zautner A, Groß U (2010): Campylobacter jejuni: a brief overview on pathogenicity-associated factors and disease-mediating mechanisms.Int $\mathrm{J}$ Med Microbiol 300, 456-461 
Datta S, Niwa H, Itoh K (2003): Prevalence of 11 pathogenic genes of Campylobacter jejuni by PCR in strains isolated from humans, poultry meat and broiler and bovine faeces. J Med Microbiol 52, 345-348

de Haan CP, Kivistö R, Hänninen ML (2010) : Association of Campylobacter jejuni Cj0859c gene $(f s p)$ variants with different $C$. jejuni multilocus sequence types. Appl Environ Microbiol $\underline{76}$, 6942-6943

Deming MS, Tauxe RV, Blake PA, Dixon SE, Fowler BS, Jones TS, Lockamy EA, Patton CM, Sikes RO (1987): Campylobacter enteritis at an university: transmission from eating chicken and from cats. Am J Epidemiol 126, 526- 534

Dingle KE, Colles FM, Wareing DRA, Ure R, Fox AJ, Bolton FE, Bootsma HJ, Willems RJL, Urwin R, Maiden MCJ (2001): Multilocus Sequence Typing System for Campylobacter jejuni. J Clin Microbiol 39, 14-23

Dingle KE, Colles FM, Ure R, Wagenaar JA, Duim B, Bolton FJ, Fox AJ, Wareing DR, Maiden MC (2002): Molecular characterization of Campylobacter jejuni clones: a basis for epidemiologic investigation. Emerg Infect Dis $\underline{8}, 949-955$

EFSA (2010): The community summary report on trends and sources of zoonoses, zoonotic agents and food-borne outbreaks in the European Union in 2008.EFSA J $\underline{8}, 1496$

Endtz HP, Ang CW, van Den Braak N, Duim B, Rigter A, Price LJ, Woodward DL, Rodgers FG, Johnson WM, Wagenaar JA, Jacobs BC, Verbrugh HA, van Belkum A (2000): Molecular characterization of Campylobacter jejuni from patients with Guillain-Barre and Miller Fisher syndromes. J Clin Microbiol 38, 2297-2301 
Fearnley C, Manning G, Bagnall M, Javed MA, Wassenaar TM, Newell DG (2008): Identification of hyperinvasive Campylobacter jejuni strains isolated from poultry and human clinical sources. J Med Microbiol 57, 570-580

Feodoroff B, Ellström P, Hytiäinen H, Sarna S, Hänninen M, Rautelin H (2010): Campylobacter jejuni isolates in Finnish patients differ according to the origin of infection. Gut Pathog 2, 22

Friedman CR, Neimann J, Wegener HC, Tauxe RV: Epidemiology of Campylobacter jejuni infections in the United States and other industrialized nations. In: Campylobacter. Hrsg. v. Nachamkin I, Blaser MJ, $2^{\text {nd }}$ ed., ASM Press, Washington DC, 2000, 121-138

Gilbert M, Karwaski MF, Bernatchez S, Young NM, Taboada E, Michniewicz J, Cunningham AM, Wakarchuk WW (2002): The genetic basis for the variation in the lipo-oligosaccharide of the mucosal pathogen, Campylobacter jejuni. Biosynthesis of sialylated ganglioside mimics in the core oligosaccharide. J Biol Chem 277, 327-337

Godschalk PC, Heikema AP, Gilbert M, Komagamine T, Ang CW, Glerum J, Brochu D, Li J, Yuki N, Jacobs BC et al. (2004): The crucial role of Campylobacter jejuni genes in antiganglioside antibody induction in Guillain-Barre syndrome. J Clin Invest 114, 1659-1665

Godschalk PC, Kuijf ML, Li J, Michael FS, Ang CW, Jacobs BC, Karwaski MF, Brochu D, Moterassed A, Endtz HP et al. (2007): Structural Characterization of Campylobacter jejuni Lipooligosaccharide Outer Cores Associated with Guillain-Barre' and Miller Fisher Syndromes. Infect Immun 75, 1245-1254

Grant KA, Belandia IU, Dekker N, Richardson PT, Park SF (1997): Molecular characterization of pldA, the structural gene for a phospholipase A from Campylobacter coli, and its contribution to cell-associated hemolysis. Infect Immun $\underline{65}, 1172-1180$

Guarner F, Malagelada JR(2003): Gut flora in health and disease. Lancet $\underline{361,512-19}$ 
Guerry P (2007): Campylobacter flagella: not just for motility. Trends Microbiol $\underline{15}, 456-461$

Guillain G, Barre JA, Strohl A (1916): Sur un syndrome de radiculonévrite avec hyperalbuminose du liquide céphalo-rachidien sans réaction cellulaire. Remarques sur les charactères cliniques et graphiques des réflexes tendineux. Bull Soc Med Hop Paris $\underline{40}$, 14621470

Habib I, Uyttendaele M, De Zutter L (2010): Survival of poultry-derived Campylobacter jejuni of multilocus sequence type clonal complexes 21 and 45 under freeze, chill, oxidative, acid and heat stresses. Food Microbiol 27, 829-34

Hao Q, Saida T, Kuroki S, Nishimura M, Nukina M, Obayashi H, Saida K(1998): Antibodies to gangliosides and galactocerebroside in patients with Guillain-Barre syndrome with preceding Campylobacter jejuni and other identified infections. J Neuroimmunol $\underline{81}, 116-126$

Hänel I, Borrmann E, Müller J, Alter T (2007): Relationships between bacterial genotypes and in vitro virulence properties of Campylobacter jejuni and Campylobacter coli isolated from turkeys. J Appl Microbiol 102,433-441

Hofreuter D, Tsai J, Watson RO,Novik V,Altman B,Benitez M,Clark C, Perbost C,Jarvie T,Du L (2006): Unique Features of a Highly Pathogenic Campylobacter jejuni Strain.Infect Immun $\underline{74}, 4694-4707$

Hofreuter D, Novik V, Galán JE( 2008): Metabolic diversity in Campylobacter jejuni enhances specific tissue colonization. Cell Host Microbe $\underline{4}, 425-33$

Hotter GS, Li IH, French NP (2010): Binary genomotyping using lipooligosaccharide biosynthesis genes distinguishes between Campylobacter jejuni isolates within poultryassociated multilocus sequence types. Epidemiol Infect 138, 992-1003 
Humphrey T, O’Brien S, Madsen M (2007): Campylobacters as zoonotic pathogens: A food production perspective. Int J Food Microbiol 117, 237-257

Jacobs BC, van Doorn PA, Schmitz PI, Tio-Gillen AP, Herbrink P, Visser LH, Hooijkass H, van der Meche FG (1996): Campylobacter jejuni infections and anti-GM1 antibodies in Guillain-Barre syndrome. Ann Neurol 40,181-187

Janssen R, Krogfelt KA, Cawthraw SA, van PW Wagenaar JA, Owen R J(2008): Hostpathogen interactions in Campylobacter infections: the host perspective. Clin Microbiol Rev $\underline{21}, 505-518$

Karlyshev AV, Wren BW (2001): Detection and initial characterization of novel capsular polysaccharide among diverse Campylobacter jejuni strains using alcian blue dye. J Clin Microbiol 39,279-284

Kelly DJ ( 2001): The physiology and metabolism of Campylobacter jejuni and Helicobacter pylori. J Appl Microbiol 90,16S-24S

Konkel ME, Garvis SG, Tipton SL, Anderson DE Jr, Cieplak W Jr (1997): Identification and molecular cloning of a gene encoding a fibronectin-binding protein (CadF) from Campylobacter jejuni. Mol Microbiol 24, 953-63

Konkel ME, Kim BJ, Rivera-Amill V, Garvis SG (1999): Bacterial secreted proteins are required for the internalization of Campylobacter jejuni into cultured mammalian cells. Mol Microbiol $\underline{32}, 691-701$

Konkel ME, Monteville MR, Rivera-Amill V, Joens LA (2001): The pathogenesis of Campylobacter jejuni-mediated enteritis. Curr Issues Intest Microbiol 2, 55-71

Kumar S, Nei M, Dudley J, Tamura K (2008): MEGA: a biologistcentric software for evolutionary analysis of DNA and protein sequences.Brief Bioinform $\underline{9}$, 299-306 
Lee MD, Newell DG (2006): Campylobacter in poultry: filling an ecological niche. Avian Dis $\underline{50}, 1-9$

Ley RE, Hamady M, Lozupone C, Turnbaugh PJ, Ramey RR, Bircher JS, Schlegel ML, Tucker TA, Schrenzel MD, Knight R, Gordon JI (2008) : Evolution of mammals and their gut microbes. Science $\underline{320}, 1647-1651$

Litwin CM, Calderwood SB (1993): Role of iron in regulation of virulence genes.Clin Microbiol Rev $\underline{6}, 137-149$

Louis VR, Gillespie IA, O'Brien SJ, Russek-Cohen E, Pearson AD, Colwell RR (2005): Temperature-driven Campylobacter seasonality in England and Wales. Appl Environ Microbiol 71, 85-92

Louwen R, Heikema A, van Belkum A, Ott A, Gilbert M, Ang W, Endtz HP, Bergman MP, Nieuwenhuis EE (2008): The sialylated lipooligosaccharide outer core in Campylobacter jejuni is an important determinant for epithelial cell invasion.Infect Immun $\underline{76}, 4431-4438$

Lozupone CA, Stombaugh J I, Gordon JI, Jansson JK, Knight R(2012): Diversity, stability and resilience of the human gut microbiota. Nature $\underline{489}, 220-230$

Maiden MCJ, Bygraves JA, Feil E, Morelli G, Russell JE, Urwin R, Zhang Q, Zhou J, Zurth K, Caugant DA, Feavers IM, Achtman M, Spratt BG (1998): Multilocus sequence typing: a portable approach to the identification of clones within populations of pathogenic microorganisms. Proc Natl Acad Sci USA 95, 3140-3145

Malik-Kale P, Parker CT, Konkel ME (2008): Culture of Campylobacter jejuni with sodium deoxycholate induces virulence gene expression. Journal of bacteriology 190, 2286-2297

McSweegan E, Walker RI (1986): Identification and characterization of two Campylobacter jejuni adhesins for cellular and mucous substrates. Infect Immun 53, 141-148 
Mead PS, Slutsker L, Dietz V, McCaig LF, Bresee JS, Shapiro C, Griffin PM, Tauxe RV (1999) : In vivo tracking of Campylobacter jejuni by using a novel recombinant expressing green fluorescent protein. Appl Environ Microbiology 149,153-165

Mortensen NP, Kuijf ML, Ang CW, Schiellerup P, Krogfelt KA.Jacobs BC, van Belkum A, Endtz HP, Bergmann MP (2009): Sialylation of Campylobacter jejuni lipo-oligosaccharides is associated with severe gastro-enteritis and reactive arthritis. Microbes Infect $\underline{11}, 988-994$

Muraoka WT, Zhang Q (2011): Phenotypic and Genotypic Evidence for L-Fucose Utilization by Campylobacter jejuni. J Bacteriol 193, 1065-1075

Nichols GL (2005): Fly transmission of Campylobacter. Emerg Infect Dis 11, 361-364

Odaka M, Yuki N, Yamada M, Koga M, Takemi T, Hirata K, Kuwabara S (2003): Bickerstaff's brainstem encephalitis: clinical features of 62 cases and a subgroup associated with Guillain-Barré syndrome. Advanced Access publication 126, 2279-2290

Palyada K, Threadgill D, Stintzi A (2004): Iron Acquisition and Regulation in Campylobacter jejuni. J Bacteriol 186, 4714-4729

Park SF (2002): The physiology of Campylobacter species and its relevance to their role as foodborne pathogens. Int J Food Microbiol 4ㅜ $177-188$

Parker CT, Horn ST, Gilbert M, Miller WG, Woodward DL, Mandrell RE (2005): Comparison of Campylobacter jejuni Lipooligosaccharide Biosynthesis Loci from a Variety of Sources. J Clin Microbiol 43, 2771-2781

Parker CT, Gilbert M, Yuki N, Endtz HP, Mandrell RE (2008): Characterization of lipooligosaccharide-biosynthetic loci of Campylobacter jejuni reveals new lipooligosaccharide classes: evidence of mosaic organizations. J Bacteriol 190, 5681-5689 
Parkhill J, Wren BW, Mungall K, Ketley JM, Churcher C, Basham D (2000): The genome sequence of the food-borne pathogen Campylobacter jejuni reveals hypervariable sequences. Nature 403, 665-668.

Pei ZH, Ellison RT 3rd, Blaser MJ (1991): Identification, purification, and characterization of major antigenic proteins of Campylobacter jejuni. J Biol Chem $\underline{266}$, 16363-69

Pei ZH, Blaser MJ (1993): PEB1, the major cell-binding factor of Campylobacter jejuni, is a homolog of the binding component in gram-negative nutrient transport systems. J Biol Chem $\underline{268,18717-25}$

Penders J, Thijs C, Vink C, Stelma FF,Snijders B, Kummeling I, van den Brandt PA, Stobberingh EE (2006): Factors influencing the composition of the intestinal microbiota in early infancy. Pediatrics $\underline{118}, 511-521$

Pickett CL, Auffenberg T, Pesci EC, Sheen VL, Jusuf SS (1992): Iron acquisition and hemolysin production by Campylobacter jejuni. Infect. Immun. 60:3872-3877.

Pickett CL, Whitehouse CA (1999): The cytolethal distending toxin family.Trends Microbiol $\underline{7}, 292-297$

Ratledge C und Dover LG (2000): Iron metabolism in pathogenic bacteria. Annu Rev Microbiol 54, 881-941

Rees JH, Soudain SE, Gregson NA, Hughes RA (1995): Campylobacter jejuni infection And Guillain-Barre syndrome. N Engl J Med 333,1374-1379

Revez J, Rossi M, Ellström P, de Haan C, Rautelin H, Hänninen ML(2011): Finnish Campylobacter jejuni Strains of Multilocus Sequence Type ST-22 Complex Have Two Lineages with Different Characteristics. PLoS One $\underline{6}, 26880$ 
Richardson PT, Park SF (1995): Enterochelin acquisition in Campylobacter coli: characterization of components of a binding-protein-dependent transport system. Microbiology $\underline{141}$, $3181-3191$

Rivera-Amill V, Kim BJ, Seshu J, Konkel ME (2001): Secretion of the virulenceassociated Campylobacter invasion antigens from Campylobacter jejuni requires a stimulatory signal. J Infect Dis $\underline{183}, 1607-1616$

Robert Koch-Institut: Infektionsepidemiologisches Jahrbuch für 2011, Berlin 2012

Rollins DM, Colwill RR (1986): Viable but nonculturable stage of Campylobacter jejuni and its role in survival in the natural aquatic environment. Appl Environ Microbiol 52, 531-538

Schmidt-Ott R, Schmidt H, Feldmann S, Brass F, Krone B, Gross U (2006): Improved Serological Diagnosis Stresses the Major Role of Campylobacter jejuni in Triggering Guillain-Barré Syndrome. Clin Vaccine Immunol 13, 779-783

Sopwith W, Birtles A, Matthews M, Fox A, Gee S, Painter M, Regan M, Syed Q, Bolton E (2006): Campylobacter jejuni multilocus sequence types in humans, northwest England, 2003-2004. Emerg Infect Dis 12, 1500-7

Sopwith W, Birtles A, Matthews M, Fox A, Gee S, Painter M, Regan M, Syed Q, Bolton E (2008): Identification of potential environmentally adapted Campylobacter jejuni strain, United Kingdom. Emerg Infect Dis 14, 1769-73

Stahl M, Friis LM, Nothaft H,1, Liu X, Lic J, Szymanski CM, Stintzi A (2011): L-Fucose utilization provides Campylobacter jejuni with a competitive advantage. Proc Natl Acad Sci U S A $\underline{108}, 7194-7199$

Stecher B, Hardt WD (2008): The role of microbiota in infectious disease. Trends Microbiol $\underline{16}, 107-114$ 
Talukder KA, Aslam M, Islam Z, Azmi IJ, Dutta DK, Hossain S, Nur-E-Kamal A,Nair GB, Cravioto A, Sack DA, Endtz HP (2008): Prevalence of virulence genes and cytolethal distending toxin production in Campylobacter jejuni isolates from diarrheal patients in Bangladesh. 46 diarrheal patients in Bangladesh. J Clin Microbiol 46, 1485-1488

Tareen AM, Dasti JI, Zautner AE, Groß U, Lugert R (2011): Sulphite: cytochrome oxidoreductase deficiency in Campylobacter jejuni reduces motility, host cell adherence and invasion. Microbiology 157, 1776-1785

Tate SS, Meister A (1981): Gamma-glutamyl transpeptidase: catalytic, structural and functional aspects. Mol Cell Biochem $\underline{39}, 357-68$

Tietze E (2008): Campylobacter jejuni/ Campylobacter coli. in: GERMAP 2008-AntibiotikaResistenz und -Verbrauch, hrsg. Bundesamt für Verbraucherschutz und Lebensmittelsicherheit, Paul-Ehrlich-Gesellschaft für Chemotherapie e.V. und Infektiologie Freiburg, 1.Auflage, Antiinfectives Intelligence Gesellschaft für klinisch-mikrobiologische Forschung und Kommunikation $\mathrm{mbH}$, Rheinbach 2008, 77-78

Touati, D (2000): Iron and oxidative stress in bacteria. Arch Biochem Biophys $\underline{373}$, 1-6

Urwin R, Maiden MC (2003): Multi-locus sequence typing: a tool for global epidemiology. Trends Microbiol 11, 479-487

Vandamme P, De Ley J (1991): Proposal for a new family, Campylobacteraceae.Int J Syst Bacteriol $\underline{41}, 451-455$

Vandamme P, Van Doorn LJ, al Rashid ST, Quint WG, van der Plas J, Chan VL, On SL (1997): Campylobacter hyoilei Alderton et al. 1995 and Campylobacter coli Véron and Chatelain 1973 are subjective synonyms. Int J Syst Bacteriol 47, 1055-1060 
van Vliet AH, Ketley JM, Park SF, Penn CW (2002): The role of iron in Campylobacter gene regulation, metabolism and oxidative stress defense. FEMS Microbiol Rev $\underline{26}, 173-186$

Velayudhan J, Kelly DJ (2002): Analysis of gluconeogenic and anaplerotic enzymes in Campylobacter jejuni: an essential role for phosphoenolpyruvate carboxykinase. Microbiology 148, 685-694

Vimr ER, Aaronson W, Silver RP (1989): Genetic analysis of chromosomal mutations in the polysialic acid gene cluster of Escherichia coli K1. J Bacteriol 171, 1106-1117

Wassenaar TM (1997): Toxin production by Campylobacter spp. Clin Microbiol Rev 10, 466476

Wassenaar TM, Blaser MJ (1999): Pathophysiology of Campylobacter jejuni infections of humans.Microbes Infect $\underline{1}, 1023-1033$

Whitehouse CA, Balbo PB, Pesci EC, Cottle DL, Mirabito PM, Pickett CL (1998): Campylobacter jejuni cytolethal distending toxin causes a G2-phase cell cycle block. Infect Immun $\underline{66}$, 1934-1940

Yuki N, Susuki K, Koga M, Nishimoto Y, Odaka M, Hirata K, Taguchi K, Miyatake T, Furukawa K, Kobata T et al. (2004): Carbohydrate mimicry between human ganglioside GM1 and Campylobacter jejuni lipooligosaccharide causes Guillain-Barre syndrome. Proc Natl Acad Sci USA $\underline{101}, 11404-11409$

Zautner AE, Herrmann S, Corso J, Tareen AM, Alter T, Gross U (2011): Epidemiological Association of Different Campylobacter jejuni Groups with Metabolism-Associated Genetic Markers. Applied and Environmental Microbiology 77, 2359-2365 


\section{Danksagung:}

Ich bedanke mich bei Herrn Prof. Dr. med. Uwe Groß für die Vergabe der Doktorarbeit und Übernahme der Erstbegutachtung.

Ich möchte meinem Betreuer Dr. med. Andreas E. Zautner dafür danken, dass er mir die Anfertigung dieser interessanten Doktorarbeit ermöglicht hat. Für seine sehr gute und engagierte Betreuung der praktischen und auch theoretischen Arbeit sowie die kontinuierliche Unterstützung bin ich sehr dankbar.

Für die immer sehr gute und nette Hilfestellung beim Erlernen einiger Methoden und bei der Durchführung verschiedener Experimente danke ich Abdul Malik Tareen. Außerdem danke ich Sahra Herrmann für die Unterstützung bei der MLST-Typisierung der C. jejuni-Stämme.

Desweiteren danke ich allen Kollegen aus dem Labor für ihre Hilfe und die nette Atmosphäre.

An dieser Stelle möchte ich mich auch bei meinem Onkel Dr.Hartmut Pollack bedanken, der mir mit tatkräftiger Unterstützung und zahlreichen Tipps die Arbeit am Computer und damit die Fertigstellung der Dissertation unendlich erleichterte. 